\title{
INVESTIGATION OF THE UNDER-BODY FLOW FIELD OF A PROTOTYPE LONG-RANGE ELECTRIC VEHICLE
}

\author{
A Thesis \\ presented to \\ the Faculty of California Polytechnic State University, \\ San Luis Obispo
}

\author{
In Partial Fulfillment \\ of the Requirements for the Degree \\ Master of Science in Aerospace Engineering
}

by

Matthew Nguyen

July 2019 
(c) 2019

Matthew Nguyen

ALL RIGHTS RESERVED 


\title{
COMMITTEE MEMBERSHIP
}

\author{
TITLE: Investigation of the Under-Body Flow \\ Field of a Prototype Long-Range Electric \\ Vehicle
}

AUTHOR: Matthew Nguyen

DATE SUBMITTED: July 2019

COMMITTEE CHAIR: Paulo Iscold, Ph.D.

Associate Professor of Aerospace Engineering

COMMITTEE MEMBER: Graham Doig, Ph.D

In Charge - Aerodynamics, Canoo

COMMITTEe MeMBER: Kira Abercromby, Ph.D.

Associate Professor of Aerospace Engineering

COMMITTEE MEMBER: Aaron Drake, Ph.D.

Associate Professor of Aerospace Engineering 


\begin{abstract}
Investigation of the Under-Body Flow Field of a Prototype Long-Range Electric Vehicle Matthew Nguyen
\end{abstract}

This thesis presents changes to the design of the Prototype Vehicles Laboratory (PROVE Lab) Endurance Car, an electric car intended to break the Guinness World Record for the single-charge range of an electric vehicle. The design range is 1609.34 $\mathrm{km}$, however at the design velocity of $104.6 \mathrm{kph}$, the drag is $196 \mathrm{~N}$; which requires more battery capacity than the $100 \mathrm{kWh}$ maximum of the baseline model. With a fixed frontal area, drag reduction can come from lowered velocity or reduced $C_{D} \cdot C_{D}$ reduction is attempted in four ways: side skirts between the fenders, a raised ride height, an elongated diffuser, and a widened rear. Side skirts were added to move pressure recovery from the front ducts to the diffuser by lowering the pressure between the side skirts; this had the intended effect but increased the tendency of the flow to separation in the already-separated areas. There was no significant change in pressure drag, but the shear drag and downforce increased. The ride height was increased to reduce drag and downforce; this change did not have a significant effect on the resultant forces and the separation on the underbody was largely unchanged. The diffuser was extended by $12.7 \mathrm{~cm}$ without modifying the aspect ratio, to lower the divergence angle. The pressure and shear drag reduced by $8 \mathrm{~N}$ and $1.1 \mathrm{~N}$, respectively, and downforce decreased by $80 \mathrm{~N}$, but separation in the diffuser was not eliminated. Finally, the fourth strategy reduced the divergence angle to approximately $0^{\circ}$ by widening the center of the vehicle. This decreased pressure drag by $13 \mathrm{~N}$ and downforce by $188 \mathrm{~N}$. Additionally, this strategy allows a larger $180 \mathrm{kWh}$ battery, which permits 1609.34 $\mathrm{km}$ of range at $104.6 \mathrm{kph}$. 


\section{ACKNOWLEDGMENTS}

Thank you to Dr. Iscold, my advisor, for your patience with me throughout this process. Your advice was truly insightful and I appreciate the knowledge you imparted on me. Thank you as well to Dr. Doig, it has been a lifelong dream of mine to design a car, and I am grateful that you sent me down this path.

I am forever grateful to my parents, Thuong and Chantal, for your love and support through my educational journey. I could not have made it this far without you. Many thanks as well to my sister Allison, for commiserating with me and spellchecking my work, and to Ali Hammond, for allowing me to complain at you during

this process, and forcing me to take many well-deserved food breaks. To Allison and Ethan, have fun writing theses of your own.

Many thanks to each of the other Aerospace Engineering master's students; you have each taught me something, and I am grateful for that. Special thanks to the fellow students of the Wind Tunnel Lab, especially Ben Kenworthy, Daniel Baratta, Kyle Lukacovic, Tej Modi, and Brandon Baldovin, for teaching me more about aerodynamics and wind tunnel testing in two years than in the twenty-two before.

To the reader, I hope you find use in the results presented here, and that you learn as much as I did during this process. 


\section{TABLE OF CONTENTS}

Page

LIST OF TABLES ....................... . . . . ix

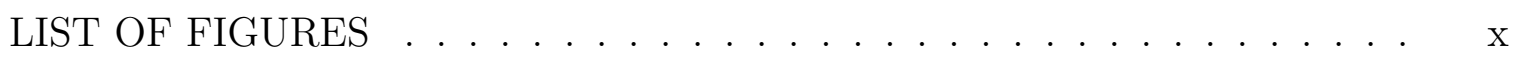

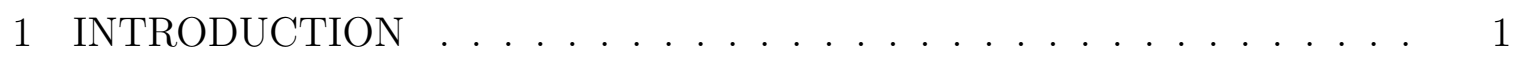

1.1 Electric Vehicles . . . . . . . . . . . . . . . . . . . . . . 1

1.1 .1 Range Anxiety . . . . . . . . . . . . . . . . 2

1.2 Endurance Car Project . . . . . . . . . . . . . . . . . 2

1.2 .1 EV Performance . . . . . . . . . . . . . . 2

1.2 .2 EV Records . . . . . . . . . . . . . . . . 3

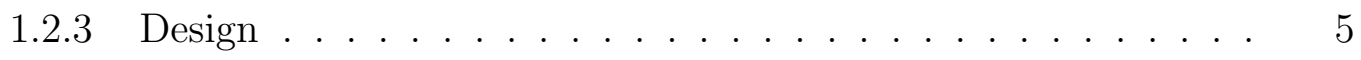

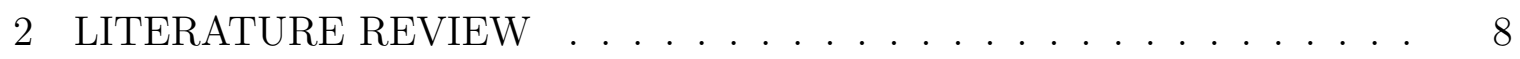

2.1 Automotive Aerodynamics . . . . . . . . . . . . . . 8

2.1 .1 Vehicle Bodies . . . . . . . . . . . . . . . 8

2.1 .2 Pressure and Shear Drag . . . . . . . . . . . . . . . 11

2.1 .3 Wheels . . . . . . . . . . . . . . . . . . . 11

2.1.4 Vehicle Ride Height . . . . . . . . . . . . . . . . . . 13

2.1.5 Aerodynamics of Electric Vehicles . . . . . . . . . . . . 13

2.2 Diffusers . . . . . . . . . . . . . . . . . . . . 14

2.2 .1 Diffuser Parameters . . . . . . . . . . . . . . . . . . 16

2.2 .2 Planar Automotive Diffusers . . . . . . . . . . . . . 17

2.2 .3 Effect of Wheels . . . . . . . . . . . . . . . . 17

2.2.4 Non-Planar and Multi-Channel Diffusers . . . . . . . . . 18

2.3 Side Skirts . . . . . . . . . . . . . . . . . . . . . . . . . 21 
2.4 Diffuser Ride Height $\ldots \ldots \ldots \ldots$

2.5 Diffuser Divergence Angle . . . . . . . . . . . . . . . . . . 25

2.6 Diffuser With No Divergence Angle . . . . . . . . . . . . . 27

3 PROBLEM STATEMENT . . . . . . . . . . . . . . . . . . . . . . . 29

3.1 Problem . . . . . . . . . . . . . . . . . . . . . . . . . . . . . . . . 29

3.2 Baseline Configuration . . . . . . . . . . . . . . . . . . 33

3.3 Drag Reduction Strategies . . . . . . . . . . . . . . . 35

3.3 .1 Addition of a Side Skirt . . . . . . . . . . . . . . . . 35

3.3 .2 Increase in Ride Height . . . . . . . . . . . . . . . . . 37

3.3 .3 Extended Diffuser . . . . . . . . . . . . . . . . . . . 39

3.3 .4 Widened Tail . . . . . . . . . . . . . . . . . . . 42

4 COMPUTATIONAL FLUID DYNAMICS . . . . . . . . . . . . 44

4.1 CFD Methodology . . . . . . . . . . . . . . . . . 44

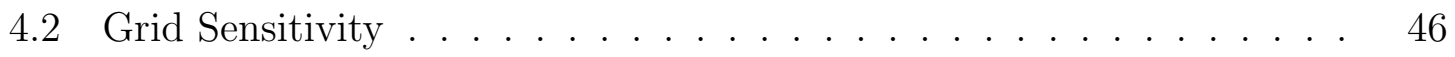

4.2 .1 Global Mesh Size . . . . . . . . . . . . . . . . . . . . . . 49

4.2 .2 Domain . . . . . . . . . . . . . . . . . 51

4.2 .3 Surface Refinement . . . . . . . . . . . . . . . . . 55

4.2 .4 Boundary Layer Cells . . . . . . . . . . . . . . . . . . . 55

4.2 .5 Turbulence Models . . . . . . . . . . . . . . . . . 56

4.2 .6 Wake Refinement . . . . . . . . . . . . . . . 58

4.2.7 Wheel Refinement . . . . . . . . . . . . . . 59

4.3 Run Conditions . . . . . . . . . . . . . . . . . . 60

4.4 CAD and CFD Simplifications . . . . . . . . . . . . 61

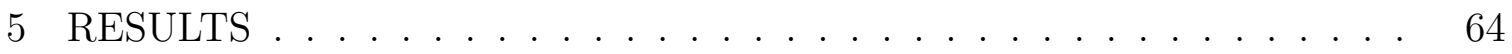

5.1 Baseline . . . . . . . . . . . . . . . . . . . . . . 64 
$5.2 \quad$ Side Skirt . . . . . . . . . . . . . . . . . . . . . . . . . 67

5.3 Ride Height $\ldots \ldots \ldots \ldots \ldots$

5.4 Extended Diffuser . . . . . . . . . . . . . . . . . . . . . . . 74

$5.5 \quad$ Widened Tail . . . . . . . . . . . . . . . . . . 78

5.6 Trends and Comparison $\ldots \ldots \ldots \ldots$. . . . . . . . . . . . . 81

5.7 Results Summary . . . . . . . . . . . . . . . . . . . . . . . . 84

5.8 Implications for the Endurance Car . . . . . . . . . . . . 85

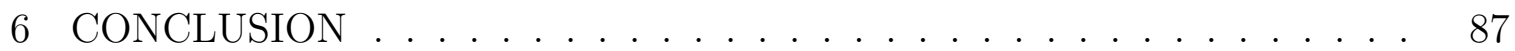

6.1 General Conclusions . . . . . . . . . . . . . . . . . 87

6.2 Future Work . . . . . . . . . . . . . . . . . . . 88

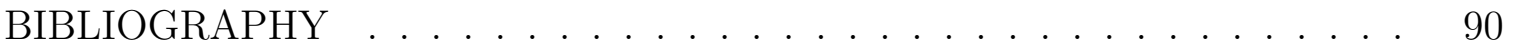
APPENDICES

A Design Renderings . . . . . . . . . . . . . . . . . 97 


\section{LIST OF TABLES}

Table

Page

4.1 Influence of Global Grid Size on Drag Values . . . . . . . . . . . . . 50

4.2 Influence of Domain Downwind Length on Drag Values . . . . . . . 51

4.3 Influence of Domain Upstream Length on Drag Values . . . . . . . 52

4.4 Influence of Domain Width on Integral Values . . . . . . . . . . 53

4.5 Influence of Domain Height on Integral Values . . . . . . . . . . . . 54

4.6 Influence of Surface Grid Size on Drag Values . . . . . . . . . . 55

4.7 Influence of Turbulence Model and Solving Method on Drag Values 57

4.8 Influence of Wake Grid Size on Drag Values . . . . . . . . . . . . 59

4.9 Influence of Wheel Grid Size on Drag Values . . . . . . . . . . . 59

4.10 CFD Physics Model . . . . . . . . . . . . . . . . 60

5.1 Resultant Forces on Baseline Model . . . . . . . . . . . . . . 64

5.2 Resultant Forces on Side Skirt Model . . . . . . . . . . . . . . 67

5.3 Resultant Forces on Raised Ride Height Model . . . . . . . . . . . 71

5.4 Resultant Forces on Extended Model . . . . . . . . . . . . . . 75

5.5 Resultant Forces on Wide Rear Model . . . . . . . . . . . . . 78

5.6 Case Force and Lift Data I . . . . . . . . . . . . . . . . . . 84

5.7 Case Force and Lift Data II . . . . . . . . . . . . . . . . . . . 84 


\section{LIST OF FIGURES}

Figure

Page

1.1 PROVE Lab Dawn Solar Car . . . . . . . . . . . . . . . 4

1.2 Sunswift eVe (left) and IVy (right) $[37] \ldots \ldots \ldots$

1.3 Example of Endurance Car Initial Design Render . . . . . . . . . . 6

2.1 Modifications to a Teardrop Body near the Ground. From Le Good et al. (2011) [32]. . . . . . . . . . . . . . . . . . . 9

2.2 Vortices on a Wheel in a Wheel House. From Regert and Lajos (2006) [39] . . . . . . . . . . . . . . . . . . . 12

2.3 The $C_{p}$ in a Venturi. From Katz $[27] \ldots \ldots$. . . . . . . . . 15

2.4 Analysis Regions on Ahmed Body with Diffuser. Adapted from Huminic et al. (2010) [20] . . . . . . . . . . . . . . . . . 16

2.5 Lift and Drag Response of Ahmed body with Wheels, Varying Diffuser Length and Divergence Angle. From Huminic and Huminic

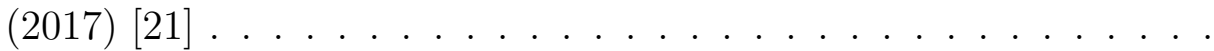

2.6 Diffuser on Ahmed Body with End Plates. From Cooper et al. (1998)

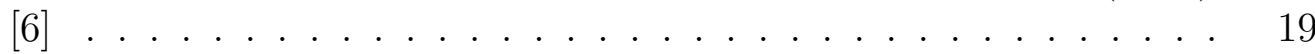

2.7 Vortices in a Diffuser with End Plates, from Katz (2006) [28] . . . . 20

2.8 Influence of Side Skirt Height on Downforce, from Katz (2006) [28] 22

2.9 Estimation of $C_{p}$ Distribution Change on Underside of Side Pod with Skirt Gap Height. Adapted From Katz (1995) [27] . . . . . . . . . . 23

2.10 Side Skirt Implementation on Truck Model. From Kim and Lee (2016) [29] . . . . . . . . . . . . . . . . . .

2.11 Oil Flow Visualization on Underside of $5^{\circ}$ Diffuser at $30 \mathrm{~m} / \mathrm{s}$ With End Plates. Adapted from Ruhrmann and Zhang (2003) [41] . . . . 24

2.12 Force Response on Ahmed Body with Varying Diffuser Angle. From Cooper et al. (1998) [6] . . . . . . . . . . . . . . . 
2.13 Pressure Distribution Along Centerline of Ahmed Body with $\theta=$ 9.64․ From Cooper et al. (1998) $[6] \ldots \ldots \ldots$

2.14 Drag Response on SAAB 9-3 Sedan and Wagon with Diffuser Divergence Angle. From Levin and Rigdal (2011) [33] . . . . . . . . 28

$3.1 \quad$ Free-Body Diagram of Vehicle on Incline . . . . . . . . . . 30

3.2 Resistance Forces on the Endurance Car, using $C_{D}=0.211 \ldots 31$

$3.3 \quad$ Range Dependence on $C_{D}$ and $V$ for $100 \mathrm{kWh}$ Battery $\ldots \ldots .33$

3.4 Baseline CAD Model . . . . . . . . . . . . . . . . . . . . . 34

3.5 Separation Zones at Rear of Baseline Model . . . . . . . . . . . . 34

3.6 Comparison of Baseline and Side Skirt Models . . . . . . . . . . 36

3.7 Comparison of Baseline and Side Skirt Models, Underbody View . . 37

3.8 Model with Raised Ride Height, Exaggerated for Visibility . . . . . 38

3.9 Divergence Angles of the Extended Rear Model . . . . . . . . . 40

3.10 The Modified areas of the Baseline Model (Profile View) . . . . . 41

3.11 The Modified Areas of the Baseline Model (Rear View) . . . . . . . 41

3.12 Separation on Underside of Baseline Model . . . . . . . . . . . . 42

3.13 Comparison of Diffuser Size on Baseline (a) and Wide Tail (b) Models 43

4.1 Origin of the CAD and CFD models $\ldots \ldots \ldots \ldots$

4.2 Finalized computational domain, measured from origin . . . . . 46

4.3 The CAD model used for the mesh study . . . . . . . . . . . 47

4.4 The global cell size (A) and refined cell size close to model (B) . . . 49

4.5 Volumetric Refinement, View Along Symmetry Plane . . . . . . . 50

$4.6 \quad$ Finalized CFD Domain Size . . . . . . . . . . . . . . . 54

$5.1 \quad$ Isosurface Showing Longitudinal Velocity Equal to $0.1 \mathrm{~m} / \mathrm{s}$, Baseline Model. (Replication of Figure 3.5) . . . . . . . . . . . . . 65 
$5.2 C_{p}$ Behavior on Underside of Baseline Model, $20.32 \mathrm{~cm}$ from Ground 66

$5.3 C_{p}$ Behavior on Underside of Side Skirt Model, $20.32 \mathrm{~cm}$ from Ground 68

5.4 Comparison of Baseline and Side Skirt Models' $C_{p}$ Distributions . . 69

5.5 Rear Separation Regions, Side Skirt Model and Baseline Model. Isosurface Showing Longitudinal Velocity Equal to $0.1 \mathrm{~m} / \mathrm{s}$. . . . . . . 70

$5.6 \quad C_{p}$ Behavior on Underside of Raised Ride Height Model, $22.86 \mathrm{~cm}$ from Ground . . . . . . . . . . . . . . . . . . . . . . . 72

5.7 Comparison of Baseline and Raised Ride Height Models' $C_{p}$ Distributions ....................... 73

5.8 Rear Separation Regions, Raised Ride Height Model and Baseline Model. Isosurface Showing Longitudinal Velocity Equal to $0.1 \mathrm{~m} / \mathrm{s} . \quad 74$

$5.9 C_{p}$ Behavior on Underside of Extended Model, $20.32 \mathrm{~cm}$ from Ground 76

5.10 Comparison of Baseline and Extended Models' $C_{p}$ Distributions . . 77

5.11 Rear Separation Regions, Extended Model and Baseline Model. Isosurface Showing Longitudinal Velocity Equal to $0.1 \mathrm{~m} / \mathrm{s}$. . . . . . . 77

$5.12 C_{p}$ Behavior on Underside of Widened Model, $20.32 \mathrm{~cm}$ from Ground 79

5.13 Comparison of Baseline and Wide Rear Models' $C_{p}$ Distributions . 80

5.14 Rear Separation Regions, Wide Rear Model and Baseline Model. Isosurface Showing Longitudinal Velocity Equal to $0.1 \mathrm{~m} / \mathrm{s} . \quad$. . . . 81

$5.15 C_{p}$ Behavior of All Cases, $20.32 \mathrm{~cm}$ from Ground. Boxed Area Shown in Figure $5.16 . \quad \ldots \ldots \ldots$. . . . . . . . . . . . . . . . . . 82

5.16 Detail of $C_{p}$ in Diffuser for All Cases, $20.32 \mathrm{~cm}$ from Ground . . . . 83

5.17 Range of Wide-Rear Model with Velocity and Battery Pack Size Variation .................... . . 85

A.1 Design Rendering A . . . . . . . . . . . . . . 97

A.2 Design Rendering B . . . . . . . . . . . . . . . . 98

A.3 Design Rendering $\mathrm{C} \ldots \ldots . \ldots . \ldots 9 . \ldots . \ldots$

A.4 Design Rendering D . . . . . . . . . . . . . . . . 99 
A.5 Design Rendering E . . . . . . . . . . . . . . . 100 
Chapter 1

INTRODUCTION

\section{$1.1 \quad$ Electric Vehicles}

Automotive transporation has progressed significantly since its inception. Compared to their primordial ancestors of the twentieth century, modern cars offer incredible range, comfort, and speed. The extant network of highways and plentiful refilling stations have made long-distance trips an almost routine experience. Advancements in handling, interior comfort, and noise reduction have made modern automotive travel to be a comparatively luxurious and comfortable experience; modern automobiles also offer much improved performance and efficiency over their forebearers.

Yet, modern vehicles are not much improved over their century-old ancestors in one regard: the continued use of internal combustion for power generation. While the early years of automobile transport saw up to a third of vehicles on American roads powered by electricity, gas-powered vehicles had surpassed electric vehicles (EVs) in ease of use and popularity by the 1920's [47]. Since then, the internal combustion engine (ICE) has remained the primary powertrain of choice.

The recent reintroduction of high volume EVs into the automotive market has spurred new consumer interest [23]. EV numbers worldwide have grown from less than half a million vehicles in 2013 to over 3 million in 2017, with total numbers projected to reach, at minimum, 130 million by 2030 [23]. Despite this huge growth, the problem of range anxiety continues to hinder widespread adoption of EVs by the general public. 


\subsubsection{Range Anxiety}

Range anxiety can be defined as psychological stress to an EV driver, based on the anticipated situation of being stranded without ability to recharge the vehicle [26]. It has been shown that drivers exhibit signs of stress upon the onset of the this condition, which could lead to avoidance of or mistrust of EVs [26]. Such fears hinder the public perception of EVs, which negatively affect their popularity and use.

\subsection{Endurance Car Project}

The Prototype Vehicles Laboratory (PROVE Lab) Endurance Car project is intended to alleviate range anxiety by demonstrating that an EV can achieve long range at highway speeds, and do so with attractive styling. The primary goal of the Endurance Car is to break the Guinness World Record for a single-charge range of an $\mathrm{EV}$, by achieving a range of 1000 miles. A secondary goal of the project is to do so at

freeway speeds (between 15 and $35 \mathrm{~m} / \mathrm{s}$ ). While the final run speed is not determined as of this writing, the design speed is $65 \mathrm{mph}(29.06 \mathrm{~m} / \mathrm{s})$.

\subsubsection{EV Performance}

Modern electric vehicles have matured enough to equal and surpass the outright performance of race cars. The Volkswagen ID $\mathrm{R}$ is a high-profile example of an EV that is more capable than its ICE-powered counterparts: it beat out ICE race cars to break the Pike's Peak Hillclimb and Goodwood Hillclimb overall records in 2018 and 2019, respectively, and set a new EV lap record at the Nurburgring in 2019, that is comparable to an ICE race car [35] [38] [16]. 
Another advantage EV's have over their internal-combustion engine (ICE) counterparts is in energy efficiency. An ICE-powered vehicle can use up to $30 \%$ of its stored energy for forward movement, with the rest of the energy lost to drivetrain and engine inefficiencies, as well as accessories [48]. However, an EV can utilize up to $94 \%$ of its stored energy for forward movement, due to the reduction in moving parts and drivetrain mechanical complexity [48]. Because of this bump in powertrain efficiency, a higher percentage of an EV's energy will go toward overcoming aerodynamic drag than an ICE counterpart [48]. Thus, a reduction in the aerodynamic drag of the body shell is much more important to an EV in increasing vehicle efficiency than in an ICE counterpart.

\subsubsection{EV Records}

As with ICE-powered vehicles, EV's have a history of performance feats through competition. As of 2019, the Guinness World Records land speed record for a solarpowered vehicle is $25.37 \mathrm{~m} / \mathrm{s}$, set in 2014 by the Ashiya University Sky Ace TIGA [17]. Shortly after this record was announced, PROVE Lab was established, and its first project was to design and build a solar car to break the record. This led to the creation of the Dawn solar car, which is designed to achieve $65 \mathrm{mph}$ with no onboard energy storage.

However, solar car records are of little direct consequence to the common consumer, as the vast majority of EVs derive their power from batteries, not solar cells. As of May 2019, the Guinness World Records record for the greatest distance travelled by an EV on a single charge without the use of solar power is 1,608.54 kilometers (999.5 miles) [18]. This record was set by 'The Phoenix', a purpose-built vehicle created by IT Asset Partners, Inc [18]. The Phoenix was built from an E39 BMW 528i with recycled batteries and components, and achieved 340 miles in April 2017, before 


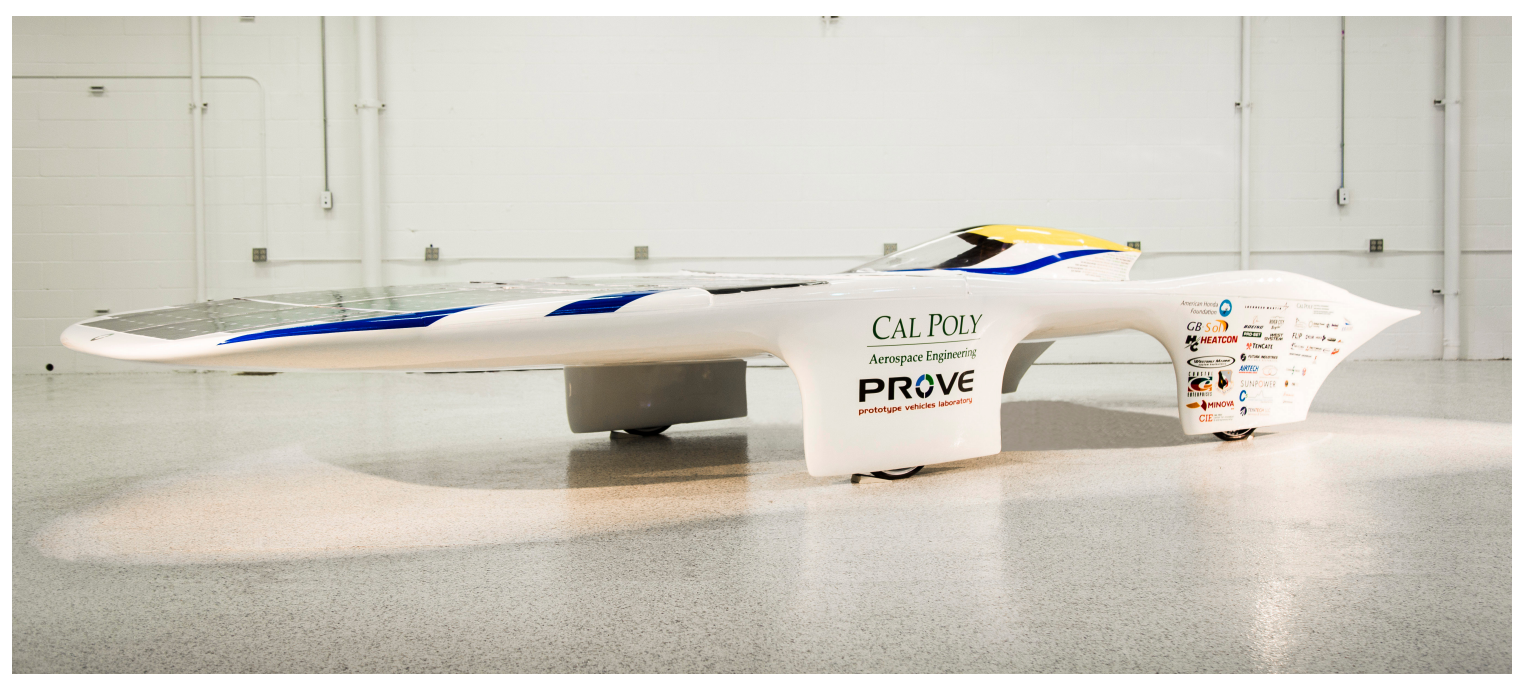

Figure 1.1: PROVE Lab Dawn Solar Car

breaking the record with updated components in October 2017 [15] [18]. The overall record for the range of a non-solar EV is $1773.8 \mathrm{~km}$, set by the Proterra Catalyst E2 Max, an all-electric bus [14].

There is precedent in aerodynamic design of long-range EV's: the World Solar Challenge (WSC). The WSC spans the height of the continent of Australia, with a total distance of 3,021 kilometers (1877 miles) [37]. Until 2012, the WSC had traditionally been run with large, wing-shaped solar vehicles, such as the SunSwift IVy in figure 1.2 [37]. However, the addition of the Cruiser class in 2012 allowed for the design and competition of vehicles with exterior styling reminiscent of conventional road cars [37]. This allowed the University of New South Wales (UNSW) Sunswift team to develop eVe, a hybrid solar-battery EV designed to have proportions similar to a supercar, with both a $4 m^{2}$ solar array and a $16 \mathrm{kWh}$ battery packaged in the vehicle [37]. The difference between the two types of vehicles can be seen in figure 1.2, in which the traditional solar car design of IVy stands in contrast with the road-car design of eVe.

The Endurance Car project has two objectives: to break the EV single-charge 


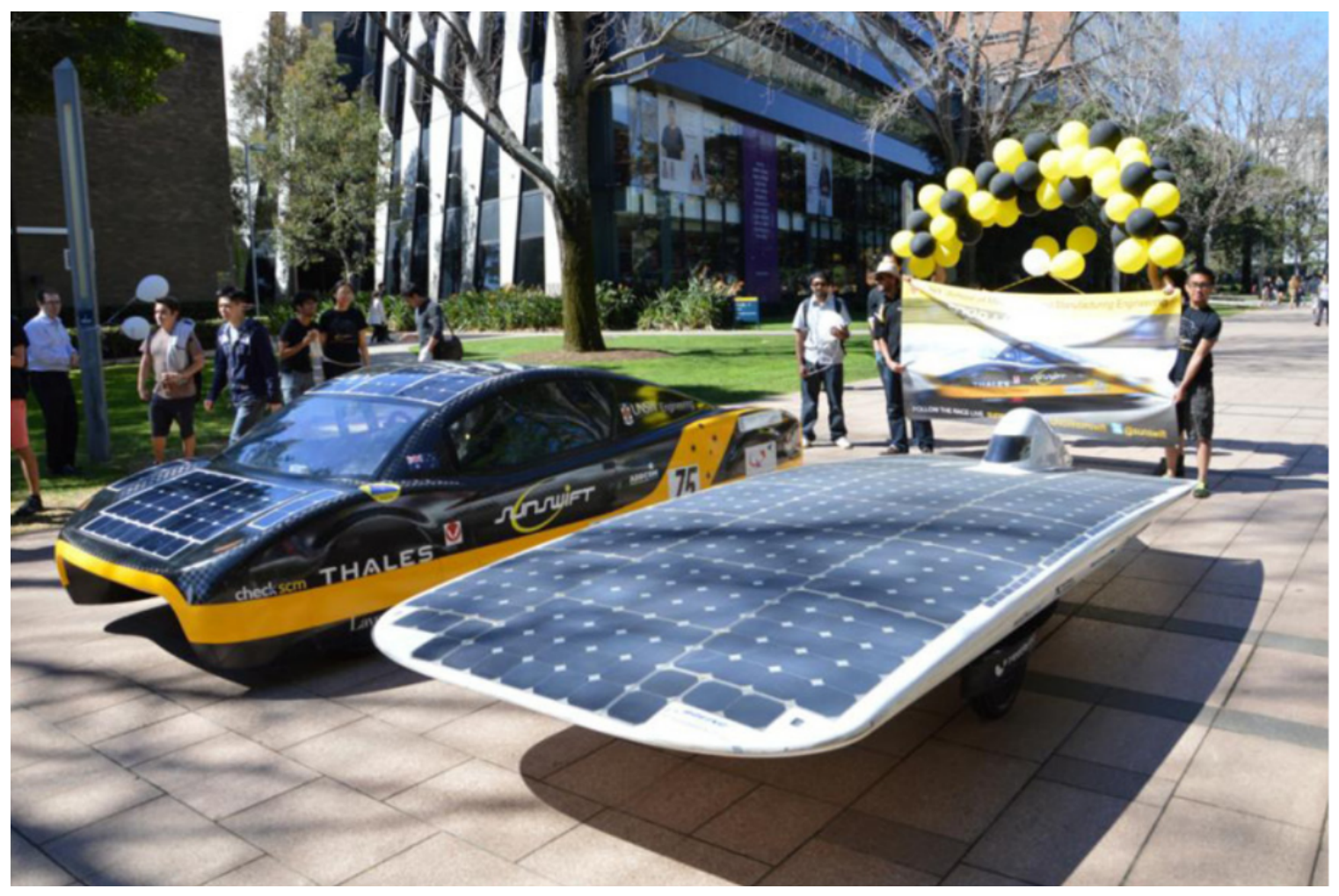

Figure 1.2: Sunswift eVe (left) and IVy (right) [37]

range record, and to do so with a vehicle that had the proportions of a sports car. A design range of 1000 miles was selected, as the Endurance Car team was aiming solely for the Guinness World Record. Additional constraints were self-imposed on the project by the team, most notably adherence to the design renderings, and that the exterior shell had to contain all of the vehicle systems except for the motors, wheels, suspension, and steering components.

\subsubsection{Design}

While aerodynamic performance and aesthetics are not inherently at odds, there is often a divide between the two in modern car design [32]. Aerodynamicists typically do not have a large amount of input into the design of the vehicle until late in the design stage, and their ability to affect the design is limited [32]. In order to break 
away from this traditional method, an initial emphasis was put on aesthetics, to generate a design similar to the initial design renderings of the vehicle. Figure 1.3 shows a preliminary design rendering of the Endurance Car. The CAD model was created from these renderings, and drew inspiration from contemporary sports cars.

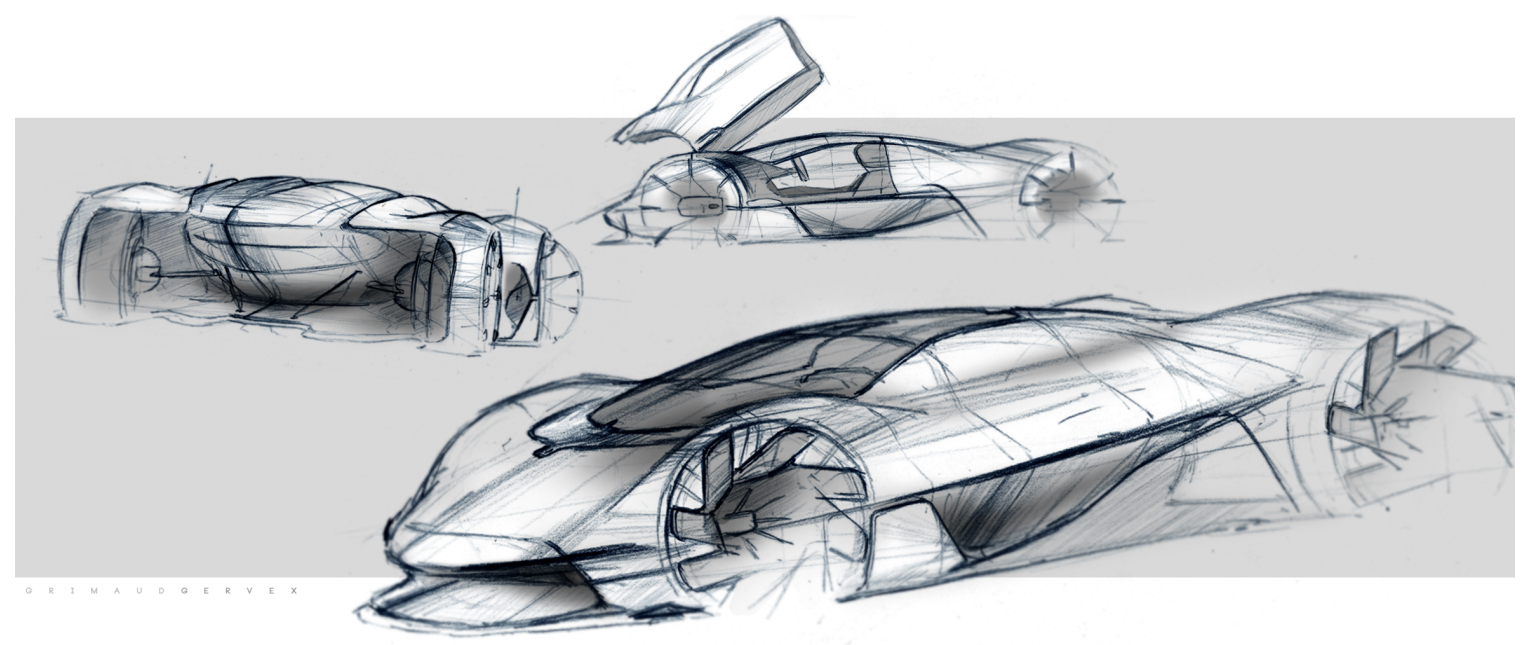

\section{Figure 1.3: Example of Endurance Car Initial Design Render}

After the aesthetic design was created, aerodynamic refinements and packaging considerations drove the design and shape of the vehicle.

The goal of this thesis is to reduce the drag of the Endurance Car via alteration of the under-body flow field, by the addition of side skirts, or by adjustment of the body ride height or geometry. A secondary goal of the project is to find a decrease in downforce. This would be beneficial because the downforce also contributes to the resistance that the vehicle must overcome during operation. 
Chapter 2

\section{LITERATURE REVIEW}

\subsection{Automotive Aerodynamics}

While the major concepts of aerodynamics stay constant between aircraft and automobiles, there are facets of their design process that differ [4]. The most major difference is that automobiles travel in close proximity to a large, solid surface, and must use wheels and tires for movement, while aircraft do not. The fact that there is a large moving plane in close proximity to a vehicle body manifests itself in the resultant forces on the vehicle; the drag on a body increases when in proximity to the ground, compared to free stream [4]. Additionally, either a low or high pressure region can easily be created beneath the automobile (depending on aerodynamic devices used),

which will have a large effect on the downforce or lift [4]. The wake of the vehicle will also be affected; the ground plane serves as a reflection point for any vortices that come off of the vehicle [4] [21].

\subsubsection{Vehicle Bodies}

In free stream, a symmetric teardrop body with $t / c=0.25$ will have $C D=0.05$ [4] [32]. The effect of a teardrop in free stream, and near the ground is shown in figure 2.1. However, when lowered toward the ground, the drag of the teardrop increases significantly [19]. If the body is cut in half such that only its top half remains, as in part $\mathrm{B}$ of the figure, the body will have $C D=0.13$ [32]. The minimum drag of the

body near the ground occurs if the resulting edge from the cut in part B is filleted ( shown in part $\mathrm{C}$ in the figure), which has $C D=0.09$ [32]. Once wheels are added 
back to the body, its drag increases again, to $C D=0.15$ [32]; this can be seen in part $\mathrm{D}$ of the figure.

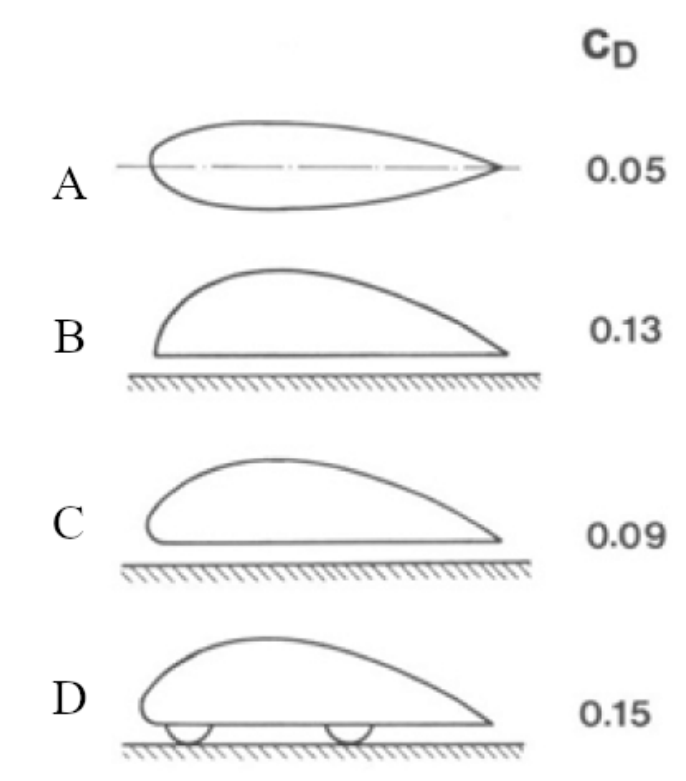

Figure 2.1: Modifications to a Teardrop Body near the Ground. From Le Good et al. (2011) [32].

However, a modern road vehicle's body does not easily lend itself to an aerodynamic shape such as a teardrop [4]. The common requirements of seating two passengers side-by-side, an engine, and cargo space, tend to lead to a rectangular cross-section, with a two or three box profile [4]. Because of this incongruity, there are two general directions that historical aerodynamically-efficient vehicles take as their starting point: an aerodynamic body, such as the teardrop shape, or the more common approach of a production-car shape from a designer that has been shaped to reduce drag [4]. It is not impossible, however, to design a vehicle that can have a conventional passenger arrangement and a relatively low drag coefficient; one notable example is the Pininfarina CNR-PF, which had $C D=0.16$, and was intended to be a conventional-looking vehicle [4]. The Pininfarina was a concept car; in practice, a low-drag shape can be reached in the form of a Kamm-back design [4]. For a car with a teardrop-shaped profile, it is likely that separation will happen in the aft section 
of the body [19]. Kamm found that if the rear of the vehicle is truncated shortly upstream of where the separation takes place, there is minimal drag penalty [19]. This is a Kamm-back design, and can be found on many aerodynamically-inclined vehicles.

It is not just the visible portions of a vehicle that need to be aerodynamically shaped; the underside of a car plays a role in drag. It is estimated that the underside of a vehicle can have $C D_{\text {underside }}=0.07$ by itself, when the exhaust, chassis, and suspension are considered [4]. Smoothing out the underside by hiding these features helps to lower this value. The increased speed that a smooth underbody provides will magnify any effect that the wheels have on the underbody flow [36], so care must be taken to ensure that the increased drag from the wheels does not outweigh the gains from the smoothed floor. An additional way to lower the drag of the underbody of a vehicle is to induce upsweep, in the form of a diffuser [4]. This is expanded upon in section 2.2 .

Aside from the drag of the shape itself, another source of drag is the trailing vortices that can be incurred by the body of the car [4]. Like on the tips of an aircraft wing, trailing vortices that appear on automobiles form from local pressure gradients across intersections and corners [19]. A trailing vortex can be the source of drag because it serves to lower the pressure on the rear surface of a vehicle, which serves to pull the vehicle backward [4].

The drag on an automotive body can be separated into two parts: the pressure drag, and the shear drag [4]. The pressure drag is the component of drag caused by unbalanced pressure, and the shear drag is generated from the skin friction on the body [4]. 


\subsubsection{Pressure and Shear Drag}

Automotive bodies are commonly referred to as bluff bodies, or bodies whose drag is dominated by pressure drag [45]. Pressure drag is caused in part by boundary layer separation on a body [45]. Boundary layer separation is caused by an adverse pressure gradient and zero or reversed flow near the surface of a body [1].

In contrast to pressure drag, shear drag mainly comes from the skin friction from attached flows over a vehicle [45]. The drag on a modern vehicle with little separation is dominated by the shear drag [4]. The shear drag is minimized when the laminar boundary layer is achieved on a majority of the vehicle; however, this is difficult to achieve in practice due to the velocities (Reynolds numbers) that road vehicles travel at [4]. Even if a laminar boundary layer cannot be obtained, a favorable pressure gradient over the vehicle will discourage boundary layer growth, which assists in keeping shear drag to a minimum [4].

\subsubsection{Wheels}

A wheel in an airflow induces a very convoluted flow field inside of a wheel housing. Figure 2.2 shows the vortices shed by a rotating wheel in a wheel housing. There are eight of note around the wheel house, denoted, by A, B, C, E, H, S, R, and L [39]. Vortices $\mathrm{R}$ and $\mathrm{L}$ are shed by the interaction between the wheel and the road surface [39]. It can be seen from figure 2.2 that vortex $\mathrm{H}$ forms at the front of the wheel house, and connects to vortex $\mathrm{C}$, which starts at the leading edge of the wheel house rim, and bridges to the face of the wheel [39]. Vortex A starts on the inside surface of the wheel, and travels across the upper surface of the tire to the outside of the wheel house [39]. Vortex B has similar behavior, but exists behind the wheel [39]. As shown in figure 2.2, vortex E starts on the trailing side of the tire, and exits the 
wheelhouse downward, to trail behind the wheel [39]. Vortex S starts on the surface behind the wheel house, and follows the contour of the wheel house opening before turning downstream [39]. The position and strength of each of these vortices depends on the wheelhouse geometry and layout, as well as the yaw angle of the oncoming flow [39].

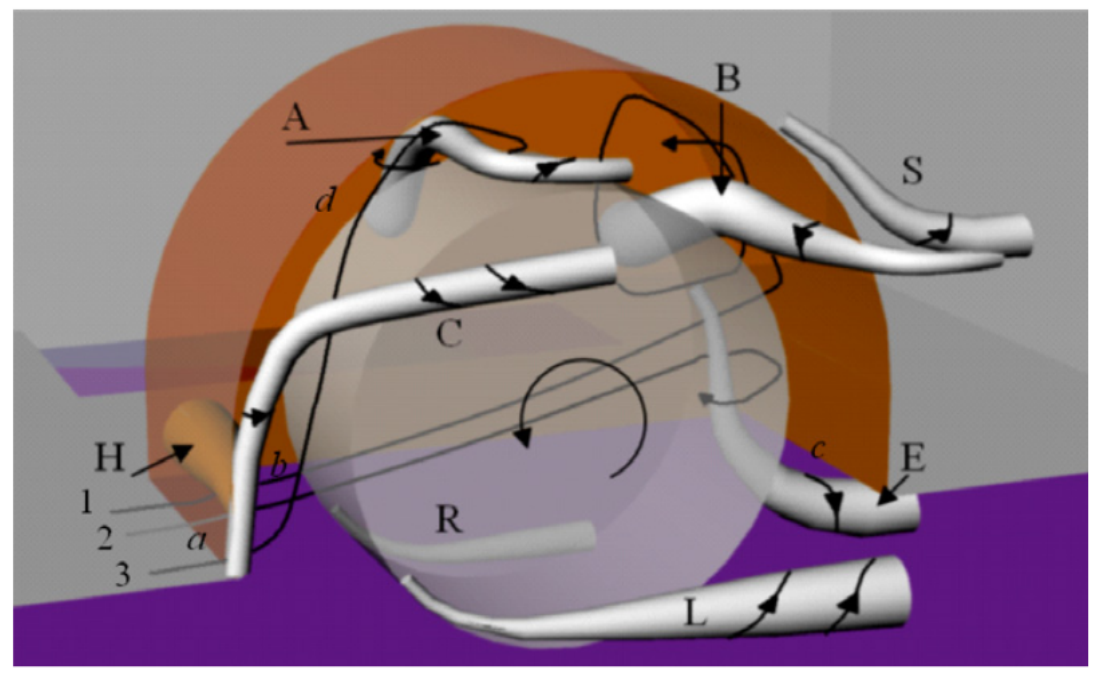

Figure 2.2: Vortices on a Wheel in a Wheel House. From Regert and Lajos (2006) [39]

The choice of a wheel can have a large impact on a vehicle's drag coefficient, even for closed-wheel vehicles [9]. The drag coefficient on a Tesla Model S varies from $C D=0.211$ to $C D=0.257$ depending on the size and design of the wheel: open-face designs (in which the wheel face is dominated by the gaps between spokes) had a higher contribution to the drag coefficient than designs with aerodynamic covers [9]. However, the extreme case, a flat, completely solid wheel, had worse aerodynamic performance than a vented, flat wheel [9]. 


\subsubsection{Vehicle Ride Height}

The Venturi effect takes place under the vehicle body for the majority of ride heights [4]. However, it is possible to lower the ride height to such an extent that it interferes with the boundary layer on the bottom of the vehicle [4]. In such instances, the boundary layer interacts with the ground to constrict the flow, and produce lift on the body [4]. Further investigation of the effect of ride height is in section 2.4.

\subsubsection{Aerodynamics of Electric Vehicles}

As noted in chapter 1, the drivetrain efficiency of EV's is much higher than that of their ICE counterparts. Because of their greater efficiency, EV's must expend a greater percentage of their stored energy toward overcoming drag, and drag reduction has much larger importance on efficiency than for an ICE vehicle. Design for low drag is a fundamental part of EV design, as evidenced by the inclusion of an aerodynamicist

during the initial sketch phases of the development of the Tesla Model S [36]. Barnard lays out several design principles for low-drag vehicles, a selection are outlined below $[4]:$

1. Smooth, unbroken lines with favorable pressure gradients as far back as possible should be used.

2. Strongly unfavorable pressure gradients at the rear should be avoided.

3. The form should produce negligible lift in ground proximity.

4. The underbody should be as smooth and continuous as possible, and should sweep up slightly at the rear. 
5. There should be no sharp angles, except where necessary to avoid cross-wind instability.

6. The front should start at a stagnation line, and curve up in a continuous line.

7. All body panels should have minimal gaps.

8. Excrescences (objects sticking into flow) should be avoided as much as possible.

For the most part, the exterior design process does not change for an EV compared to an ICE vehicle [4]. EV's have much lower cooling requirements than equivalentenergy ICE vehicles [36]. However, there is still the need for a cooling system, which will cause drag [36]. Because of the more flexible architecture of an EV, one possible way to reduce this drag is to vent the exhaust of the cooling system onto the leading edge of the tire, to raise its static pressure [36].

\subsection{Diffusers}

Diffuser analysis touches upon all aspects of the aerodynamic analysis of a vehicle, as changes to the diffuser affect the flow along the entirety of the underside of a body, as well as at the rear, and even the top [4]. An additional benefit of diffuser analysis is that there is a large body of research on the diffuser design, and its impact on road vehicle performance. This allows an educated hypothesis of the impact to the Endurance Car body from the changes made in this work, before the CAD model is even opened.

One common way that diffusers are analyzed is as a venturi. A venturi is a common aerodynamic device characterized by three sections: a converging section, a constantarea section, and an expanding section [27]. The pressure along the centerline of an ideal venturi decreases in the converging section, and increases back to its freestream 
value along the expanding section of the venturi [27]. A diagram of a venturi can be seen in figure 2.3. The decrease and increase of pressure coefficient, $C_{p}$, along the centerline of a venturi is commonly called the Venturi effect.

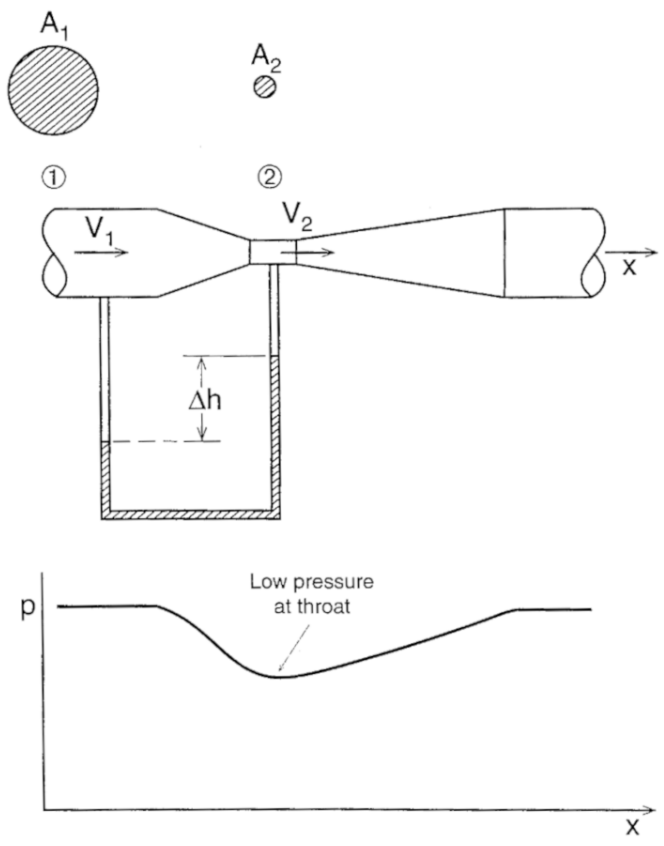

Figure 2.3: The $C_{p}$ in a Venturi. From Katz [27]

Katz (1995) shows that the pressure coefficient along the center line of an underbody on a generic automotive body follows a similar trajectory to that of a venturi [27]. This is supported by the fact that analysis of an automotive underbody can be split into three geometrically distinct regions: a converging section (inlet), a constantarea section, and an expanding section (diffuser) [22]. It is therefore common practice to analyze and to shape the underside of an automotive body as if it were a venturi [27]. Figure 2.4 shows the underside of an Ahmed body broken into said regimes.

There are three phenomena that are useful in describing diffuser performance: ground interaction, underbody upsweep, and diffuser pumping [6]. Ground interaction relates the ride height of the diffuser from the ground with the amount of downforce created [6]. For an inviscid case, the downforce increases to infinity as the ride 
$\odot \mathrm{b}$

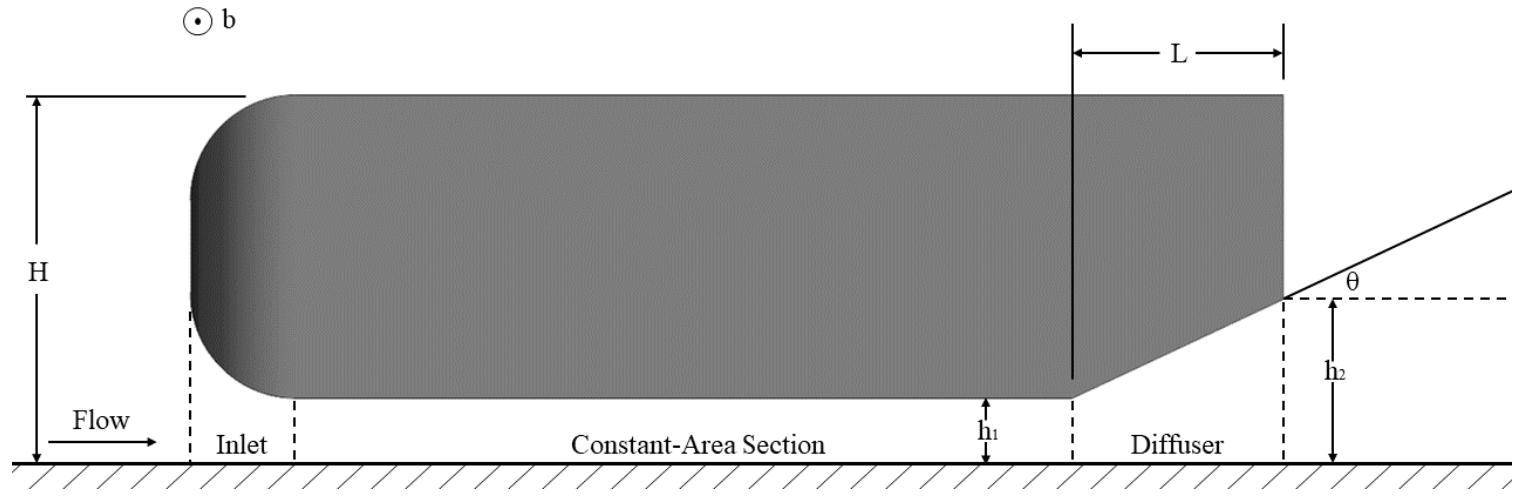

Figure 2.4: Analysis Regions on Ahmed Body with Diffuser. Adapted from Huminic et al. (2010) [20].

height lowers to zero [6]; viscous cases have been shown to follow a similar trend, and diffuser downforce increases as ride height decreases [6]. The presence of upsweep in the diffuser of a symmetric body has been shown to produce downforce on the body [6]. Diffuser pumping refers to the consideration that a diffuser will reduce the static pressure below a body further than if the body did not have a diffuser [6]. The primary parameters by which diffuser pumping can be altered are through the area ratio and the length of the diffuser [6].

\subsubsection{Diffuser Parameters}

In general, a diffuser with a rectangular cross section and planar surfaces can be described by five parameters: the divergence angle $\theta$, diffuser length $L$, entrance height $h_{1}$, exit height $h_{2}$, and depth $b$ [42]. Additionally, the height of the model $H$ and the

entrance size determine the non-dimensionalized ride height $\frac{h_{1}}{H}[6]$. These parameters are shown in figure 2.4. A diffuser's shape can be altered by these parameters, to improve its performance at the design condition. 


\subsubsection{Planar Automotive Diffusers}

One of the most prevalent automotive diffusers is the planar diffuser. A planar diffuser is one that has a flat, planar upper surface. Huminic et al. examine the effect of planar diffusers on an Ahmed body with $35^{\circ}$ upper slant angle [20]. The diffusers were compared against a baseline Ahmed body with a flat underbody [20]. The diffusers had divergence angles between $\theta=1^{0}$ and $\theta=15^{0}$ with lengths $L=0 L_{\text {model }}$ to $L=0.5 L_{\text {model }}[20]$. The results show that for an Ahmed body with said diffusers, the magnitudes of both $C_{D}$ and $C_{L}$ trend downward in all cases [20].

\subsubsection{Effect of Wheels}

The presence of wheels on the underside of an automotive shape also has a large effect on the flow in the diffuser [21]. Huminic and Huminic find that for an Ahmed body with wheels and a diffuser, a standing vortex on the wheel interacts with the vortex at the edge of the diffuser [21]. In turn, this affects the drag and lift of the body [21]. The $C_{L}$ is reduced for every divergence angle, given constant length [21]. This can be seen in figure 2.5: the strength of the effect grows with increased divergence angle and increased diffuser length [21]. The drag response, however, is more complicated.

The addition of wheels to the Ahmed body not only greatly increases the drag, but also modifies the diffuser response. Figure 2.5 shows the drag results of the aforementioned study by Huminic and Huminic. The drag increases slightly for all

divergence angles of the $\frac{l_{d}}{L}=0.1$ case [21]. The $\frac{l_{d}}{L}=0.2$ case generally follows the pattern set by that of its wheel-less counterpart [21]. The $\frac{l_{d}}{L}=0.3$ case sees a decrease in drag until $3^{\circ}$, at which point the trend inverts and the drag then increases at $6^{\circ}$ [21]. This behavior can be explained by the behavior of the two standing vortices 

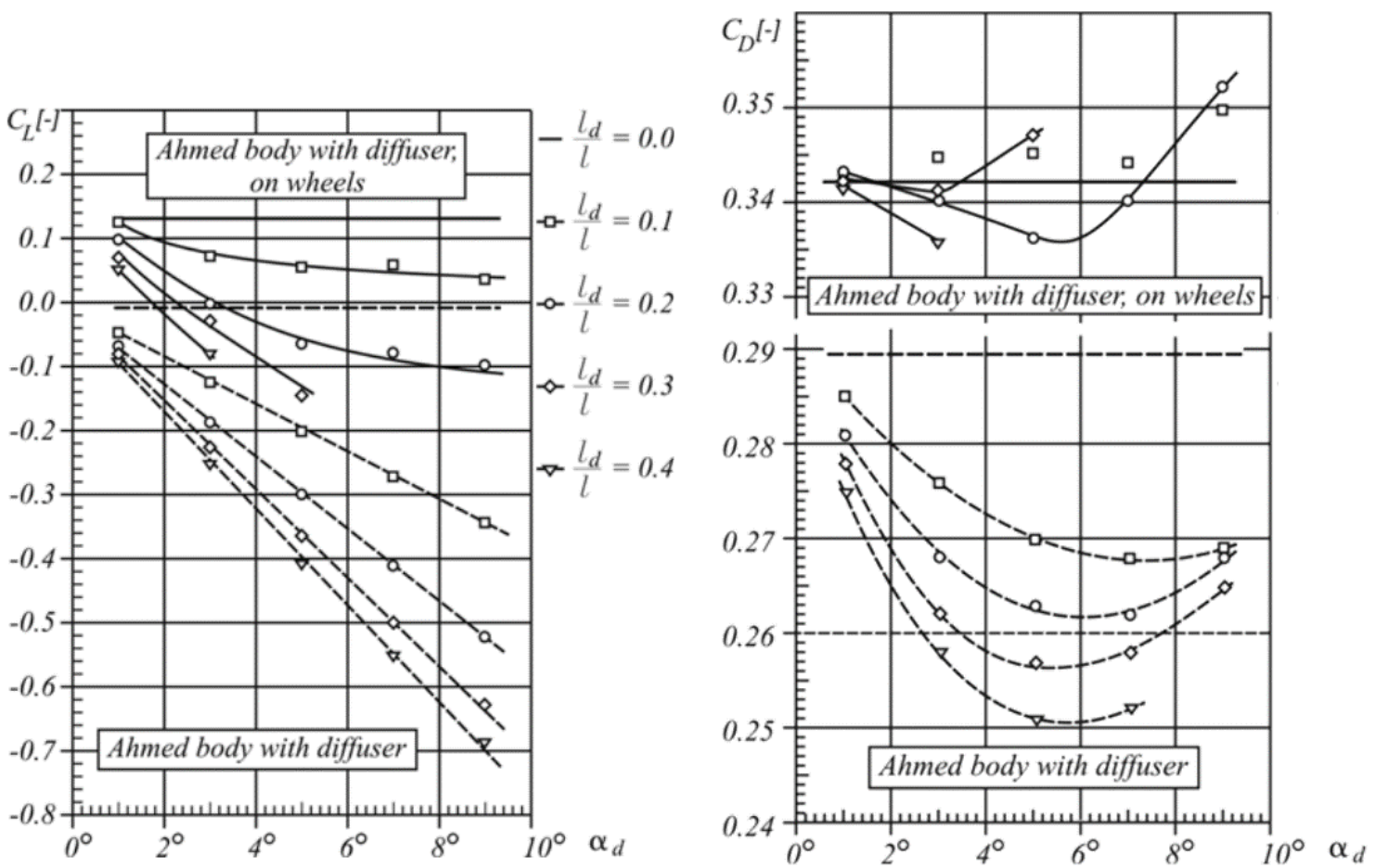

Figure 2.5: Lift and Drag Response of Ahmed body with Wheels, Varying Diffuser Length and Divergence Angle. From Huminic and Huminic (2017) [21]

at the diffuser edges and their interaction with the ground and vortices caused by the wheels [21]: for diffuser angles lower than the minimum drag angle, the vortices reduce with increased diffuser angle due to the interference of the ground plane, thus reducing drag [21]. As the divergence angle increases, the vortices from the wheels interfere with those in the diffuser, causing a corresponding increase in drag due to vortex strength and separation in the diffuser [21].

\subsubsection{Non-Planar and Multi-Channel Diffusers}

The above results apply to single-channel diffusers without end plates [11][20][21]. End plates are vertical devices that are attached to an aerodynamic body to separate the flow on either side of the plate. An example of a diffuser with end plates can be 
seen in figure 2.6. As seen in the figure, the end plates are mounted in the diffuser to extend vertically downward from the diffuse surface, and are flush with the exterior of the body [6].

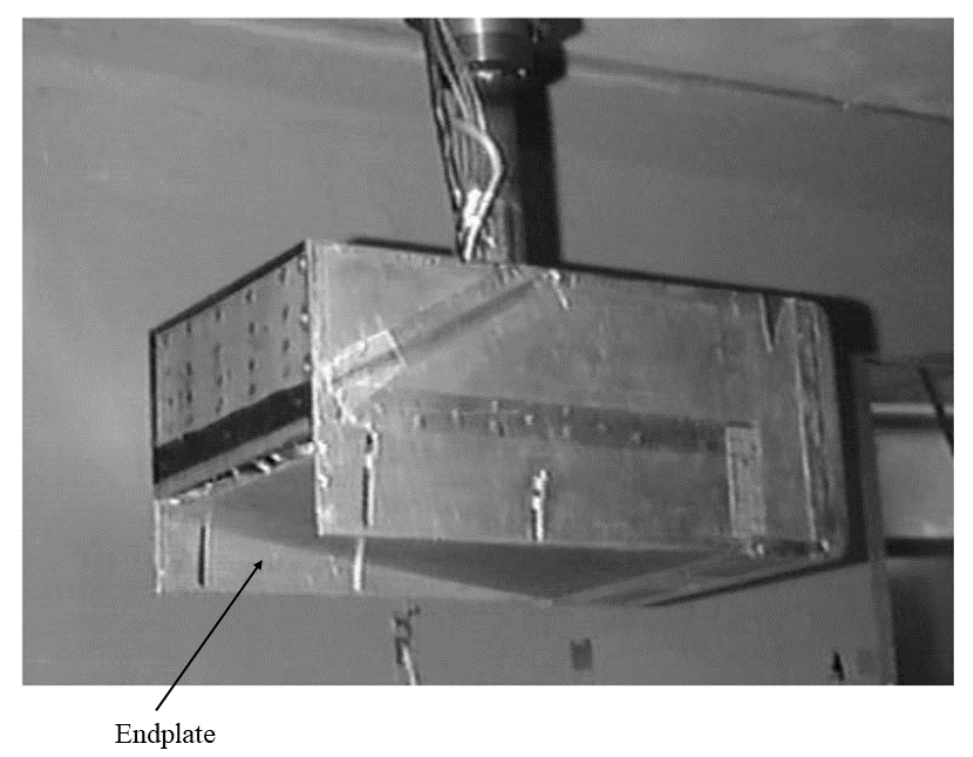

Figure 2.6: Diffuser on Ahmed Body with End Plates. From Cooper et al. (1998) [6]

A lack of end plates on a diffuser can beneficial due to the formation of two counterrotating trailing vortices along the edges of the diffuser [24]. These vortices are important because they introduce upwash onto the diffuser face, delaying separation [24]. When end plates are added to a diffuser, the ability of the vortices to form is reduced, and thus the ability to delay separation is hampered [24]. However, the addition of end plates onto a diffuser can have useful effects, as discussed in section 2.3 .

Jowsey (2013) finds that an Ahmed body with two channels (created from the addition of an additional end plate along the centerline of the diffuser) and end plates demonstrates a reduction of up to $\Delta C_{D}=0.02$ over an Ahmed body fitted with a diffuser with end plates, depending on combination of $\theta$ and $L$ [24]. Additionally, 


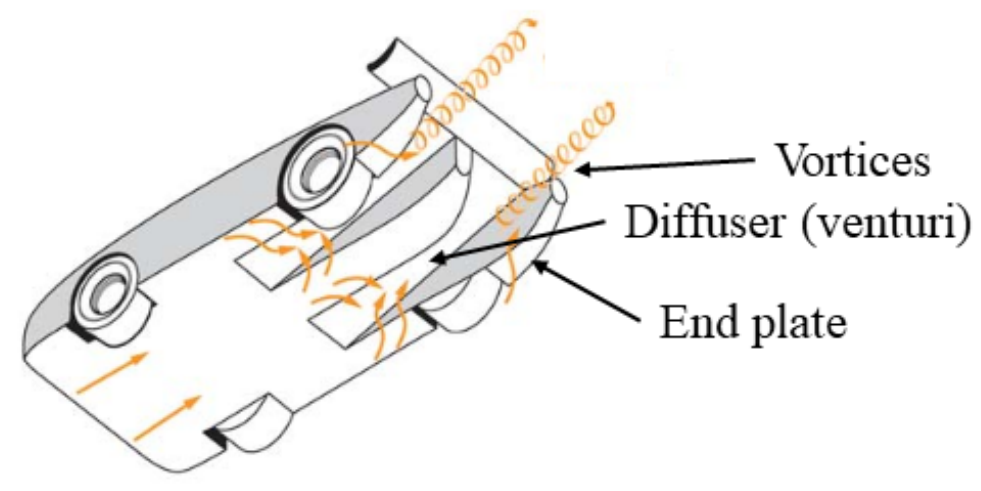

Figure 2.7: Vortices in a Diffuser with End Plates, from Katz (2006) [28]

Jowsey observes that $\frac{C_{L}}{C_{D}}$ trends upward as both $\theta$ and $L$ go toward zero [24].

Passive control of the flow is important in diffusers that have tendencies toward stall. The addition of a streamlined shape into the diffuser has the potential to affect the flow away from stall [11]. Ehirim et al. (2019) find that on an Ahmed body with a square back and a full-width diffuser with $\frac{L}{L_{c}}=0.4$ and $\theta=17^{\circ}$, the addition of a spanwise bump or inverted airfoil can have large changes on the diffuser flow structure [12]. The addition of a bump with $h_{b} u m p=0.004 L_{c}$ and length $L=0.07 L_{c}$ onto the rearmost part of the diffuser.

However, both modified geometries were found to have increased flow turbulence along the outermost parts of the diffuser [12] . Further, in both cases, the addition of modified diffuser geometry increased the drag on the model by 1.8 percent [12]. Toward the outside of the diffuser, the inverted wing shows a large increase in relative velocity in the wake below the wing, but this behavior is absent along the centerline of the body [12]. The inverted airfoil geometry also increases the flow turbulence in the wake downstream of the body [12]. 


\section{$2.3 \quad$ Side Skirts}

Side skirts have a long history in automotive racing applications and in downforce production. Early race cars used flexible side skirts that slid along the ground to seal off the low pressure under-body flow from the flow along the side of the vehicle [28] [4]. These helped to reduce the pressure under the vehicle, and consequently increased the downforce [28] [4].

Sliding skirts have the problem of being sensitive to road surface quality, so development quickly turned to side skirts that minimize the gap between the skirt and the road surface [28]. When used in combination with a diffuser (venturi), as shown in figure 2.8, a side skirt can massively increase the downforce-to-drag ratio of the vehicle body [27]. Figure 2.8 shows the relationship of skirt gap height (distance between road surface and bottom of skirt) and downforce. As can be seen from the figure, a small change in gap height has large consequences for downforce generation.

Figure 2.9 shows an estimation of the relationship between the skirt gap height and the $C_{p}$ distribution on the underside of a side pod [27]. While the gap heights are estimations, the figure clearly shows that decreasing gap height greatly improves the pressure recovery of the diffuser, and thus the downforce on the pod [27].

Even for a portion of a vehicle that is not intended to produce downforce, the addition of side skirts can have an effect on the drag. Kim and Lee (2016) evaluate the effects of side skirts on a $\frac{1}{5}$ scale truck [29]. For a side skirt that completely blocks off the under-body flow of the truck, as seen in figure 2.10, the drag is reduced by $3.1 \%$ [29]. When the skirt is bent inward directly behind the rear wheels, the drag reduces by $6.1 \%$ over the non-skirt case. The separation region from the wheels is reduced by the addition of side skirts, for both the front and rear wheels [29]. 


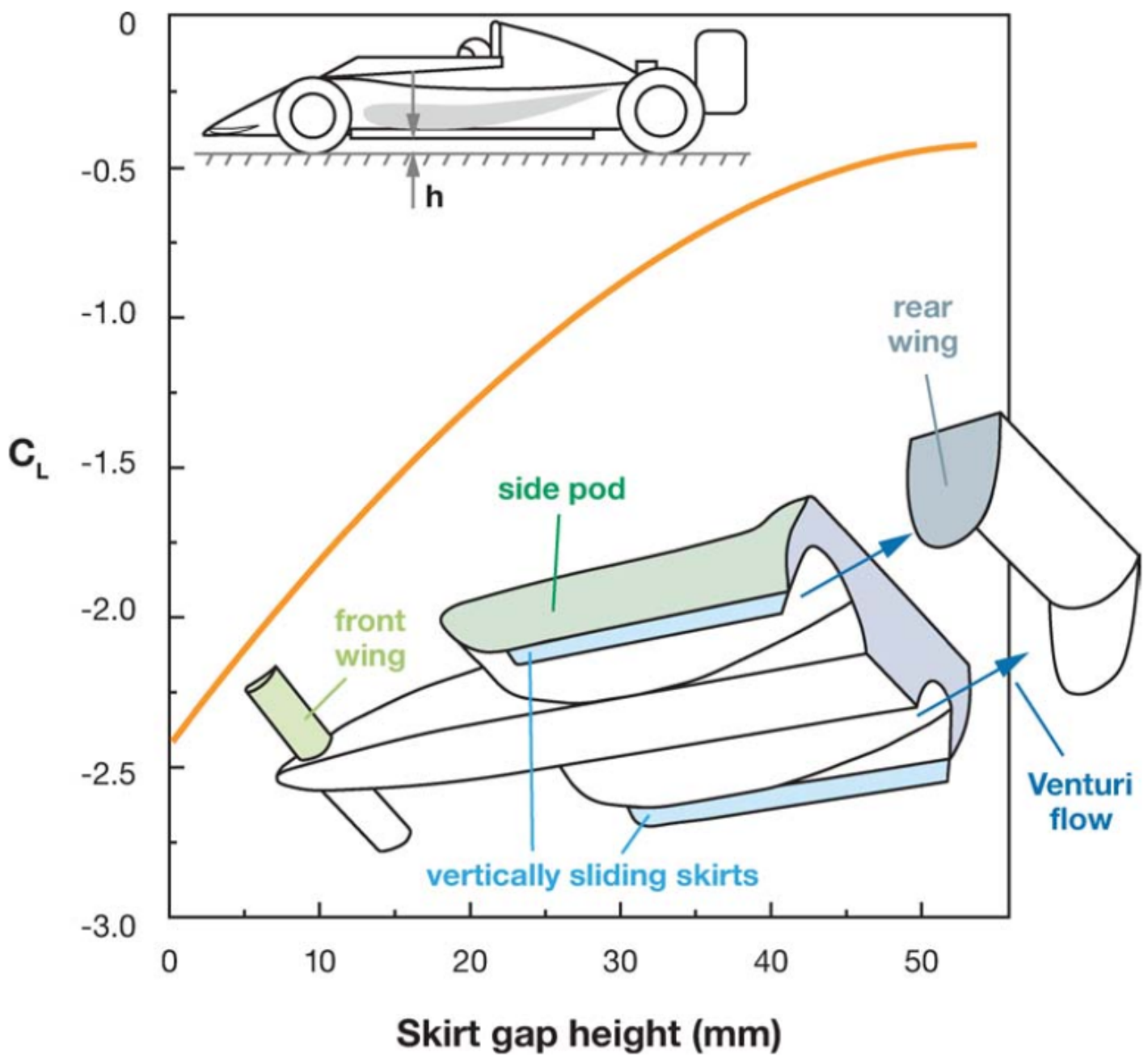

Figure 2.8: Influence of Side Skirt Height on Downforce, from Katz (2006) $[28]$

One common method of analyzing a venturi is to treat it as a wing in ground effect [27]. As with wings on aircraft, it is common to fit end plates onto the wings of race cars to reduce the effect of the tip vortices [4]. If the end plates are sufficiently long, the wing will act very similar to an infinite wing, which does not have a trailing vortex [4]. 

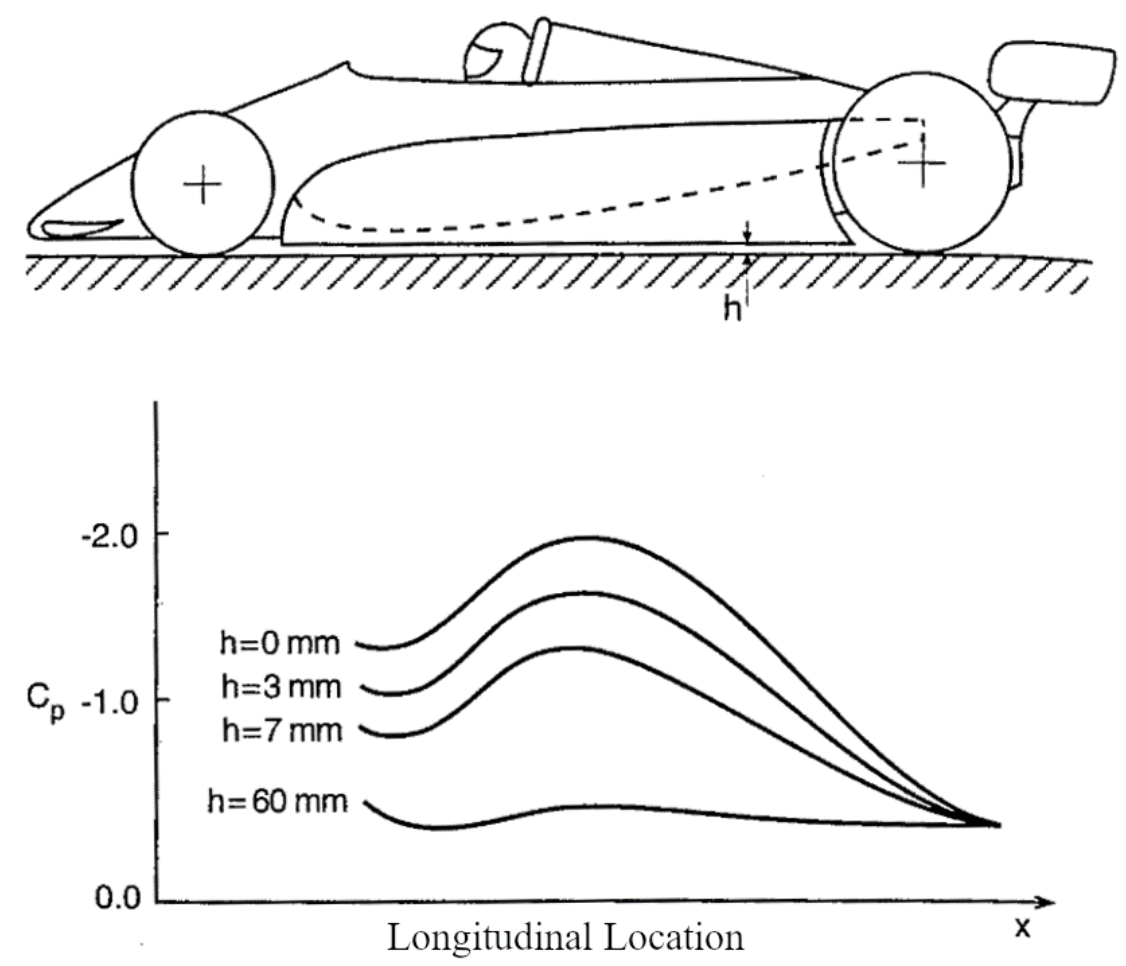

Figure 2.9: Estimation of $C_{p}$ Distribution Change on Underside of Side Pod with Skirt Gap Height. Adapted From Katz (1995) [27]

(a)

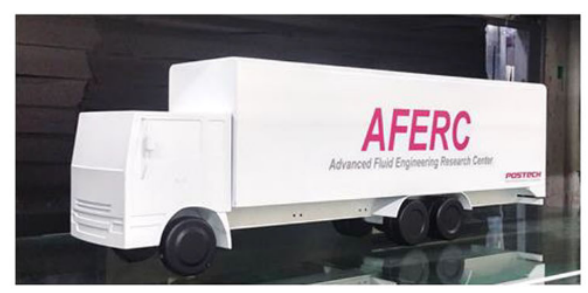

(b)

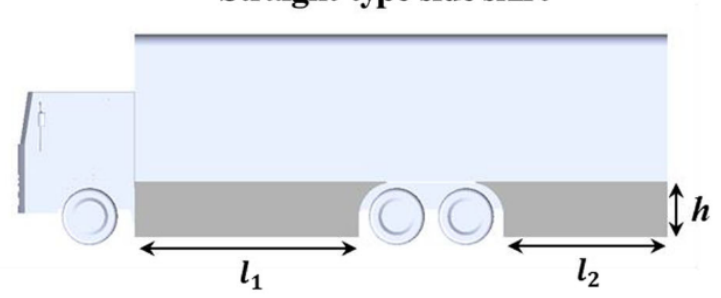

(c)

Flap-type side skirt
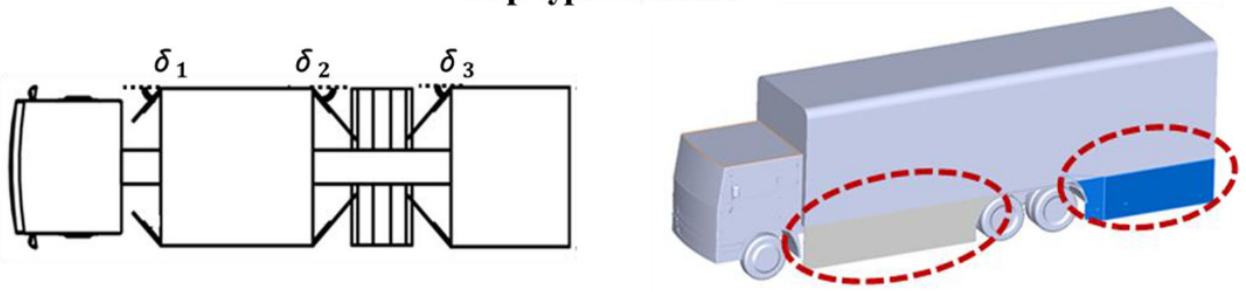

Figure 2.10: Side Skirt Implementation on Truck Model. From Kim and Lee (2016) [29] 
In a similar manner, introducing side plates onto a diffuser or wing in ground effect will reduce the effect of these vortices on drag [4]. The effect of tip vortices on a diffuser can be seen in figure 2.11. As outlined by Ruhrmann and Zhang (2003), the tip vortex does induce upwash onto the diffuser, which aids in reducing separation [41].

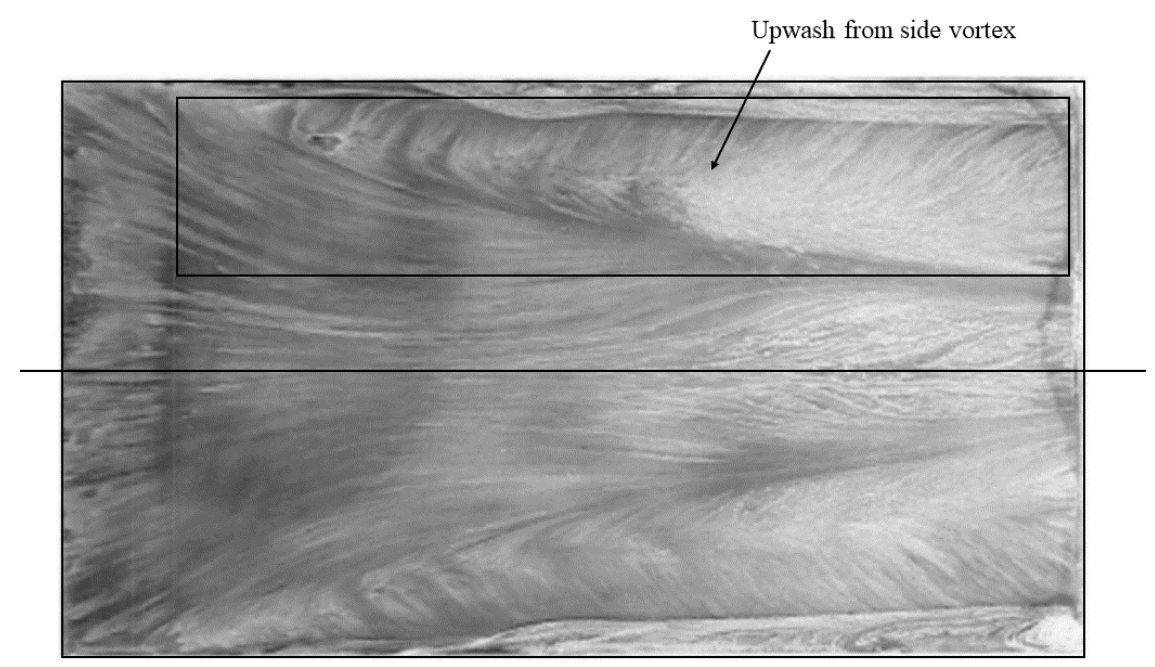

Figure 2.11: Oil Flow Visualization on Underside of $5^{\circ}$ Diffuser at $30 \mathrm{~m} / \mathrm{s}$ With End Plates. Adapted from Ruhrmann and Zhang (2003) [41]

\subsection{Diffuser Ride Height}

One of the simplest changes to a body that can affect the lift and drag is a change in the ride height. Cooper et al.(1998) investigate an Ahmed body with variable diffuser angle and end plates at a variety of ride heights [6]. The results show that for a constant diffuser angle, the $C_{D}$ increases with increasing ride height up to $\frac{h}{H}=0.05$. Past that value, the $C_{D}$ decreases with increasing ride height [6]. The lift exhibits similar behavior; the Ahmed body $C_{L}$ becomes more negative with increasing ride height up to $\frac{h}{H}=0.06$, and becomes more positive with increasing ride height past that value [6]. 

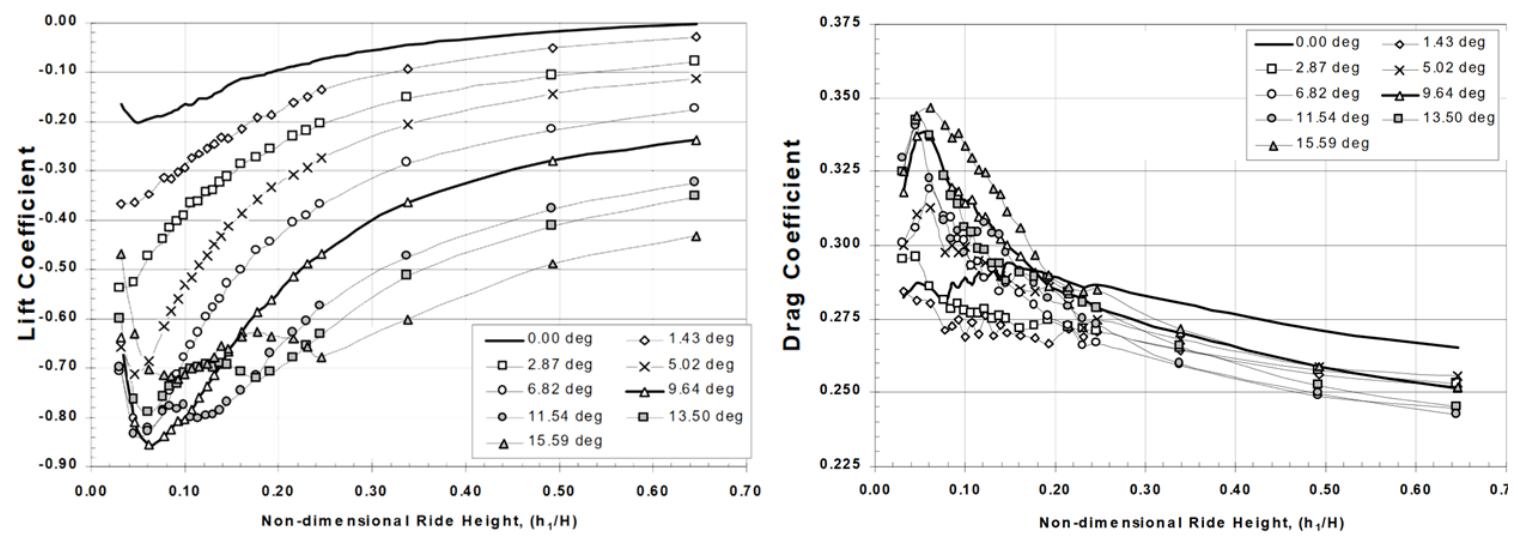

Figure 2.12: Force Response on Ahmed Body with Varying Diffuser Angle. From Cooper et al. (1998) [6]

Experimental results show that for an Ahmed body with a $\theta=9.64^{0}$ planar diffuser with end plates, increasing the ride height of the body is the most effective means of reducing the drag across divergence angle and diffuser length [6] [7].

The underbody pressure gradient is also affected by a change in ride height. Cooper shows that the pressure along the underside of an Ahmed body with a diffuser is reduced with decreasing ride height [6]. This means that the adverse pressure gradient in the diffuser increases, as can be seen from figure 2.13 [6].

\subsection{Diffuser Divergence Angle}

Another parameter that is important in determining the flow field underneath a diffuser-equipped body is the divergence angle. The divergence angle of the diffuser plays a large role in inducing or reducing separation in the diffuser.

Ruhrmann and Zhang (2006) show that diffuser angle has a large effect on the flow field in the diffuser; a $5^{\circ}$ diffuser exhibits stable flow and no separation [41]. However, separation exists on the diffuser with increasing divergence angles, starting 


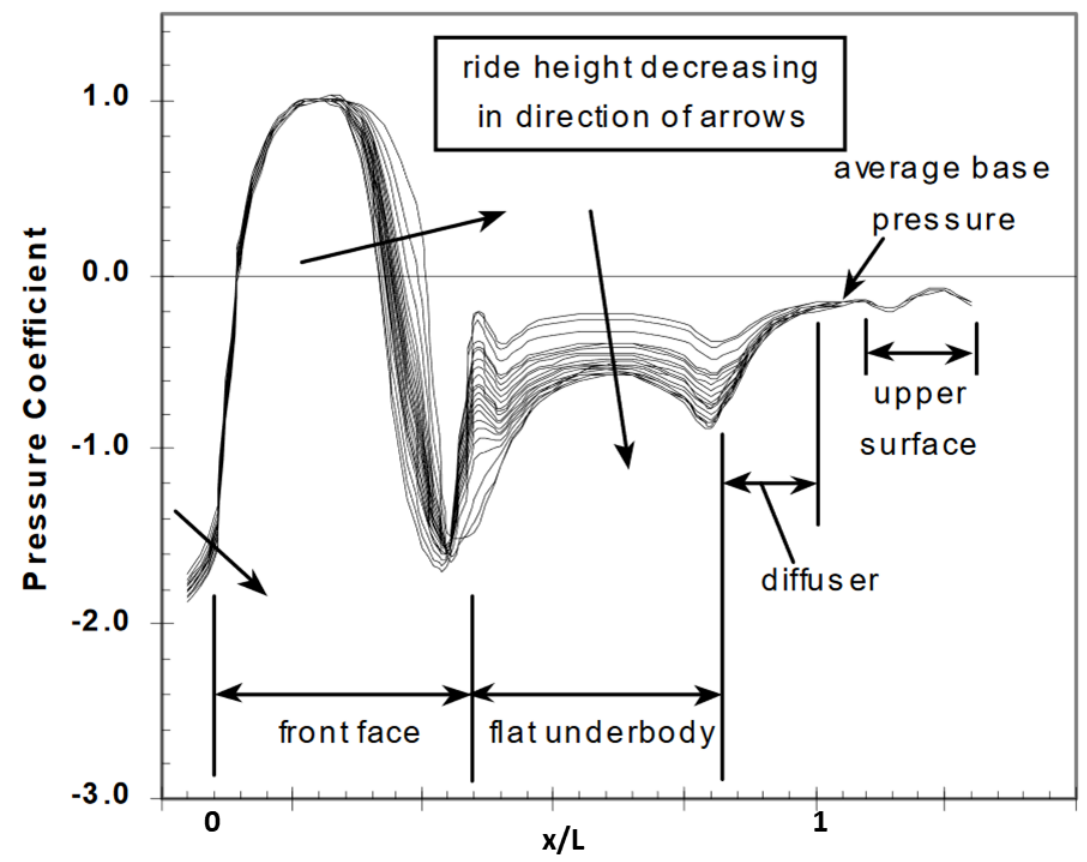

Figure 2.13: Pressure Distribution Along Centerline of Ahmed Body with $\theta=9.64^{\circ}$. From Cooper et al. (1998) $[6]$

at $10^{\circ}[41]$. For angles past $10^{\circ}$, the flow separation moves forward until it reaches a favorable $\left(C_{p}\right.$ decreasing) pressure gradient at the front of the diffuser [41] [13].

The divergence angle also plays a role in the lift and drag response of the body. As mentioned in section 2.2.3, Huminic and Huminic (2017) find that the drag on an Ahmed body decreases with increasing divergence angle between $0^{\circ}$ and $6^{\circ}$, and that the drag increases with divergence angle between $6^{\circ}$ and $9^{\circ}[21]$. The downforce increases with increasing divergence angle for all angles tested between $0^{\circ}$ and $9^{\circ}[21]$. When wheels are added to the same models, the effect of divergence angle reduces for the lift case [21]. The addition of wheels modifies the drag behavior significantly; the effect can be seen in figure 2.5. This behavior can be attributed vortices that are generated at the wheel interacting with the tip vortices seen in the diffuser; for diffuser angles higher that $6^{\circ}$, the wheel-trailing vortices strengthen the diffuser vortices, which increases drag [21]. 
Cooper et al. (1998) find that for an Ahmed body at a given ride height, a reduction in divergence angle will reduce the drag and the downforce on the body [6]. This behavior can be seen in figure 2.12 in section 2.4 .

For a real-world vehicle body, Levin and Rigdal (2011) examine the effect of the divergence angle of a short diffuser of a SAAB 9-3 sedan and wagon [33]. Figure 2.14 shows the drag response with the angle sweep done by in the study.

The sedan exhibits the least drag with an $8^{\circ}$ diffuser, and the downforce on the model is increased most by the $8^{\circ}$ one as well [33]. The drag on the wagon was reduced the most by the $5^{\circ}$ diffuser, but the $10^{\circ}$ diffuser had the most downforce [33].

\subsection{Diffuser With No Divergence Angle}

One of the most drastic changes that can be made is to have the diffuser angle be $0^{\circ}$. This case is often used as a reference case to compare the effect of a diffuser to a body without one.

Cooper et al. $(1998,2000)$ find that the downforce on an Ahmed body with a diffuser divergence angle of $0^{\circ}$ and moving ground plane is reduced, at any ride height, compared to a diffuser with $1.43^{\circ}$ and higher divergence angles [6] [7]. This behavior can be seen in figure 2.12, in which the magnitude of the $C_{L}$ of an Ahmed body is much lower than the $C_{L}$ of the Ahmed bodies with diffusers [6].

Below a ride height of 0.2 , an Ahmed body with no diffuser over a moving ground plane has less than or roughly equal drag than a diffuser with a divergence angle of at least $5.02^{\circ}[6]$. This can be seen in the $C_{D}$ plot in figure 2.12. Above ride heights of 0.2 , this trend inverts: the drag of an Ahmed body with no diffuser is higher than bodies with diffusers [6]. 

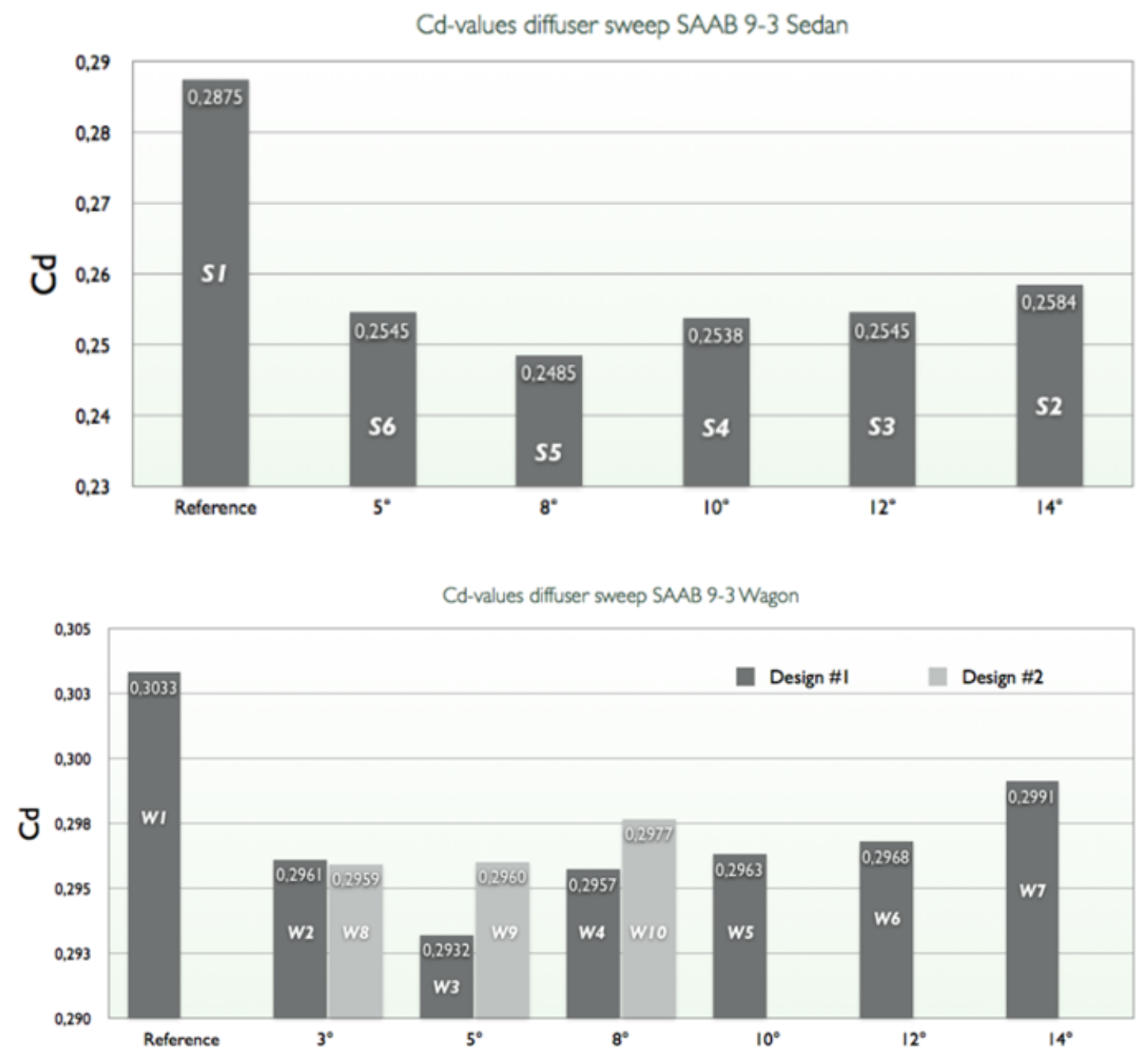

Figure 2.14: Drag Response on SAAB 9-3 Sedan and Wagon with Diffuser Divergence Angle. From Levin and Rigdal (2011) [33]

For a passenger car, such as the SAAB 9-3 examined by Levin and Rigdal (2011), the drag is higher than that of the cases with an angled diffuser. As shown in figure 2.14, the sedan body with non-angled diffuser had $C_{D, 0}=0.2875$ compared to the highest drag value of a sedan with a diffuser, $C_{D, 14}=0.2584$ for the $14^{\circ}$ case [33]. The wagon body had a similar response; the $0^{\circ}$ diffuser body returned $C_{D, 0}=0.3033$, while the highest drag with a diffuser was $C_{D, 14}=0.2991$ for the $14^{\circ}$ diffuser case. 
Chapter 3

\section{PROBLEM STATEMENT}

\subsection{Problem}

The primary objective of the PROVE Lab Endurance Car project is to travel at least $1609.34 \mathrm{~km}(1000 \mathrm{mi})$ at freeway speeds on a single battery charge. Individually, travelling that distance or at freeway speeds on a single battery charge is not difficult; however, the challenge is in designing a single vehicle capable of both feats.

One of the natural challenges of such an attempt is to find a setting that permits operation for over 1600 continuous kilometers. A racetrack is a natural fit for this feat, as race tracks offer a long, smooth, road surface that can be lapped repeatedly until the vehicle has completed the required distance. Additionally, race tracks are sufficiently banked enough in the turns that the turning condition does not deviate significantly from the straight-line condition, for the purposes of the design team's goals. For this reason, the straight-line condition is the main design condition for the aerodynamic analysis of the Endurance Car.

Because the main design case for the Endurance Car is a straight line, the aerodynamic analysis of the vehicle is greatly simplified. Figure 3.1 shows the free-body diagram of the vehicle in forward motion on a generic incline. There are a multitude of forces that the vehicle experiences during operation, but the most important forces on the Endurance Car at the design conditions are the rolling resistance of the tires and the aerodynamic drag force. Collectively, these two forces make up the resistance force that opposes forward motion of the vehicle. 


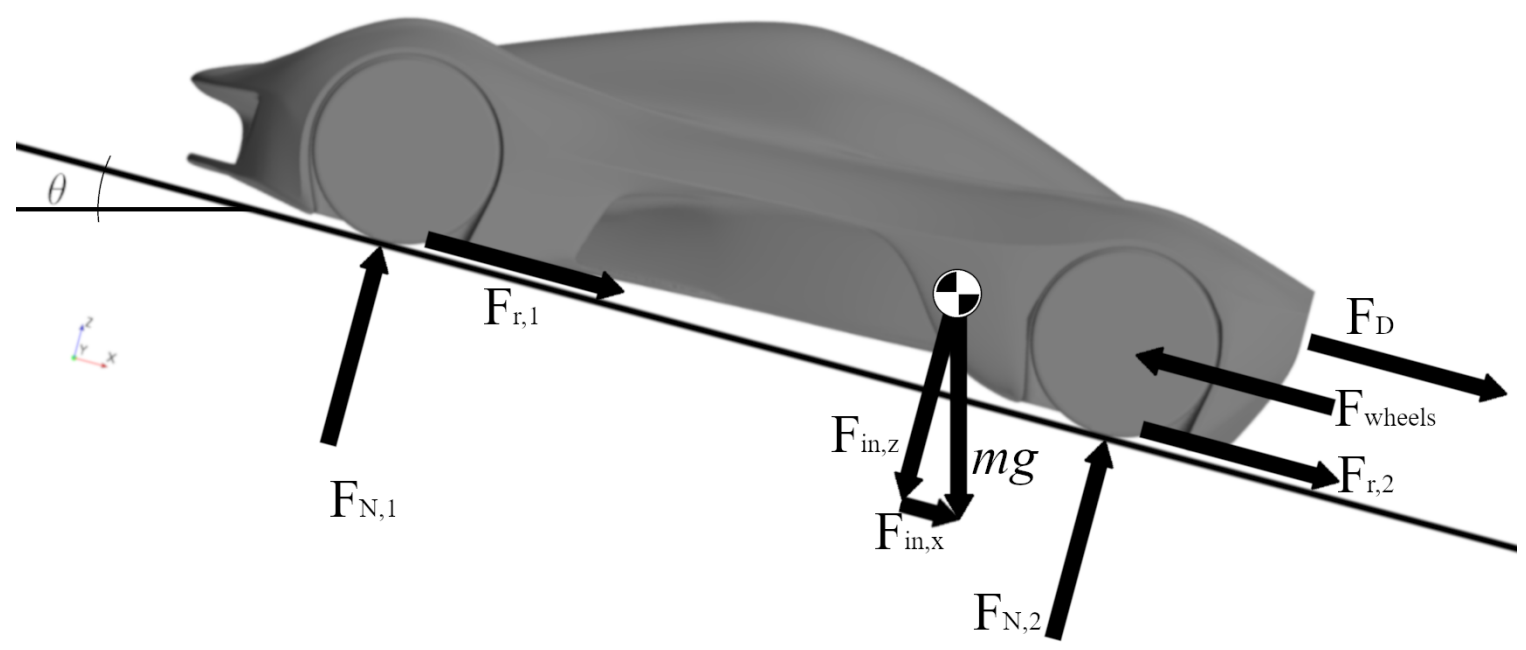

Figure 3.1: Free-Body Diagram of Vehicle on Incline

The equation of motion of the vehicle during operation can be determined from Newton's second law applied in the direction of forward movement:

$F_{\text {wheels }}-F_{D}-F_{\text {in }}-F_{r}=F_{\text {wheels }}-\frac{1}{2} \rho \dot{x}^{2} A_{\text {front }} C_{D}-m g \sin (\theta)-k_{r}\left(m g-F_{\text {Lift }}\right)=m \ddot{x}$

The equation of motion consists of the following forces: the force at the wheels from the motors $\left(F_{\text {wheels }}\right)$, the drag force $\left(F_{D}=\frac{1}{2} \rho V^{2} A_{\text {front }} C_{D}\right)$, the force from the weight on an incline $\left(F_{\text {in }}=m g \sin (\theta)\right)$, and the rolling resistance force $\left(F_{r}=\right.$ $\left.k_{r}\left(m g-F_{\text {Lift }}\right)\right)$. The rolling resistance force is dependent on the rolling resistance coefficient $k_{r}$, the weight $m g$, and the lift $F_{\text {Lift }}$. Both the lift and the rolling resistance coefficient are dependent on velocity; the lift goes with the square of velocity, but $k_{r}$ is mostly constant with velocity at speeds lower than $100 \mathrm{kph}$, and increases with velocity above $100 \mathrm{kph}[4]$.

The vehicle operation is designed toward a flat, level surface and thus the vehicle is assumed to be at $0^{\circ}$ inclination. The vehicle is also assumed to maintain a constant 
velocity at steady-state. With these assumptions in place, equation 3.1 reduces to:

$$
F_{\text {wheels }}=\frac{1}{2} \rho V^{2} A_{\text {front }} C_{D}+k_{r}\left(m g-F_{\text {Lift }}\right)
$$

Equation 3.2 shows that any reduction in resistance force would reduce the force needed to move the vehicle. This is important because reduced tractive effort equates to a reduced amount of work over the vehicle's range. This can be seen from the definition of work as shown in equation 3.3:

$$
W=\left(F_{\text {wheels }}\right) R_{\text {design }}=\left(\frac{1}{2} \rho V^{2} A_{\text {front }} C_{D}+k_{r}\left(m g-F_{\text {Lift }}\right)\right) R_{\text {design }}
$$

The work is defined as the force exerted by the wheels $F_{\text {wheels }}$ multiplied by the range $R$. Any reduction in the work would directly correlate the an equivalent reduction in the energy capacity needed in the battery pack, as the Endurance Car battery capacity is sized by equation 3.4 :

$$
E_{\text {battery }}=\frac{E_{\text {needed }}}{\eta_{\text {powertrain }}}=\frac{W}{\eta_{\text {powertrain }}}
$$

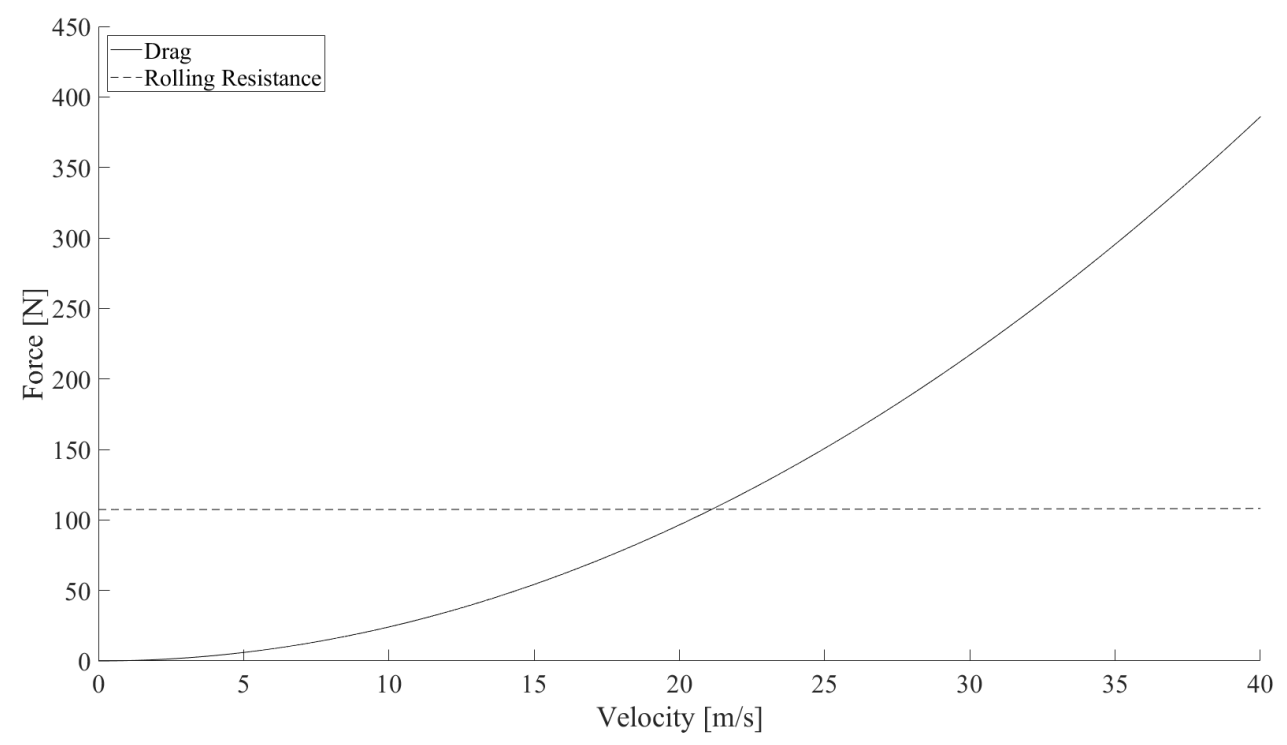

Figure 3.2: Resistance Forces on the Endurance Car, using $C_{D}=0.211$ 
Figure 3.2 shows both rolling resistance and drag on the Endurance Car as functions of velocity. As can be seen from the figure, the resistance on the vehicle is dominated by the rolling resistance at low velocity. At approximately $22 \mathrm{~m} / \mathrm{s}$, the two forces are equal, and the role inverts; drag increases quadratically, and dominates the resistance force as velocity increases.

The drag is controlled by the $C_{D}$, given a fixed frontal area and velocity. The extent of drag's impact on range can be seen in figure 3.3; for any given velocity, the range drops with $C_{D}$.

The actual range of the vehicle $\left(R_{\text {actual }}\right)$ is derived from the energy needed during operation, in relation to the amount of energy that the battery pack can store. This relationship is shown in equation 3.5; the range is derived from the battery pack capacity divided by the resistance force, assuming the battery goes from fully charged to fully depleted.

$$
R_{a c t u a l}=\frac{E_{b a t t e r y}}{F_{r}}
$$

Figure 3.3 shows the dependence of the vehicle range on the drag coefficient and velocity, at the baseline battery pack size of $100 \mathrm{kWh}$, which is the largest battery that fits in the baseline model. The run velocity of the vehicle is desired to be between 15 and $35 \mathrm{~m} / \mathrm{s}$ (between $33.6 \mathrm{mph}$ and $78.3 \mathrm{mph}$ ), and a range of $C_{D}$ values are input into the carpet plot to find combinations that achieve a range greater than 1609.34 $\mathrm{km}$ (represented by the dashed line). The figure shows that at the baseline drag coefficient of $C_{D}=0.211$, the maximum velocity that the Endurance Car can travel at to achieve the record is approximately $18 \mathrm{~m} / \mathrm{s}(40.3 \mathrm{mph})$. As can be seen in the figure, any decrease in the $C_{D}$ would allow the vehicle to travel at a higher velocity for the design range. 


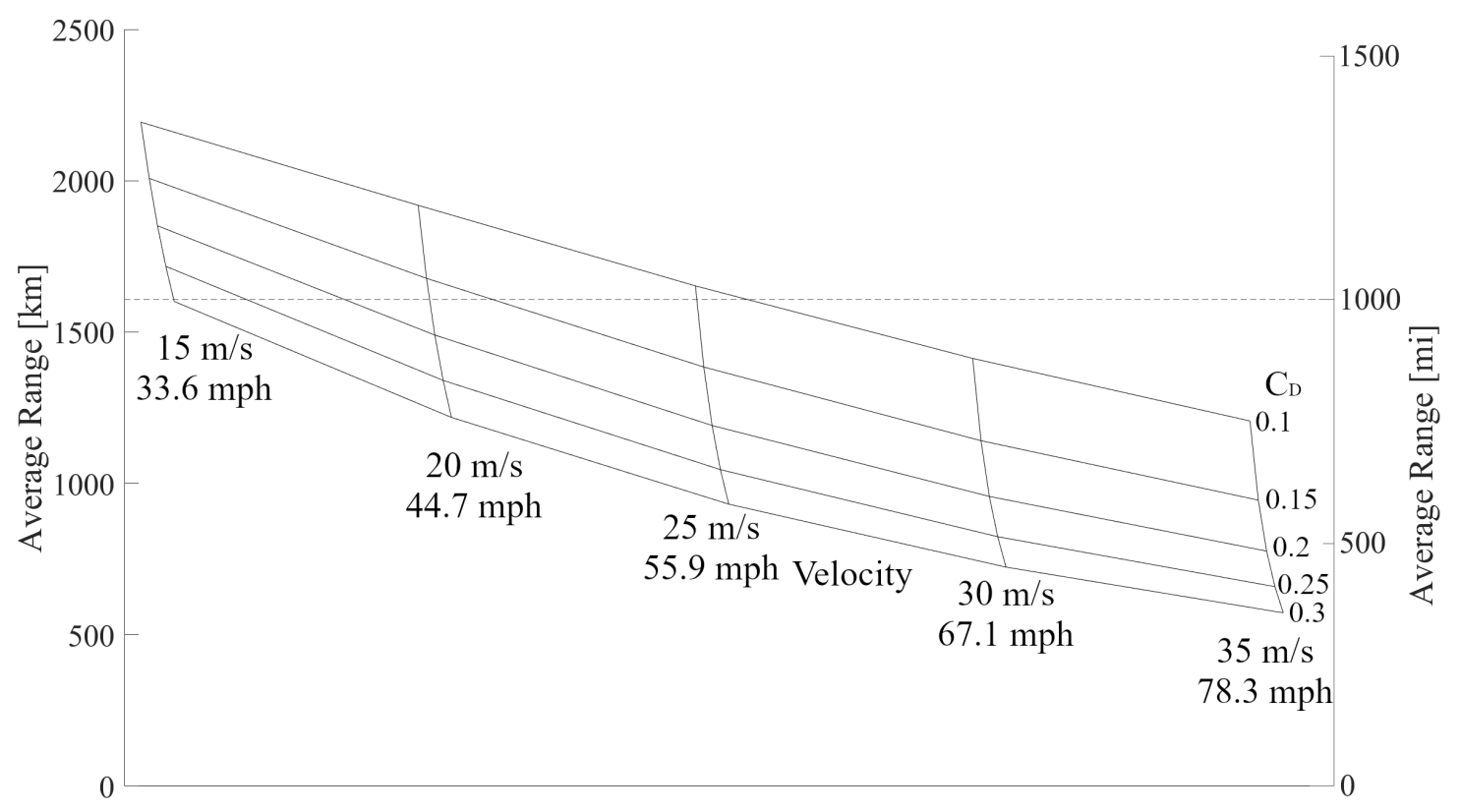

Figure 3.3: Range Dependence on $C_{D}$ and $V$ for $100 \mathrm{kWh}$ Battery

\subsection{Baseline Configuration}

The baseline model of the Endurance Car is shown in figure 3.4. The design features two symmetric ducts (the front ducts) that are intended to reduce the effective frontal area of the vehicle. The front ducts channel flow along the inside of the front fenders, and exhaust into a channel along the side of the vehicle. This channel leads into the diffuser, which is intended to expand the flow inside of the rear fenders.

CFD was used as the primary method of analysis; the CFD setup and methodology are discussed in detail in chapter 4. Computational results of the baseline model show that the model exhibits a large separation zone in the diffuser, along the rear fenders. As can be seen in figure 3.5, the separated zones in the diffuser merge with the stagnant region behind the base of the rear fenders to create a single large area of recirculation. Additionally, one can see from figure 3.5 that there is a separated area behind the front wheel and at the outlet of the front duct. Reduction of the effect 


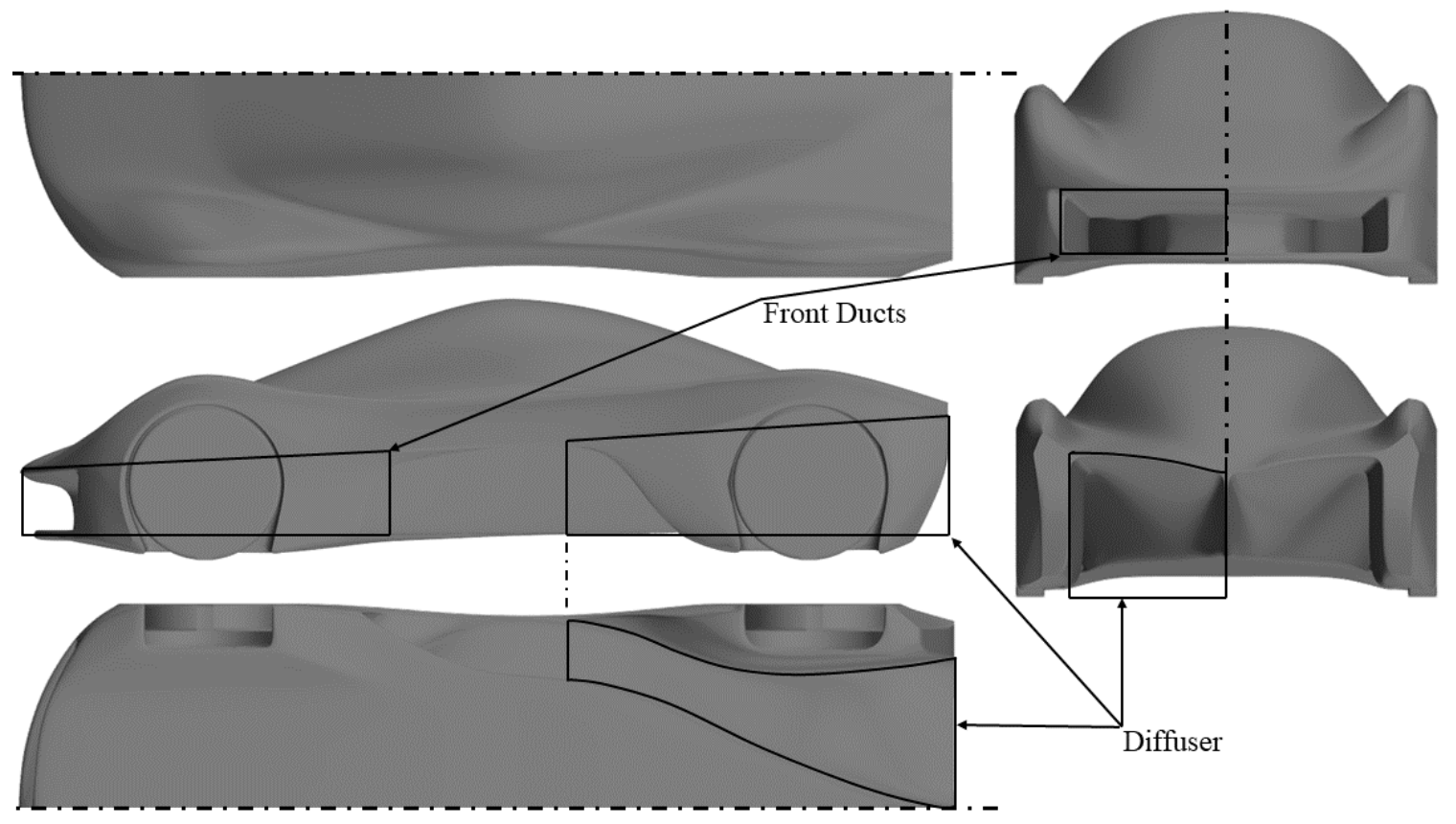

Figure 3.4: Baseline CAD Model

of these separation zones is key to the success of the project, as the current system configuration cannot tolerate the baseline model's drag coefficient.
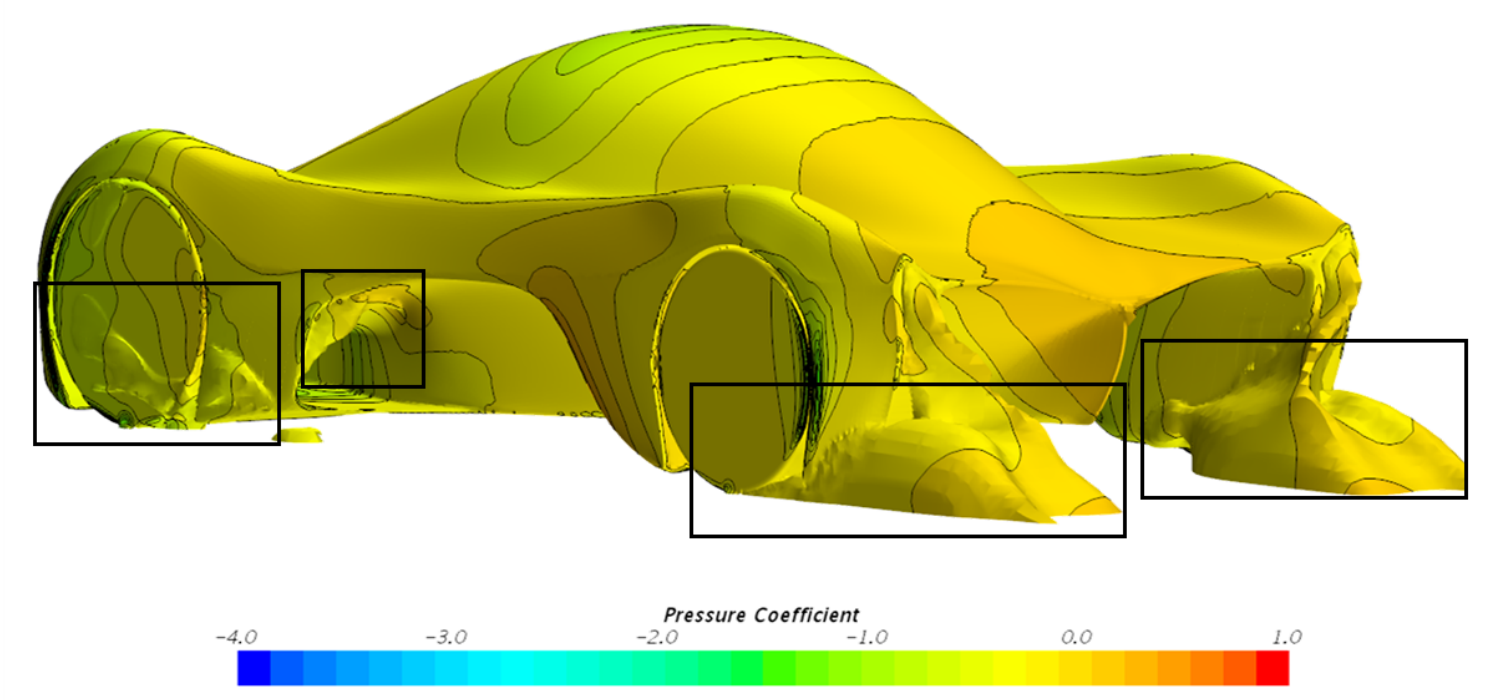

Figure 3.5: Separation Zones at Rear of Baseline Model 


\subsection{Drag Reduction Strategies}

As suggested by the literature review are four strategies that may reduce the pressure drag of the vehicle. These strategies are: the addition of a side skirt, increase in ride height, extended diffuser length, and a widened tail. The four strategies are outlined in more depth in the following sections.

\subsubsection{Addition of a Side Skirt}

A steep pressure gradient exists in the exhaust of the front ducts, as the flow from the duct merges with that around the outside of the fender. This pressure gradient can be seen in front of point $\mathrm{B}$ in figure 5.2 in chapter 5 . The geometry of this intersection can be seen in figures 3.4 and 3.5. It can also be seen from figure 3.5 that there is a coincidental separated area in this region. The steep pressure gradient exists because of the intersection of the two flows; the internal flow must recover pressure to equal that of the external flow. To achieve this, the flow along the duct expands as it leaves the duct.

As the flow encounters the diffuser, it undergoes the Venturi effect again, as it is accelerated then slowed again by the geometry of the diffuser. However, the need for expansion back to freestream pressure is not as great as the amount of expansion introduced by the diffuser, and the flow separates. This separation can be seen in figure 3.5 .

It has been long known that the addition of a side skirt to the underside of a vehicle will lower the pressure on the underbody [28]. This effect was applied to the vehicle to reduce the separation in the underbody, and consequently the pressure drag. 

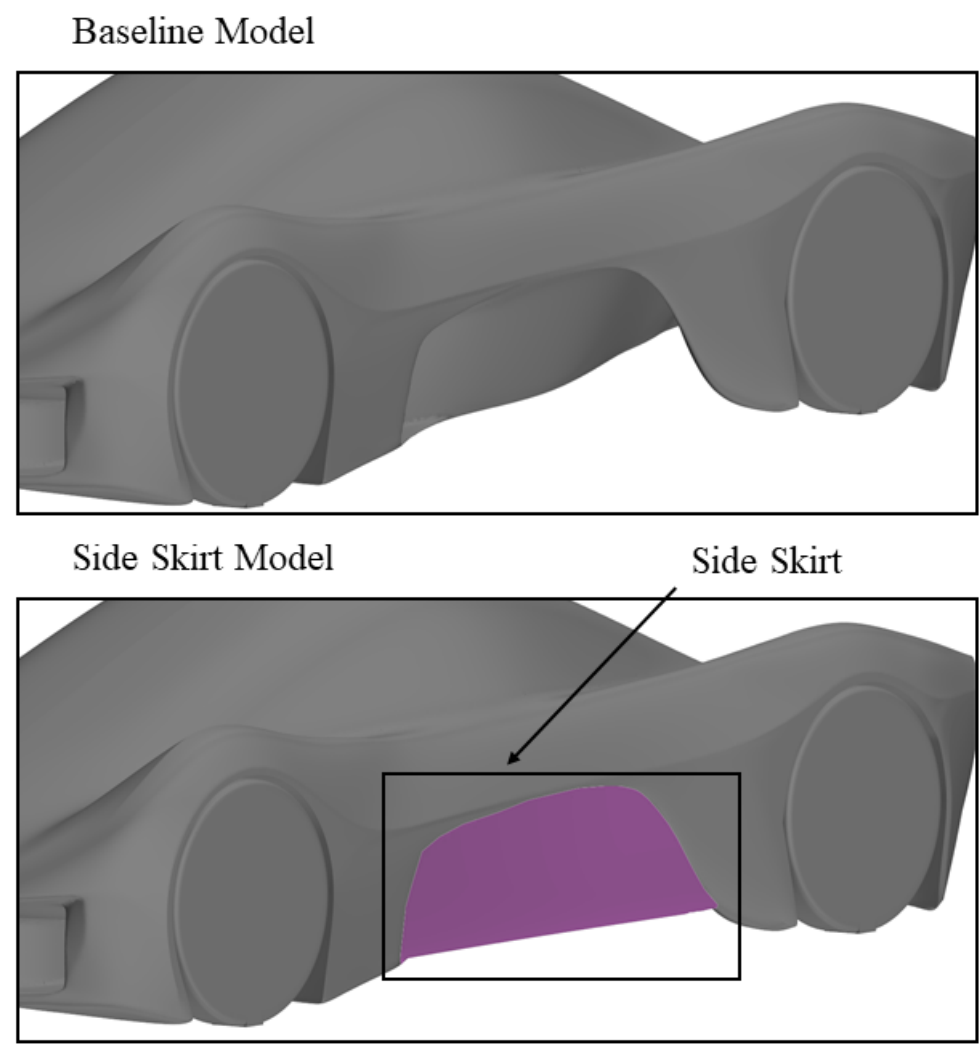

\section{Figure 3.6: Comparison of Baseline and Side Skirt Models}

On the baseline model, the flow recovers pressure at the exhaust of the front ducts. This is an issue because the flow consequently separates at the exhaust of the front ducts. Additionally, the flow separates in the diffuser, because it cannot expand with the geometry of the diffuser and simultaneously exit at the base pressure. The reduced pressure gradient on along the underbody would reduce the adverse pressure gradient at the exhaust of the front ducts, which would reduce the tendency of the flow to separation at that location. In addition, lowered pressure along the underbody would increase the recovery in the diffuser, which would reduce separation along the fender.

The side skirt follows the belt line of the Endurance Car both vertically and horizontally. The skirt extends vertically from 3.5" above the ground to the fenders 


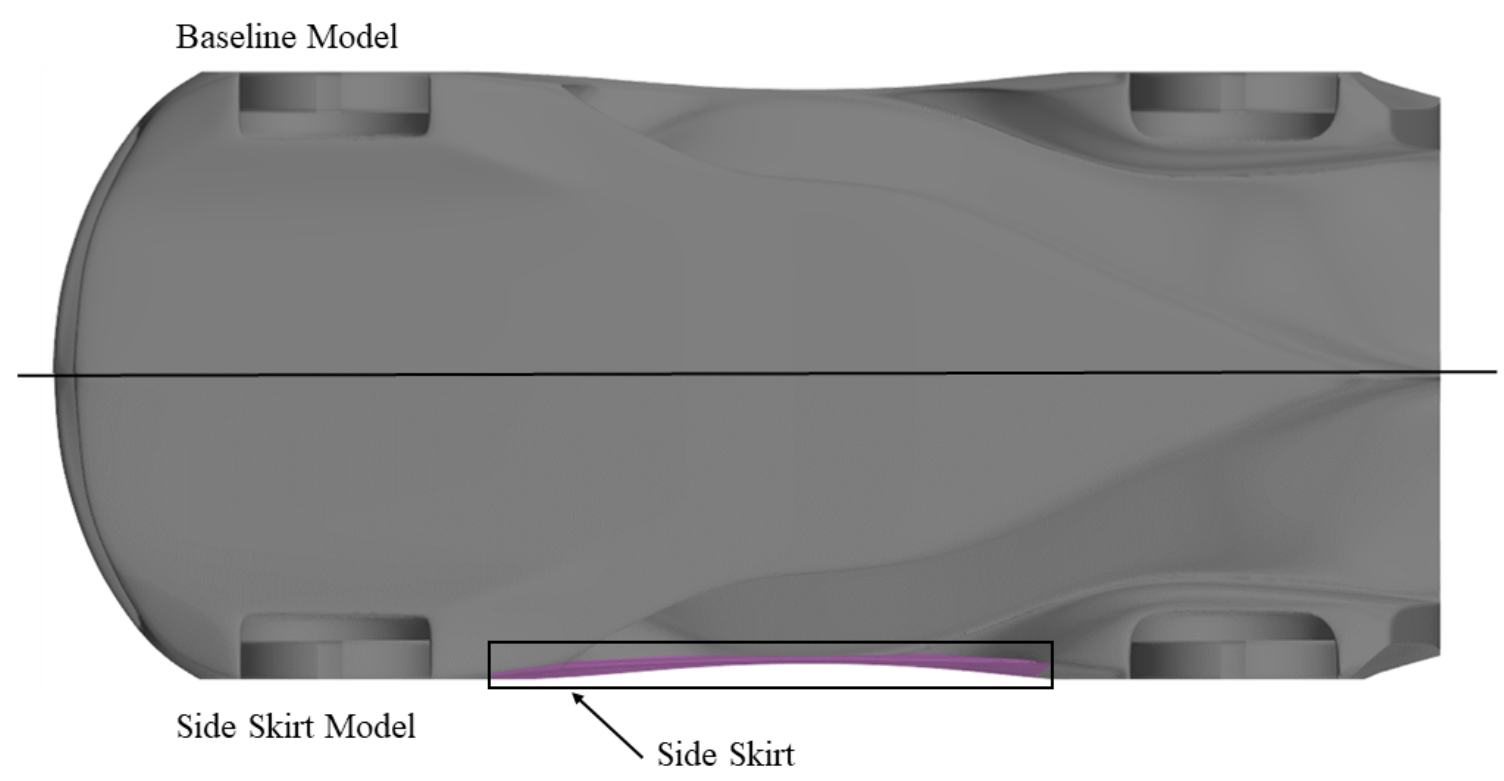

Figure 3.7: Comparison of Baseline and Side Skirt Models, Underbody View

and belt line along the side of the model, as shown in figure 3.6. A planform view of the Endurance Car from underneath can be seen in figure 3.7, and shows that the side skirt follows the curve of the belt line along the side of the Endurance Car. Care was taken to ensure the intersection of the skirt and body was smooth. This was done for aesthetics, and to ensure that the introduction of a skirt constrained its effects to the flow along the body, and did not artificially induce additional flow features in the external flow field.

\subsubsection{Increase in Ride Height}

Another potential method for decreasing the drag is an increase in ride height. As discussed in chapter 2 , the ride height of an automotive body with a diffuser plays an important role in the diffuser strength. An Ahmed body with a $13.5^{\circ}$ diffuser experiences a reduction in $C_{D}$ of $3.8 \%$ between a ride height of 0.079 and 0.101 ; a corresponding decrease in $C_{D}$ of the Endurance Car would give $C_{D}=0.203$. In 
addition, the downforce on an Ahmed body decreases by $4.1 \%$ with the same ride height increase [6]. This corresponds to a projected decrease in downforce on the baseline model to $C_{L}=-0.077$ and $297 \mathrm{~N}$.
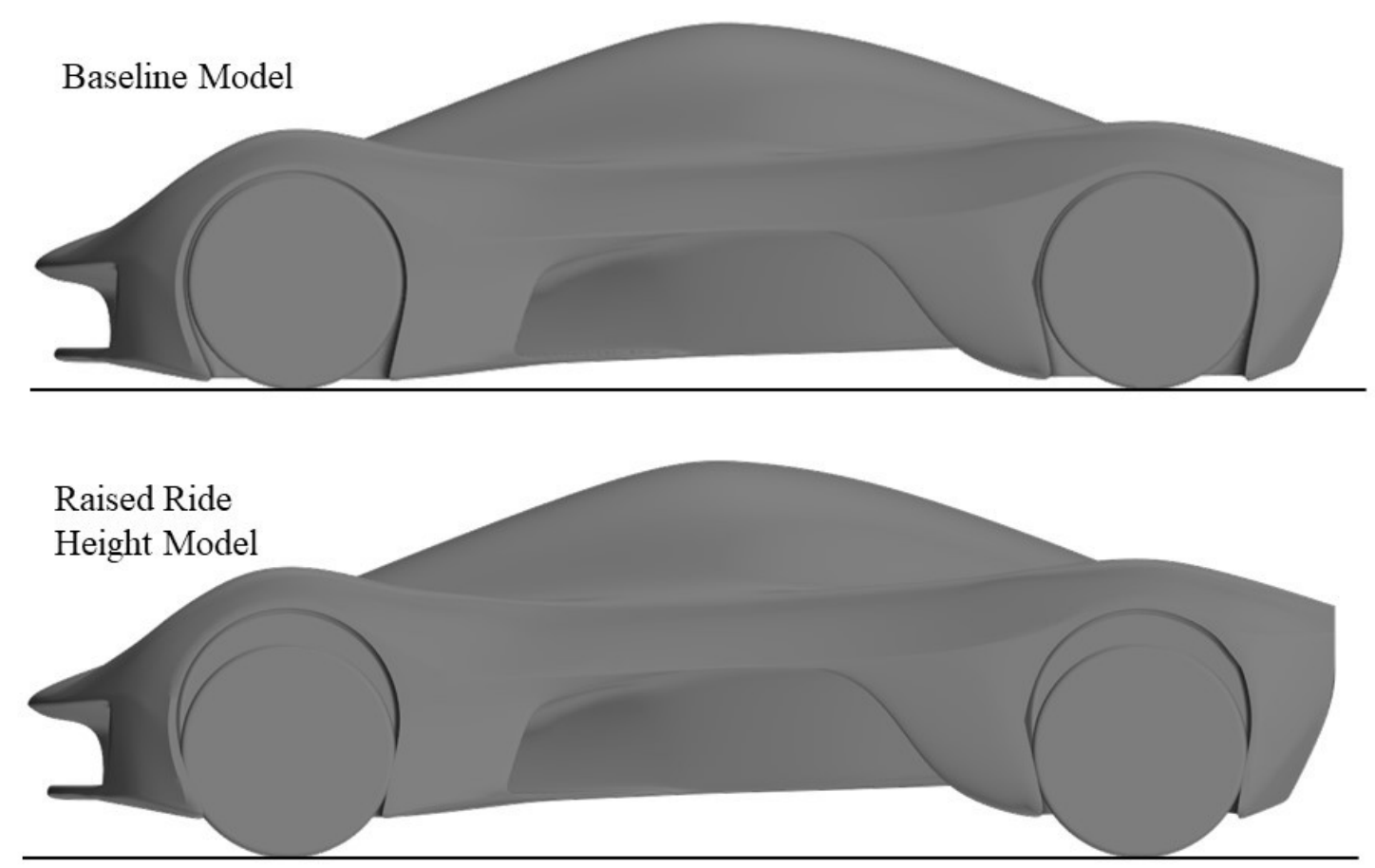

Figure 3.8: Model with Raised Ride Height, Exaggerated for Visibility

The most significant concern in raising the ride height is the ability of the model to accommodate such a modification without significant changes to the model design. The ride height of the baseline model was set at $3.5 \mathrm{in}(8.89 \mathrm{~cm})$ from the ground to underside of the body by the Endurance Car team. Non-dimensionalized to the height of the baseline configuration, this ride height is $\frac{h_{1}}{H}=0.079$. This height was chosen as it allowed the suspension to fit around the front ductwork, and deflect fully to absorb shocks during operation. As can be seen from figure 3.8, the wheel housings of the baseline model did not allow for a large amount of adjustment in ride height. Thus, the main metric in sizing the change was the clearance that the wheel would have at an adjusted ride height. The wheel housings could accept a 1 
in $(2.54 \mathrm{~cm})$ increase in the ride height to $\frac{h}{H}=0.101$, so that value was used as the raised height configuration. Figure 3.8 shows this ride height increase exaggerated for visibility. This model shows the baseline ride height compared to an exaggerated model at $\frac{h_{1}}{H}=0.079$.

\subsubsection{Extended Diffuser}

The diffuser has an average divergence angle of $3^{\circ}$ in the vertical direction along its length. However, the diffuser of the baseline model expands much more in the horizontal direction: the divergence angle in that dimension varies along the length of the diffuser. An additional complication of the diffuser is the cross section area.

From point $\mathrm{A}$ to point $\mathrm{B}$, the cross section of the diffuser is triangular. The cross section grows from $0.08 m^{2}$ at point $\mathrm{A}$ to $0.1 \mathrm{~m}^{2}$ at point $\mathrm{B}$. At point $\mathrm{B}$, the diffuser begins to transition from a triangular cross section to a rectangular one. This transformation is takes up the entirety of the diffuser from point B rearward on both the baseline and extended models. On both models, the cross section area of the tail is $0.135 m^{2}$. For both models, the forward portion of the diffuser has an expansion ratio of $\zeta_{\text {front }}=0.80$, and the rearward portion of the diffuser has an expansion ratio of $\zeta_{\text {rear }}=0.74$.

The extended body was created by shifting selected areas of the baseline model rearward. These selected areas can be seen in figures 3.10 and 3.11. The rear fenders and rear wheels were moved back by 5 in $(12.7 \mathrm{~cm})$. This was done to decrease the effective divergence angle of the rearmost diffuser section. A lower divergence angle was desired due to the stalled nature of the rearmost section. A lower divergence angle reduces the severity of the adverse pressure gradient in the diffuser, which would lower the tendency of the diffuser to separate. The effective divergence angle was decreased 


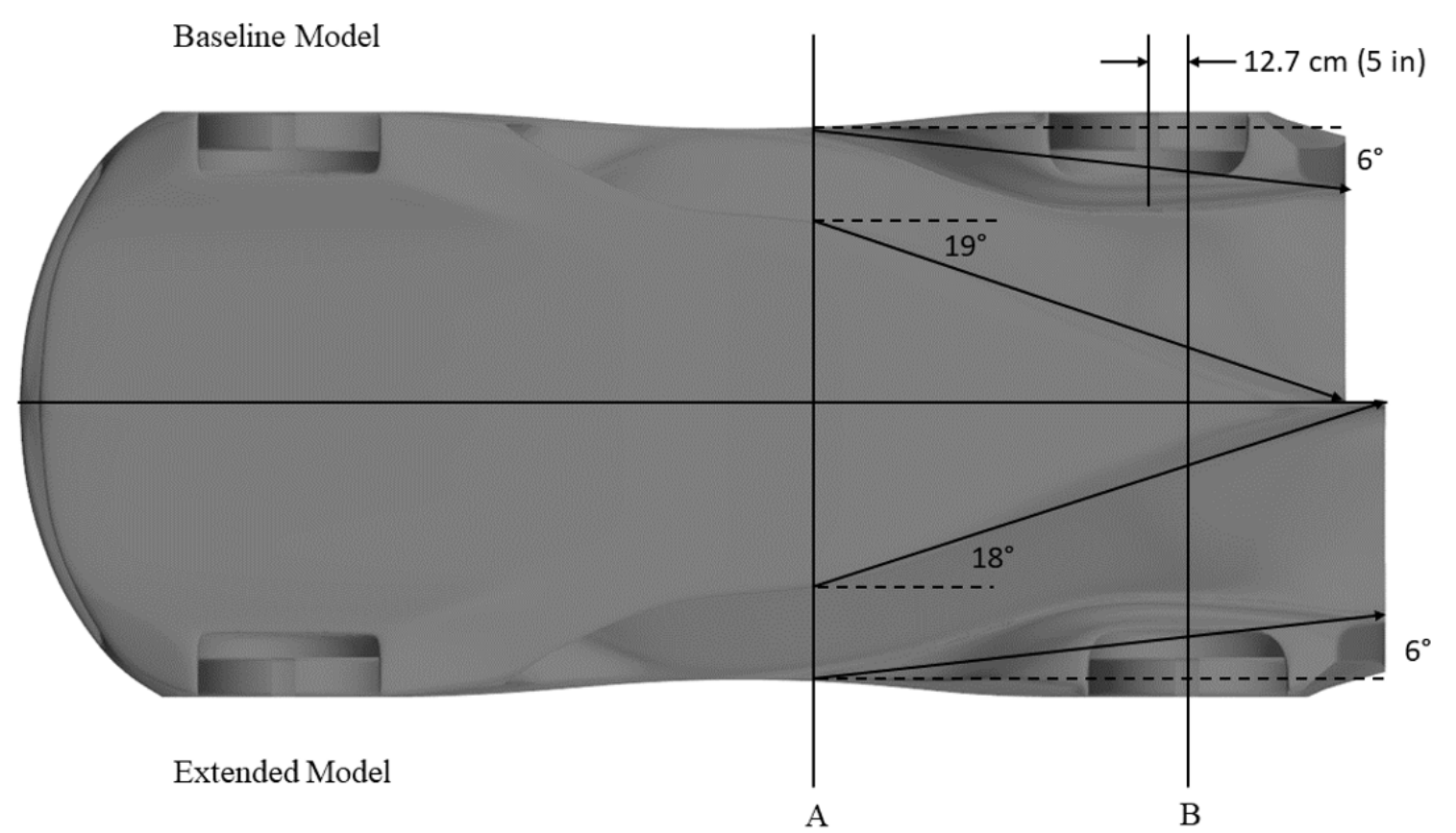

Figure 3.9: Divergence Angles of the Extended Rear Model

from $13^{\circ}$ in the baseline model to $12^{\circ}$ in the extended one.

Cooper et al. (1998) find that the drag coefficient on an Ahmed body drops by $4.7 \%$ when the diffuser angle is lowered from $13.50^{\circ}$ to $11.54^{\circ}$ [6]. The downforce on the Ahmed body increases by $5.1^{\circ}$ with the same change [6]. This value predicts that the baseline models' drag coefficient would decrease to $C_{D}=0.201$ and the downforce would increase to $C_{L}=0.084$ and $326 \mathrm{~N}$. However, this study did not include wheels on the Ahmed body [6]. Levin and Rigdal (2011) find that the drag coefficient of a SAAB 9-3 sedan decreases by $1.5^{\circ}$ for a decrease in diffuser angle from $14^{\circ}$ to $12^{\circ}$ [33]. The downforce on the 9-3 decreases by $12.3^{\circ}$ when the same diffuser change is made [33]. Translated onto the baseline model, these changes predict a new drag coefficient of $C_{D}=0.208$, a new lift coefficient of $C_{L}=-0.07$, and a downforce value of $272 \mathrm{~N}$.

While a larger change in angle than $1^{o}$ is desirable for evaluation of the strategy, the structural limitations of the vehicle's proposed chassis prevented elongation of the 


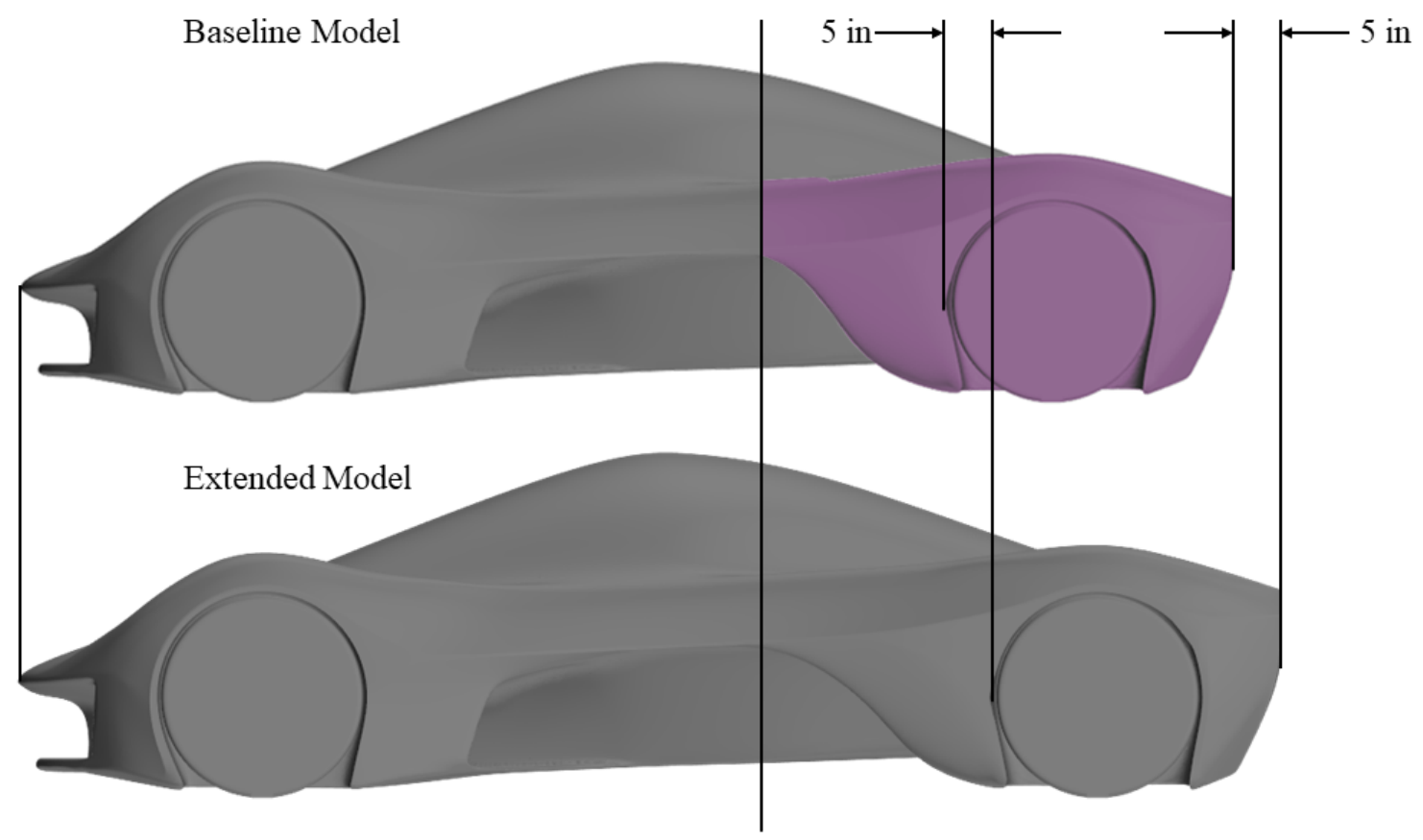

Figure 3.10: The Modified areas of the Baseline Model (Profile View)

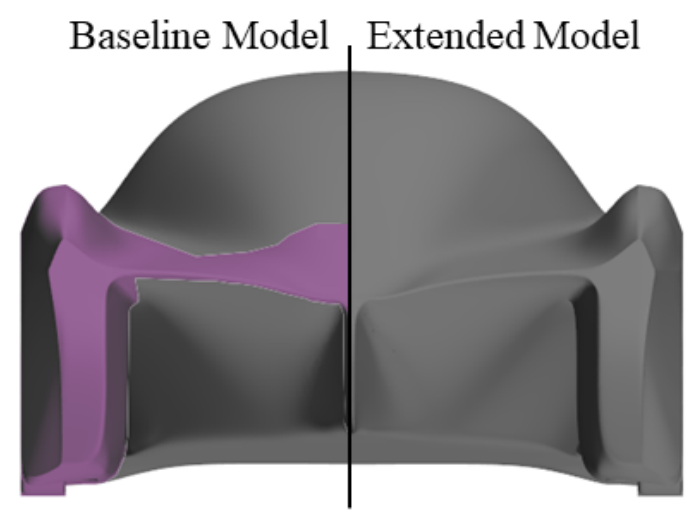

Figure 3.11: The Modified Areas of the Baseline Model (Rear View)

rear further. An alternative method of reducing the divergence angle is to widen the tail of the vehicle, which is discussed in section 3.3.4. 


\subsubsection{Widened Tail}

Separation can cause a large percentage of the pressure drag on a vehicle. The separated region at the rear of the baseline model was observed to follow the contour of the rear fender, to keep a roughly constant effective cross section area. This effect can be seen in figure 3.12; line A traces the outer line of the main body. This shape is mirrored by line $\mathrm{B}$, the approximate dividing line between the separated region and the flow. The size of the separation region and consequent recirculation bubble can be seen by the mass of blue streamlines directly behind the vehicle in the figure.

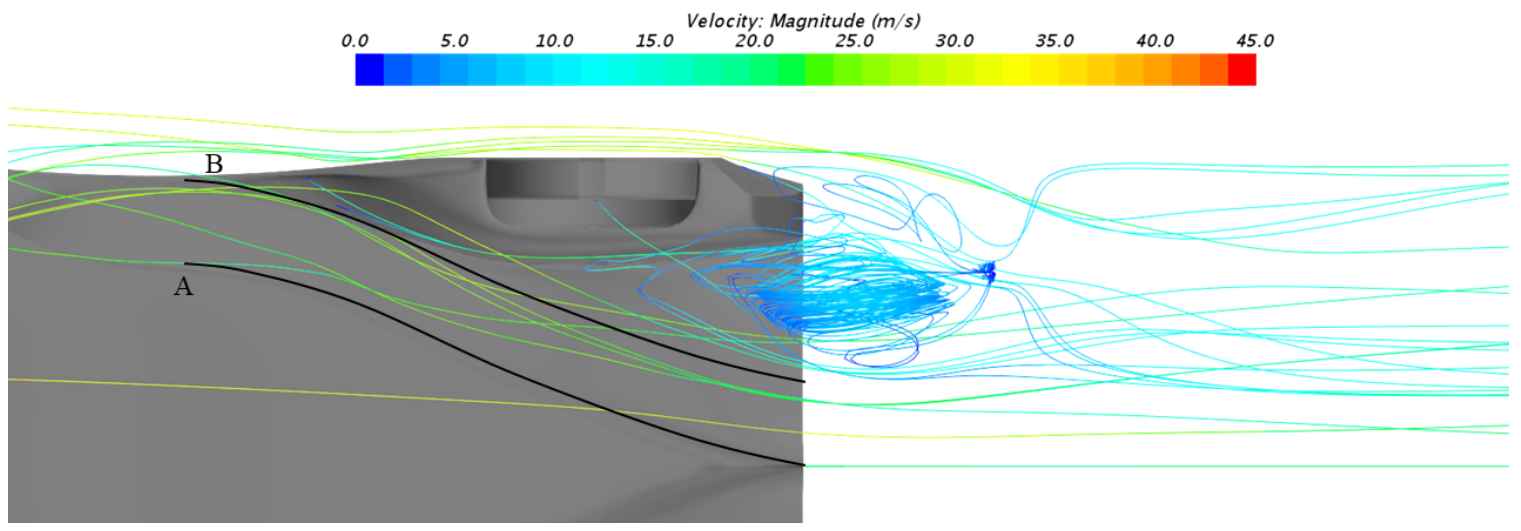

Figure 3.12: Separation on Underside of Baseline Model

Similar to the extended diffuser case, the divergence angle was modified. Instead of an extended diffuser, the tail of the vehicle was widened to create a roughly constant diffuser cross section area. This was done with the intention to eliminate the separated area of the rear fenders by removing the possibility for flow expansion along the diffuser. The modifications made can be seen in figure 3.13, the baseline model (A) expands greatly through the diffuser, but the widened model (B) exhibits a diffuser with roughly constant cross-section area along the rear fender. 


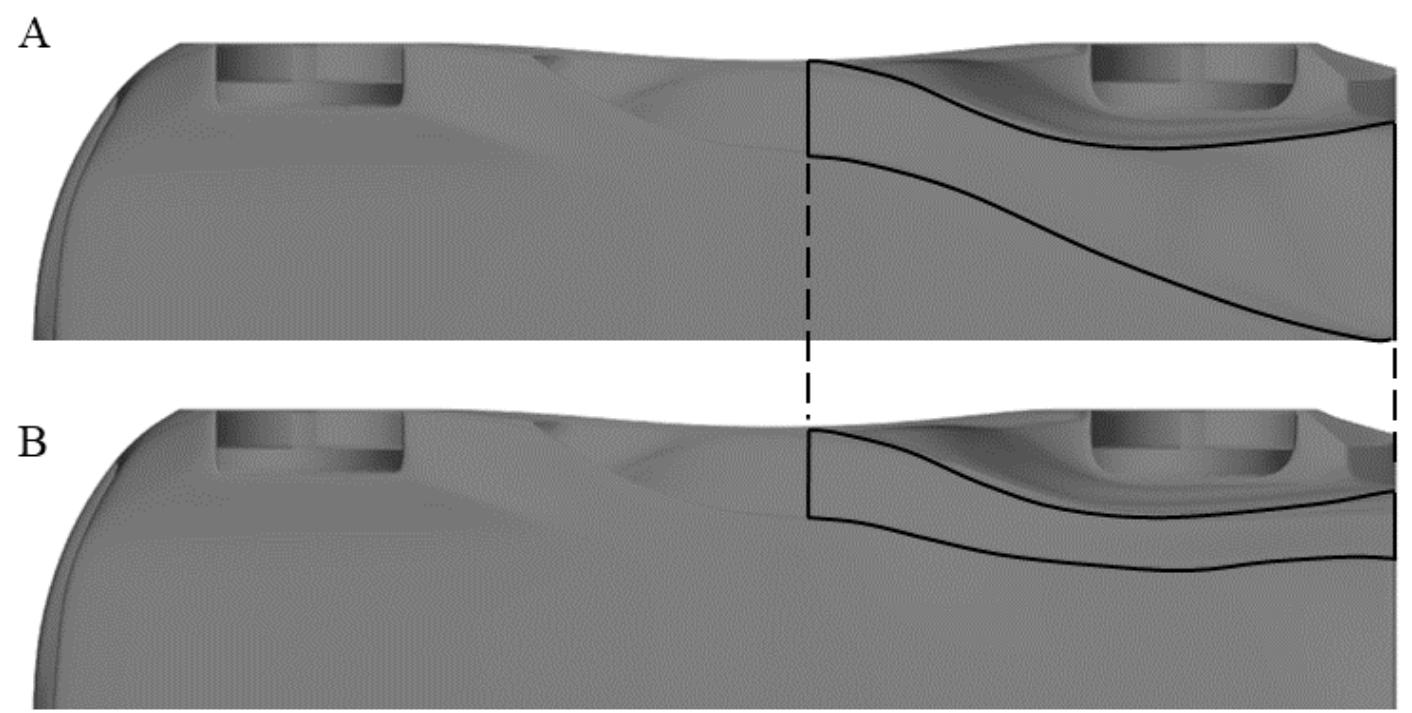

Figure 3.13: Comparison of Diffuser Size on Baseline (a) and Wide Tail (b) Models

For an Ahmed body, the drag reduces by $11.0 \%$ when the diffuser angle is reduced from $13.5^{\circ}$ to $0.0^{\circ}[6]$. The downforce reduces by $75.7 \%$ when the diffuser is reduced to $0.0 \%$ [6]. This change would reduce the drag coefficient to $C_{D}=0.188$ and increase the lift coefficient to $C_{L}=-0.019$, respectively. The downforce would decrease to 75 N. 
Chapter 4

COMPUTATIONAL FLUID DYNAMICS

\subsection{CFD Methodology}

CFD was used to determine the outcomes of the aforementioned case studies. The CAD models were exported into parasolid model files in Siemens NX and imported directly into a mesh in STAR CCM+ 12.06. STAR-CCM+ was selected as the solver both for user familiarity, and because the Cal Poly Bishop HPC Cluster has the ability to run parallelized STAR-CCM+ simulations. The Bishop HPC is capable of running a single user's simulation at 48 threads for up to 30 days [5]. Simulations were run on the Bishop HPC at 24 threads for 12 hours each, to allow multiple simulations to be run simultaneously. Each simulation was checked for convergence after the HPC cluster had completed the simulation job. A simulation was considered converged if the relative oscillations in drag value reached less than $\pm 1 \%$ of a mean value for 200 iterations. To save computation time, and because the models were longitudinally symmetric, only the left half (driver's side) of the vehicle was simulated, and the results were mirrored during post-processing.

The origin is located along the centerline of the model, along the axis that connects the bottom of the front wheels. This can be seen from figure 4.1; the coordinate axes are placed at the origin of the model. This origin was used in both the CAD and CFD for the construction of the CAD and CFD models, as well as placement and sizing of the domain, volumetric control, and wake refinement. 


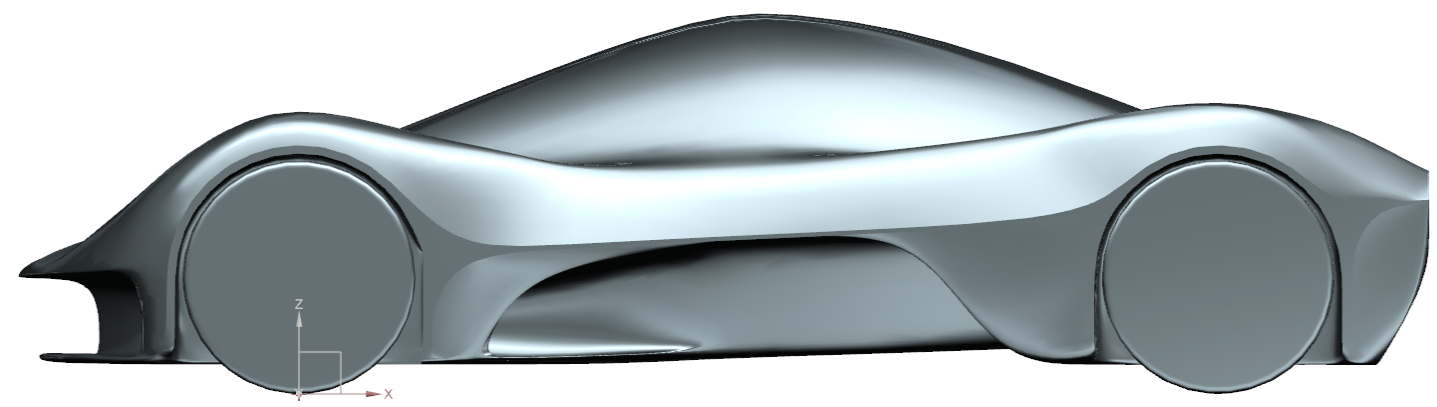

Figure 4.1: Origin of the CAD and CFD models

The wheels were modeled as rotating cylinders, instead of a wheel with spokes. This was done because the wheel design and tire designs were not finalized by the Endurance Car team until after results were generated. Because of the lack of a finalized design, a featureless wheel was arbitrarily chosen. The design of the wheel face impacts the drag coefficient of the vehicle, as a closed-face wheel lowers vehicle drag over open-faced wheels [9]. The rotation rate of the wheels was found from the design speed:

$$
\omega=\frac{V}{r}=\frac{29.06 \mathrm{~m} / \mathrm{s}}{0.35 \mathrm{~m}}=83 \mathrm{rad} / \mathrm{s}
$$

A small block was added to the bottom of each wheel to aid in generation of the computational grid. This was done to avoid an infinitely small surface at the intersection of the wheel and the ground plane [31]. Additionally, the ground plane was modeled as a slip wall to ensure that a boundary layer did not develop on it, but was set to be stationary. An alternative method is to set the wall to a non-slip condition and have its speed match that of the freestream, to match the relative movement of a non-slip road surface. The addition of a moving ground into a simulation has been shown to increase drag on a passenger vehicle [30]. 


\subsection{Grid Sensitivity}

A preliminary mesh study was performed by the PROVE Lab aerodynamics team at the outset of the Endurance Car project to determine a computational domain that delivered accurate results, while keeping computation time low. The result of that domain is presented as the mesh study baseline domain.

Figure 4.2 shows the computational domain used as the mesh study baseline. As can be seen from the figure, the domain that was used extends $6.25 \mathrm{~L}$ in front, $10 \mathrm{~L}$ behind, $1.25 L$ laterally, and $1.75 L$ vertically, from the origin of the CAD model.

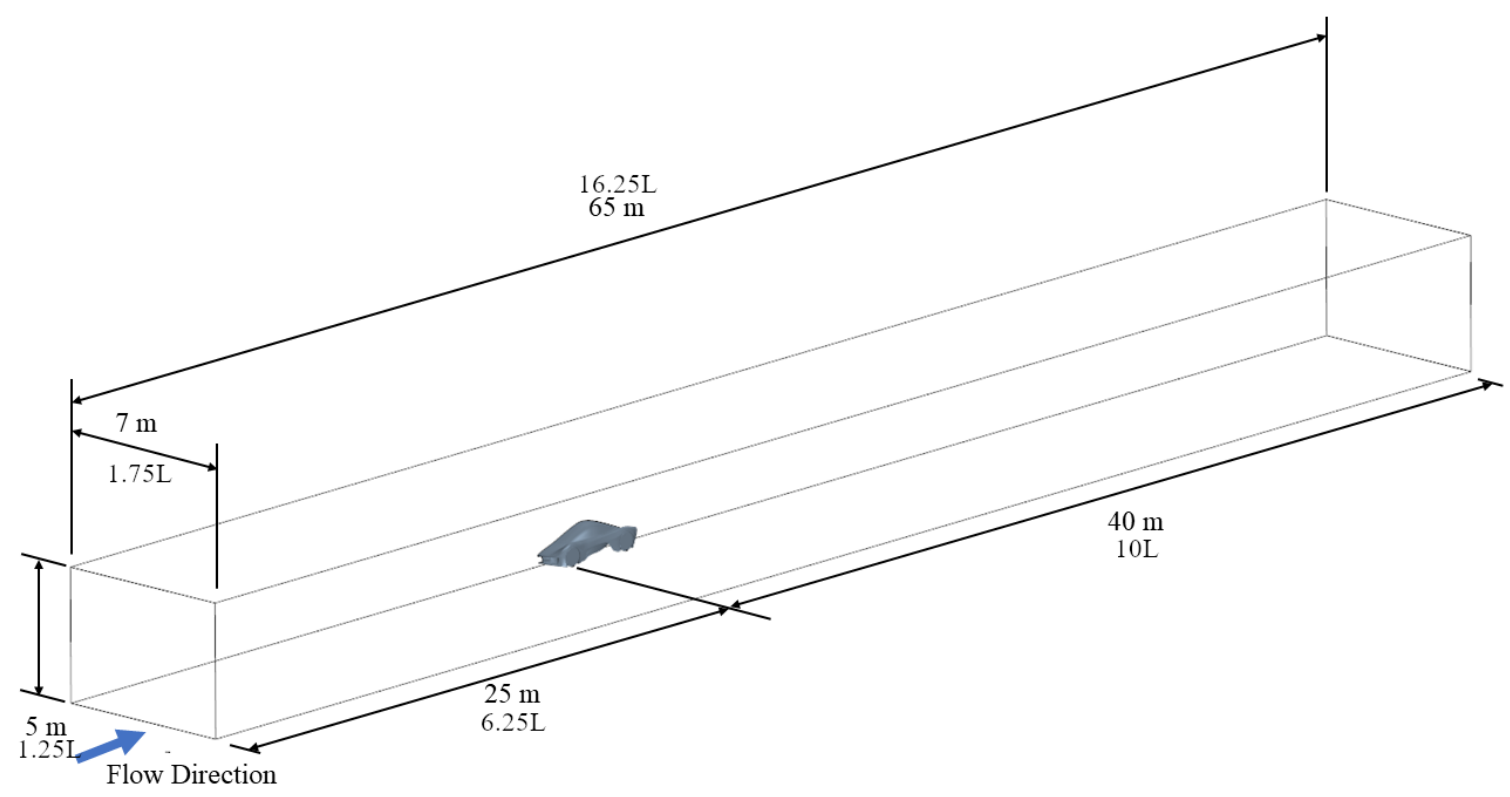

\section{Figure 4.2: Finalized computational domain, measured from origin}

One of the most important trade-offs in grid construction is resolution versus computation time. The mesh settings were selected to give resolution to the CFD results without expending excessive compute time.

Due to time constraints on the project, the mesh study was done with a preliminary version of the Endurance Car model. This car contained many of the design and 
aesthetic features of the models described herein. However, it did not include a front duct or wheels, and was slightly shorter than the baseline model. The mesh study was run before the wheels and wheel housings were modeled in the CAD model. The mesh study model had a length of $L_{C}=4 \mathrm{~m}$, in comparison to the baseline model's $L_{C, 1}=4.065 \mathrm{~m}$. Because of the minor scale of this change, the the effect of the length change is taken as negligible.

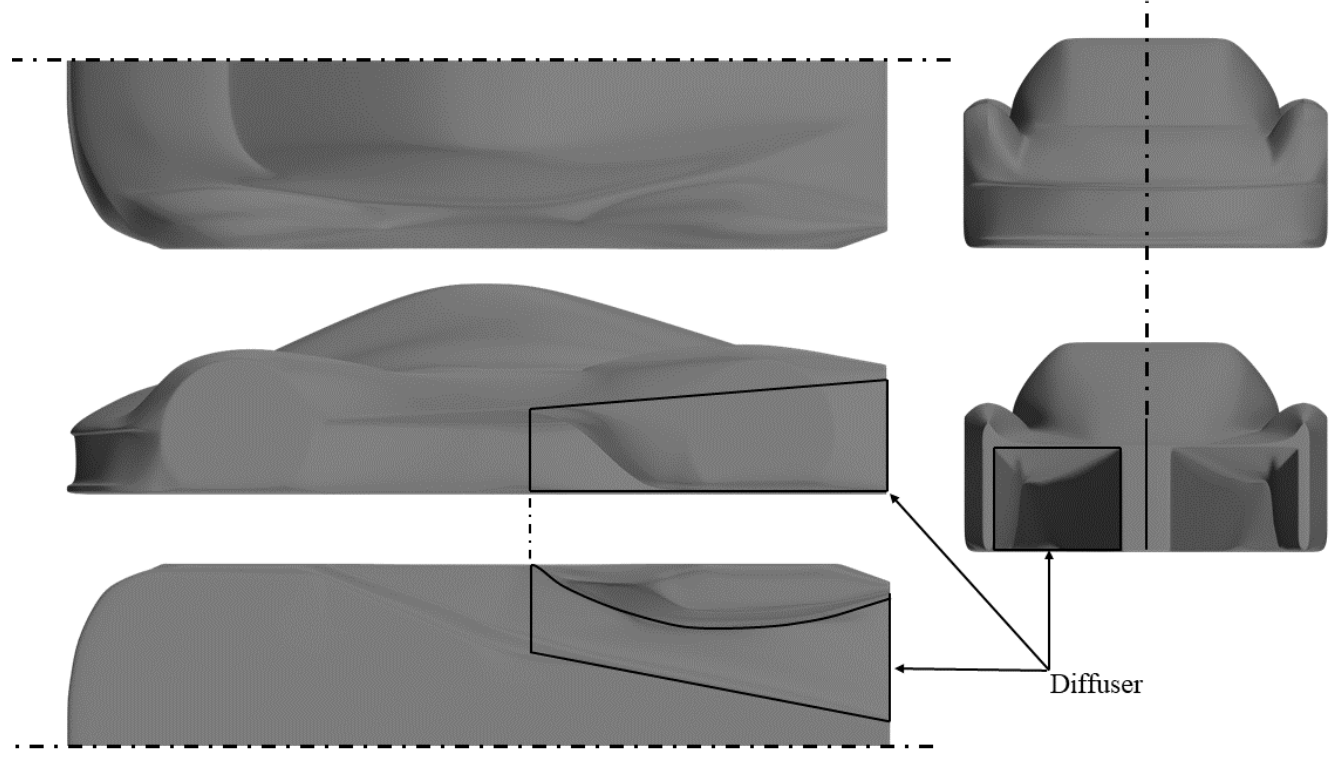

Figure 4.3: The CAD model used for the mesh study

The lack of a front duct and wheels has an effect on the results of the simulations. As can be seen from figure 4.3, the cabin of the mesh study baseline model was shaped to have a teardrop-style shape on both the top and bottom to mitigate the effect of the non-existent duct. The addition of wheels into the simulation was observed to cause higher variance in the drag and lift values, as well as increase the computation steps needed for convergence.

The resultant value was found from the mean of the parameter values for the final 200 iterations of the simulation. Simulations were taken to be in agreement if the 
resultant values for both pressure and shear drag matched to $1 \%$ of the resultant values. The error in these values for the sensitivity studies was found from the grid convergence index (GCI) values from an analysis on the global cell size. The GCI was found from the method outlined by Roache (1997) [40] and Slater (2008) [44], using the value of the total drag (sum of the pressure and shear drag).

The relative difference between two simulations is found from the paramter $\epsilon$ [44]:

$$
\epsilon=\frac{f_{1}-f_{2}}{f_{1}}
$$

The difference between the two simulations, as expressed by the relative difference in their mesh characteristic lengths $\left(l_{1}\right.$ and $\left.l_{2}\right)$, can be found from the parameter $r[44]$ :

$$
r=\frac{l_{1}}{l_{2}}
$$

The order of convergence $(p)$ for three simulations can be found from the following relation [44]:

$$
p=\ln \frac{f_{3}-f_{2}}{f_{2}-f_{1}} / \ln (r)
$$

The GCI between two simulations is found from the factor of safety $F_{s}$ and the above parameters [44]:

$$
G C I_{12}=F_{s}\left|\frac{\epsilon}{\left(r_{12}^{p}-1\right)}\right| * 100 \%
$$

For the three simulations that examined the global mesh size (discussed in section 4.2.1 below), the GCI between the $1 \mathrm{~m}$ and $0.5 \mathrm{~m}$ cell size simulations is $G C I_{12}=0.58 \%$ 
and the GCI between the $0.5 \mathrm{~m}$ and $0.25 \mathrm{~m}$ cell size simulations is $G C I_{23}=0.76 \%$. Because the $0.25 \mathrm{~m}$ grid was ultimately selected, an error size of $0.76 \%$ was used. This value was used across the entirety of the mesh study, save for the wheel refinement study.

\subsubsection{Global Mesh Size}

The global grid size was selected to ensure resolution close to the vehicle. The global cells are isotropic; in other words, they are cubes with a uniform side length. These cells can be seen in figure 4.4. The view in the figure is looking downstream from the inlet; the global cells are in region $\mathrm{A}$, and the cells of the volumetric control are in region $\mathrm{B}$. The effects of three global minimum sizes were examined: $1 \mathrm{~m}, 0.5$ $\mathrm{m}$, and $0.25 \mathrm{~m}$.

A

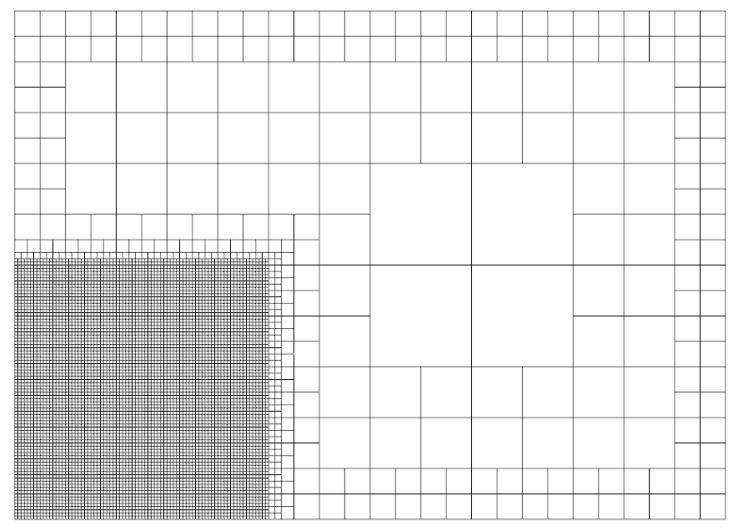

Figure 4.4: The global cell size (A) and refined cell size close to model (B)

As can be seen from table 4.1, the global size does not appear to be a factor in the integral drag values, for the sizes examined. The global cell size does not have much effect on the drag value due to the volumetric refinement close to the surface of the model: there is a rectangular domain that surrounds the car to step down the cell size in the vicinity of the model. This refinement takes out any effect of the 
Table 4.1: Influence of Global Grid Size on Drag Values

\begin{tabular}{|c|c|c|}
\hline Side Length $(\mathrm{m})$ & Pressure Drag $(\mathrm{N})$ & Shear Drag $(\mathrm{N})$ \\
\hline \hline 1.00 & $159 \pm 1$ & $47.2 \pm 0.4$ \\
\hline 0.50 & $159 \pm 1$ & $47.1 \pm 0.4$ \\
\hline 0.25 & $159 \pm 1$ & $47.1 \pm 0.4$ \\
\hline
\end{tabular}

global cell size on the results of the simulation. The relative sizes of the rectangular volumetric refinement and the domain can be seen in figures 4.4 and 4.5. The cell size did not appear to have a significant effect on computation time or grid cell count, so the global size was set to $0.25 \mathrm{~m}$, with a maximum size of $1 \mathrm{~m}$.

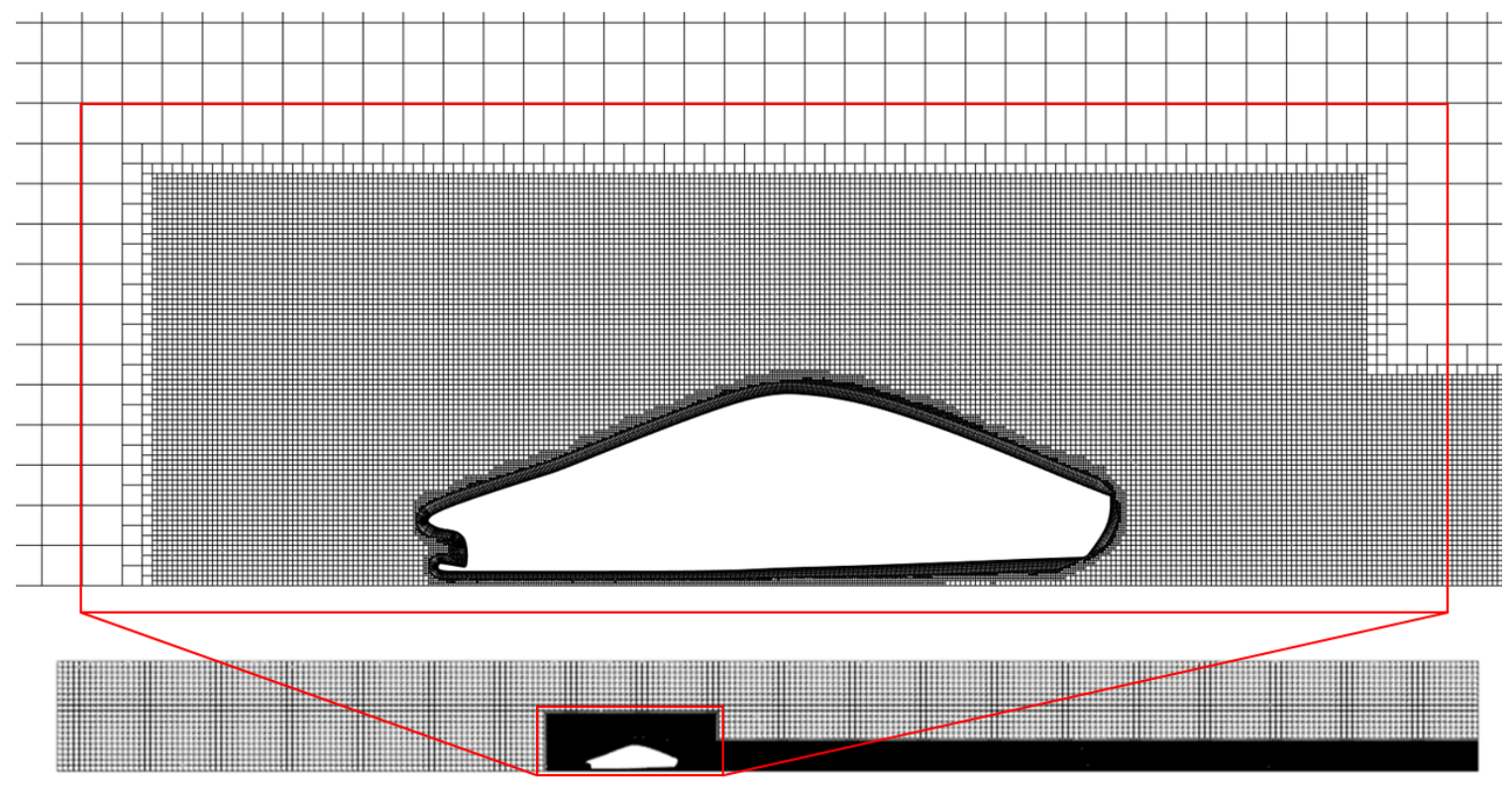

Figure 4.5: Volumetric Refinement, View Along Symmetry Plane 


\subsubsection{Domain}

The most prominent parameter of the simulations is the side lengths of the domain. The domain of the mesh study baseline extends $6.25 \mathrm{~L}$ in front of the origin and $10 \mathrm{~L}$ behind. The rear of the domain offers the most prominent opportunity for reduction due to its length. Table 4.2 shows the study that was done on the domain length to a domain downstream length that delivered accurate results.

\section{Table 4.2: Influence of Domain Downwind Length on Drag Values}

\begin{tabular}{|c|c|c|}
\hline Length $\left(\frac{l}{L}\right)$ & Pressure Drag (N) & Shear Drag (N) \\
\hline \hline 11.0 & $159 \pm 1$ & $47.1 \pm 0.4$ \\
\hline 10.5 & $159 \pm 1$ & $47.1 \pm 0.4$ \\
\hline 10.0 & $159 \pm 1$ & $47.1 \pm 0.4$ \\
\hline 9.5 & $159 \pm 1$ & $47.1 \pm 0.4$ \\
\hline 9.0 & $159 \pm 1$ & $47.1 \pm 0.4$ \\
\hline 8.5 & $159 \pm 1$ & $47.1 \pm 0.4$ \\
\hline 8.0 & $159 \pm 1$ & $47.1 \pm 0.4$ \\
\hline 7.5 & $159 \pm 1$ & $47.1 \pm 0.4$ \\
\hline
\end{tabular}

It can be seen from table 4.2 that changes to the domain length did not have a significant effect on the drag values. The variation between values is within the resultant values' error bounds. Because of the agreement in value, the results in table 4.2 indicate that the solution is overresolved in the baseline form, and that the downwind length of the domain can be lowered. However, the downwind section should have sufficient length to view the behavior of the wake. The downwind length was thus set to $8 L$ in order to ensure that the wake behavior was resolved. 
A sensitivity study was run on the upstream portion of the domain, in addition to the downwind portion. The results of the forward sensitivity study can be seen in table 4.3. Simulations were run with upstream lengths of $6 L, 6.25 L, 6.5 L, 7 L$, and $8 L$ to find the upstream distance that would allow for flow settling and not affect the resultant values of the model.

Table 4.3: Influence of Domain Upstream Length on Drag Values

\begin{tabular}{|c|c|c|}
\hline Length $\left(\frac{l}{L}\right)$ & Pressure Drag (N) & Shear Drag (N) \\
\hline \hline 6.0 & $159 \pm 1$ & $47.1 \pm 0.4$ \\
\hline 6.25 & $159 \pm 1$ & $47.1 \pm 0.4$ \\
\hline 6.5 & $159 \pm 1$ & $47.1 \pm 0.4$ \\
\hline 7.0 & $159 \pm 1$ & $47.1 \pm 0.4$ \\
\hline 8.0 & $159 \pm 1$ & $47.1 \pm 0.4$ \\
\hline
\end{tabular}

It can be seen from table 4.3 that the examined lengths had little effect on the resultant values of the simulations. As with the upstream length, these values are also within the error bound. This agreement means that the upstream length is similarly overresolved, as was the case with the downstream length. Because of the lack of significant difference between the simulations, the $7 L$ case was selected for the finalized grid, as it had the shortest run time.

The width of the domain is also important in ensuring accurate simulation of freestream. Eight cases were run: one each in $0.5 \mathrm{~L}$ increments from $1 \mathrm{~L}$ to $3.5 \mathrm{~L}$, with the additional cases of the baseline $(1.25 \mathrm{~L})$ and a case at $3.25 \mathrm{~L}$. The results of this study are presented in table 4.4 .

The domain width study clearly shows that the width has a more visible effect on the simulation results than domain length. As can be seen in table 4.4, the pressure 


\section{Table 4.4: Influence of Domain Width on Integral Values}

\begin{tabular}{|c|c|c|}
\hline Length $\left(\frac{l}{L}\right)$ & Pressure Drag (N) & Shear Drag (N) \\
\hline \hline 1.0 & $159 \pm 1$ & $47.1 \pm 0.4$ \\
\hline 1.25 & $159 \pm 1$ & $47.1 \pm 0.4$ \\
\hline 1.5 & $159 \pm 1$ & $47.1 \pm 0.4$ \\
\hline 2.0 & $157 \pm 1$ & $46.9 \pm 0.4$ \\
\hline 2.5 & $157 \pm 1$ & $46.8 \pm 0.4$ \\
\hline 3.0 & $158 \pm 1$ & $46.8 \pm 0.4$ \\
\hline 3.25 & $157 \pm 1$ & $46.8 \pm 0.4$ \\
\hline 3.5 & $157 \pm 1$ & $46.7 \pm 0.4$ \\
\hline
\end{tabular}

drag varied from $159 \mathrm{~N}$ at widths of 1.0 and $1.25 \mathrm{~m}$, and 157 and $157 \mathrm{~N}$ at larger widths. The shear drag had the same trend, decreasing from $47.1 \mathrm{~N}$ at $1.25 \mathrm{~m}$ to 46.7 $\mathrm{N}$ at $3.5 \mathrm{~m}$. As lengths above $2.0 \mathrm{~m}$ did not appear to have a significant effect on the resultant values, a width of $3.25 \mathrm{~m}$ was arbitrarily selected.

The domain height was an additional focus of result sensitivity. Simulations were with $0.5 \mathrm{~L}$ increments in height between $1.5 \mathrm{~L}$ and $3.5 \mathrm{~L}$, with additional simulations at heights of $1.25 \mathrm{~L}$ and $2.25 \mathrm{~L}$. Additionally, the mesh study baseline simulation had a height of $1.75 \mathrm{~L}$. The results of this study are shown in table 4.5 .

As can be seen in the table, the shear drag generally decreased from the lowest height to the tallest. The pressure drag shows a decrease from $159 \mathrm{~N}$ below $2.0 \mathrm{~m}$ to $158 \mathrm{~N}$ at and above that height. A domain height of $2.5 \mathrm{~m}$ was selected, as it was above this apparent inflection point at $2.0 \mathrm{~m}$.

The domain size that was determined in this sensitivity study can be seen in figure 4.6. This domain has the longitudinal dimensions of $7 L$ upstream of the origin and $8 L$ 


\section{Table 4.5: Influence of Domain Height on Integral Values}

\begin{tabular}{|c|c|c|}
\hline Length $\left(\frac{l}{L}\right)$ & Pressure Drag (N) & Shear Drag (N) \\
\hline \hline 1.25 & $159 \pm 1$ & $47.1 \pm 0.4$ \\
\hline 1.50 & $159 \pm 1$ & $47.2 \pm 0.4$ \\
\hline 1.75 & $159 \pm 1$ & $47.1 \pm 0.4$ \\
\hline 2.0 & $158 \pm 1$ & $47.1 \pm 0.4$ \\
\hline 2.25 & $158 \pm 1$ & $47.0 \pm 0.4$ \\
\hline 2.5 & $158 \pm 1$ & $46.8 \pm 0.4$ \\
\hline 3.0 & $157 \pm 1$ & $46.8 \pm 0.4$ \\
\hline 3.5 & $158 \pm 1$ & $46.9 \pm 0.4$ \\
\hline
\end{tabular}

downstream of the origin. The width of the domain was set to $3.25 \mathrm{~L}$, and the height at $2.5 \mathrm{~L}$. These corresponded to the dimensions shown in the figure. The domain was filled in with the finalized global cell size, wake refinement, wheel size, and vehicle surface size outlined in the following sections.

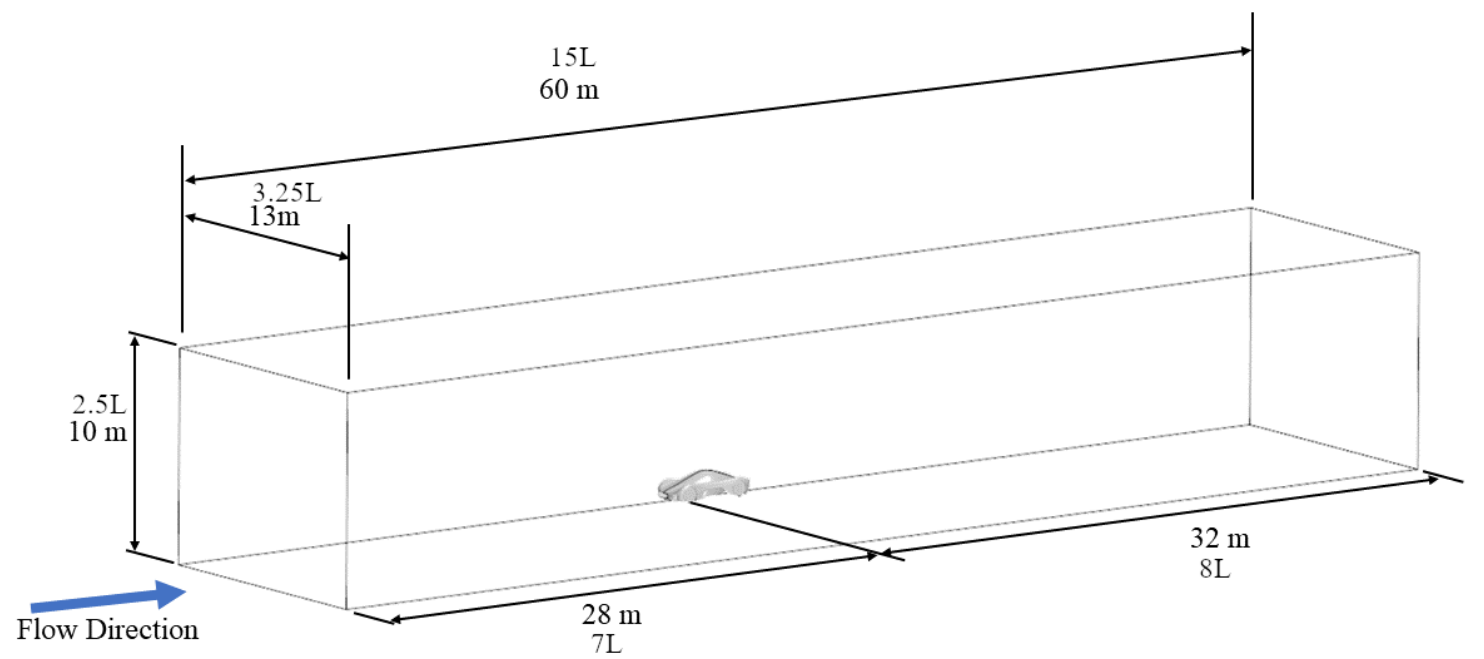

Figure 4.6: Finalized CFD Domain Size 


\subsubsection{Surface Refinement}

The surface of the Endurance Car body is a complex shape, with both large and small radii of curvature. The surface needed to be captured with a fine resolution to ensure that an accurate representation of near-surface flow was captured by the CFD. To ensure this, several studies were attempted on the car body surface size.

For all cases, the minimum surface size was set to be $\frac{1}{10}$ of the maximum size. This was done to ensure that the mesher had sufficient flexibility in surface grid size to accurately represent the geometry of the vehicle, and reduce computation time.

\section{Table 4.6: Influence of Surface Grid Size on Drag Values}

\begin{tabular}{|c|c|c|}
\hline Surface Size $(\mathrm{cm})$ & Pressure Drag $(\mathrm{N})$ & Shear Drag (N) \\
\hline \hline 1.0 & $159 \pm 1$ & $47.1 \pm 0.4$ \\
\hline 0.5 & $159 \pm 1$ & $47.1 \pm 0.4$ \\
\hline
\end{tabular}

The maximum surface size was set to $1.0 \mathrm{~cm}$ to ease in meshing. As can be seen from table 4.6, the pressure drag and shear drag of the $0.5 \mathrm{~cm}$ case are both within rounding error of their $1.0 \mathrm{~cm}$ counterparts' values. However, a $0.5 \mathrm{~cm}$ grid could not be reliably generated on the vehicle, so the $1.0 \mathrm{~cm}$ surface size was selected. A smaller surface size would have allowed the grid to conform more precisely to the surface of the vehicle, and thus offered finer resolution of the flow field on and near the surface.

\subsubsection{Boundary Layer Cells}

To compute the boundary layer height at the rear of the vehicle, the Endurance Car was approximated by a flat plate of the same length. Using the equation for a turbulent boundary layer as outlined by Schlichting [43], the boundary layer height 
at the rear of the vehicle (assuming attached flow over the entire vehicle) was found to be:

$$
\delta=\frac{0.37 L}{R e^{\frac{1}{5}}}=0.07 m
$$

Boundary layer capture cells were then applied to the car body surface, with the above value as the maximum height. The boundary layer cells contained seven vertical rows of cells, each 1.5 times the height of the one below it. These cells were allowed to grow with the geometry of the vehicle to adapt to the geometry of the vehicle, in particular the complex geometry of the front of the vehicle.

\subsubsection{Turbulence Models}

There are three turbulence models that STAR-CCM+ is capable of using, that would be applicable to the problem at hand. These models are the $k-\epsilon, k-\omega$, and Spalart-Allmaras turbulence models. Both the $k-\epsilon$ and $k-\omega$ models are dual equation models, and Spalart-Allmaras is a single-equation model.

The $k-\epsilon$ and $k-\omega$ models are named for three variables: the turbulent kinetic energy $\mathrm{k}$, the kinetic energy decay rate $\epsilon$, and the ratio between the two, $\omega=\frac{\epsilon}{k}$ [50]. Each of the titular variables is found from one of the equations in each model [50]. The $k-\epsilon$ model is known to not predict near-wall flows as well as the other turbulence models examined [50]. The $k-\omega$ model has been shown to have accurate

predictions for adverse pressure gradients and separated flows [50], a positive attribute for the present study. However, the $k-\omega$ model cannot predict the free stream as accurately as $k-\epsilon$ or Spalart-Allmaras. To combat this, the Menter $k-\omega$ model compensates by using the $k-\epsilon$ model in freestream, to take advantage of the benefits of each. The Spalart-Allmaras turbulence model uses a single equation to find the kinematic eddy viscosity and mixing length, but is not good for complex flow fields 
[49]. Spalart-Allmaras was examined as it is robust to low grid quality and has quick convergence.

In addition to turbulence model, there is the option to use segregated solving, or coupled solving. These terms arise from how the simulation solves for the flow field properties. In segregated solving, the CFD solver solves an equation for a single flow field variable for the entire flow field, and then repeats for all variables. In contrast, coupled solving entails finding the solution for each flow field variable at a specified grid point, then repeating for the rest of the grid [2].

Table 4.7: Influence of Turbulence Model and Solving Method on Drag Values

\begin{tabular}{|c|c|c|c|}
\hline Model & Solving & Pressure Drag (N) & Shear Drag (N) \\
\hline \hline$k-\epsilon$ & Coupled & $130 \pm 1$ & $53.3 \pm 0.4$ \\
\hline$k-\epsilon$ & Segregated & $126 \pm 1$ & $52.8 \pm 0.4$ \\
\hline$k-\omega$ & Coupled & $102 \pm 1$ & $46.9 \pm 0.4$ \\
\hline$k-\omega$ & Segregated & $104 \pm 1$ & $48.4 \pm 0.4$ \\
\hline Spalart - Allmaras & Coupled & $159 \pm 1$ & $47.1 \pm 0.4$ \\
\hline Spalart - Allmaras & Segregated & $157 \pm 1$ & $47.3 \pm 0.4$ \\
\hline
\end{tabular}

It can be seen from table 4.7 that there are marked differences in the drag values from each combination of turbulence model and solving method. Most notably, the table shows that each turbulence model gives a different value for the drag. The table shows that the $k-\omega$ model gives the lowest drag values, followed by the $k-$ $\epsilon$ and Spalart-Allmaras models. The $k-\omega$ model was selected as the turbulence model for two reasons: its improved performance with separation and adverse pressure gradients, and the ability to use the Menter $k-\omega$ model. 
Table 4.7 also shows a difference in the use of coupled solving and segregated solving. For the $\mathrm{k}-\epsilon$ and Spalart-Allmaras turbulence models, the segregated solving pressure drag is either less than the pressure drag of the coupled solver, while it is higher for the $\mathrm{k}-\omega$ model. Table 4.7 shows that the shear drag slightly increases with the addition of segregated solving for both the k- $\omega$ and Spalart-Allmaras models, and decreases for $\mathrm{k}-\epsilon$ turbulence model. Segregated solving was selected, as the change in drag is within the nominal limit of $1 \%$ difference, and its selection decreased computation time.

\subsubsection{Wake Refinement}

The wake is one of the most important part of the computational mesh. Accurate analysis of the pressure and velocity at the rear of the vehicle body are crucial in understanding the underbody flow. A small study of mesh sizes were run to determine the solution that would deliver resolution to the wake, without compromising computation time.

Two simulations run, in addition to the baseline case. A case each with no wake refinement, and wake refinement cells with $10 \mathrm{~cm}$ side length were run in addition to the baseline case, which had a side length of $4 \mathrm{~cm}$. As can be seen from the table, the addition of wake refinement did not significantly change the magnitude of the resultant drag values on the model.

The pressure and shear drag values of all three cases are within rounding error. The $4 \mathrm{~cm}$ case was selected due to the increased resolution that it provided in the wake of the vehicle. 


\section{Table 4.8: Influence of Wake Grid Size on Drag Values}

\begin{tabular}{|c|c|c|}
\hline Cell Size $(\mathrm{cm})$ & Pressure Drag (N) & Shear Drag (N) \\
\hline \hline $\mathrm{n} / \mathrm{a}$ & $159 \pm 1$ & $47.1 \pm 0.4$ \\
\hline 10 & $159 \pm 1$ & $47.1 \pm 0.4$ \\
\hline 4 & $159 \pm 1$ & $47.1 \pm 0.4$ \\
\hline
\end{tabular}

\subsubsection{Wheel Refinement}

The wheels pose a challenge due to their proximity to both the ground and the surface of the car. Additionally, the wheel well study could not be performed during the initial mesh sensitivity studies, as the wheels were not modeled at that time. This was mitigated by a mesh study using an alternative version of the baseline CAD model. The ground plane was modeled as a slip wall to avoid boundary layer buildup, and the wheels were modeled as stationary cylinders. The GCI (drag-based) was recalculated for the different model to find a new relative error in the simulations of $1.6 \%$.

Table 4.9: Influence of Wheel Grid Size on Drag Values

\begin{tabular}{|c|c|c|}
\hline Surface Size $(\mathrm{cm})$ & Pressure Drag (N) & Shear Drag (N) \\
\hline \hline 1.5 & $158 \pm 3$ & $44.4 \pm 0.7$ \\
\hline 1.0 & $163 \pm 3$ & $43.8 \pm 0.7$ \\
\hline 0.5 & $167 \pm 3$ & $43.4 \pm 0.7$ \\
\hline
\end{tabular}

Three wheel surface sizes were run: $1.5 \mathrm{~cm}, 1.0 \mathrm{~cm}$, and $0.5 \mathrm{~cm}$. It can be seen from table 4.9 that the pressure drag value varied greatly with the wheel surface size. The large spread in pressure drag values indicates that the simulation result is 
dependent on the selection of surface size. In contrast to the pressure drag, the shear drag varied within the uncertainty bound of the simulations.

The $0.5 \mathrm{~cm}$ case would have been the preferred surface size on the wheels; however the solution did not reliably save correctly, despite repeated attempts to regenerate and re-run the simulation. While this size would have allowed for greater resolution, these failures reduced confidence in the ability to reliably generate data with this parameter value. The values presented for the $0.5 \mathrm{~cm}$ solution in table 4.9 represent the values of the final iteration before the failed save, with the nominal error of $0.1 \%$ applied. For this reason, the $0.5 \mathrm{~cm}$ case was discarded. The $1.0 \mathrm{~cm}$ case had an average $y+$ value on the wheels of 50 , while the $1.5 \mathrm{~cm}$ case had an average $\mathrm{y}+$ of 60 . Due to its decreased $\mathrm{y}+$ value, the $1.0 \mathrm{~cm}$ case was selected for the finalized mesh.

\subsection{Run Conditions}

The physics model of each simulation was set up to match reference conditions. Density was held constant at $1.225 \frac{\mathrm{kg}}{\mathrm{m}^{3}}$. Because the location and time of year of a run were not set during simulation, the density and pressure were not referenced to a real-world condition. The density was held constant due to the low speed nature of the simulations.

Table 4.10: CFD Physics Model

\begin{tabular}{|c|c|}
\hline Parameter & Value \\
\hline \hline Density & $1.225 \frac{\mathrm{kg}}{\mathrm{m}^{3}}$ \\
\hline Pressure & $1 \mathrm{~atm}$ \\
\hline Turbulence & Menter $\mathrm{k}-\omega$ \\
\hline Velocity & $65 \mathrm{mph}$ \\
\hline
\end{tabular}


The simulation was a RANS time-averaged solution that was set to be at steadystate. As outlined above, the turbulence model was set to the Menter k- $\omega$ SST model. The turbulence intensity of the oncoming flow was set to $5 \%$ with a length scale of $0.215 \mathrm{~m}$, which corresponds to $0.05375 \mathrm{~L}$. These values were selected as an estimate of the highest values expected of the turbulence intensity and length scale during a run in the expected location of Mojave, California.

The original design requirement of the Endurance Car was to break the endurance record at $104.6 \mathrm{kph}(65 \mathrm{mph})$. While this requirement was eventually eliminated, the simulations run in this analysis were kept at $65 \mathrm{mph}$ to keep with the maximum design velocity of the Endurance Car. Simulations were run with the vehicle wheels placed so that their lowest point was coincident with the ground. In addition, the wheels were set to spin with a rotation rate equal to that of an equal-diameter tire travelling at $29.06 \mathrm{~m} / \mathrm{s}(65 \mathrm{mph})$.

\subsection{CAD and CFD Simplifications}

The CAD model of the Endurance Car does not correspond exactly to the expected real-world vehicle. There are several simplifications that were made to ease analysis or due to incomplete information.

First, the wheels were modeled as rotating cylinders. This was done because the final wheel design for the Endurance Car had not been by the time of modelling. CFD and coast-down studies on the Tesla Model S show that a closed-face wheel design reduces drag over open-faced variants [9]. This result implies that the drag contribution from the wheels is lower than for a more realistic open-face wheel that would be used on a real-world Endurance Car. 
Second, the front wheel house on the CAD model is too shallow to allow for realistic steering. This is because the proper size of the wheel house for the suspension and steering geometry was not known at the time of modeling, so the size of the wheel well for those components was estimated. Mavuri (2009) shows that the drag on a body with wheel houses is reduced from a baseline of $C D=0.55$ to $C D=0.51$ if the depth of the wheel well is increased [34]. This implies that the drag of the Endurance Car body is slightly over-predicted in the present study. However, this result does not include the influence of the addition of suspension or steering geometry, which would additionally affect the resultant forces [34].

Third, the body was simulated without any panel seams or gaps. These were not included on the CAD model both because their locations were not known during modelling. Such features on the surface of a body introduce drag by creating vortices or local separation inside the gap [4]. In addition, they can increase drag by tripping the boundary layer, or inducing separation [4]. This means that the present study under-predicts the drag on the body shell.

Fourth, only a half-body was simulated. In each simulation, only the driver's side of the vehicle was used. The top and the longitudinal walls of the domain were set to be symmetry planes. This enabled the effects of a full body to be investigated, while reducing the compute time of each simulation. The full vehicle was created by mirroring the driver's side results in post-processing. Integral values on the vehicle were doubled to account for the halved reference areas.

In addition to the above considerations, the ground was set to a stationary slip wall. It was shown by Koitrand and Rehnberg (2013) that a (non-slip) moving ground condition increases drag by up to $\Delta C_{D}=0.011$ over the stationary case [30]. This implies that the drag is under-predicted on in the present study. The non-slip condition on the ground would affect the flow features and properties underneath the 
car, particularly underneath the cabin, as this portion represents the narrowest gap between the vehicle and the ground plane. 
Chapter 5

RESULTS

\subsection{Baseline}

The resultant values on the baseline model are shown in table 5.1. The total drag (the sum of the pressure and shear drag forces) is dominated by the pressure drag, at $151.1 \mathrm{~N}$, compared to the shear drag at $44.4 \mathrm{~N}$. This result fits with the drag components on a bluff body as outlined by Tamai [46].

The error in the results of the CFD simulations was found from the wheel GCI values (1.6\%), as those utilized a grid study centered on the baseline model.

\section{Table 5.1: Resultant Forces on Baseline Model}

\begin{tabular}{|c|c|}
\hline Parameter & Baseline \\
\hline \hline Pressure Drag (N) & $151 \pm 2$ \\
\hline Shear Drag (N) & $44.4 \pm 0.7$ \\
\hline Lift (N) & $-310 \pm 5$ \\
\hline$C_{D}$ & $0.211 \pm 0.003$ \\
\hline$C_{L}$ & $-0.080 \pm 0.001$ \\
\hline
\end{tabular}

As discussed in chapter 3, there are several separation zones on the baseline model that contribute to the pressure drag. Most notable are the areas of separation inside of the rear fenders, and the separation zones just downstream of the front wheels. These areas of separation can be seen as the wavy, irregular shapes highlighted in figure 5.1. The figure shows that boundary layer separation exists along the latter 
portion of the inside of the rear fenders, as well as in the exhaust of the front duct. The separated region inside the rear fenders merges with the recirculation zone behind the rear fenders to create a single large area of non-attached flow.

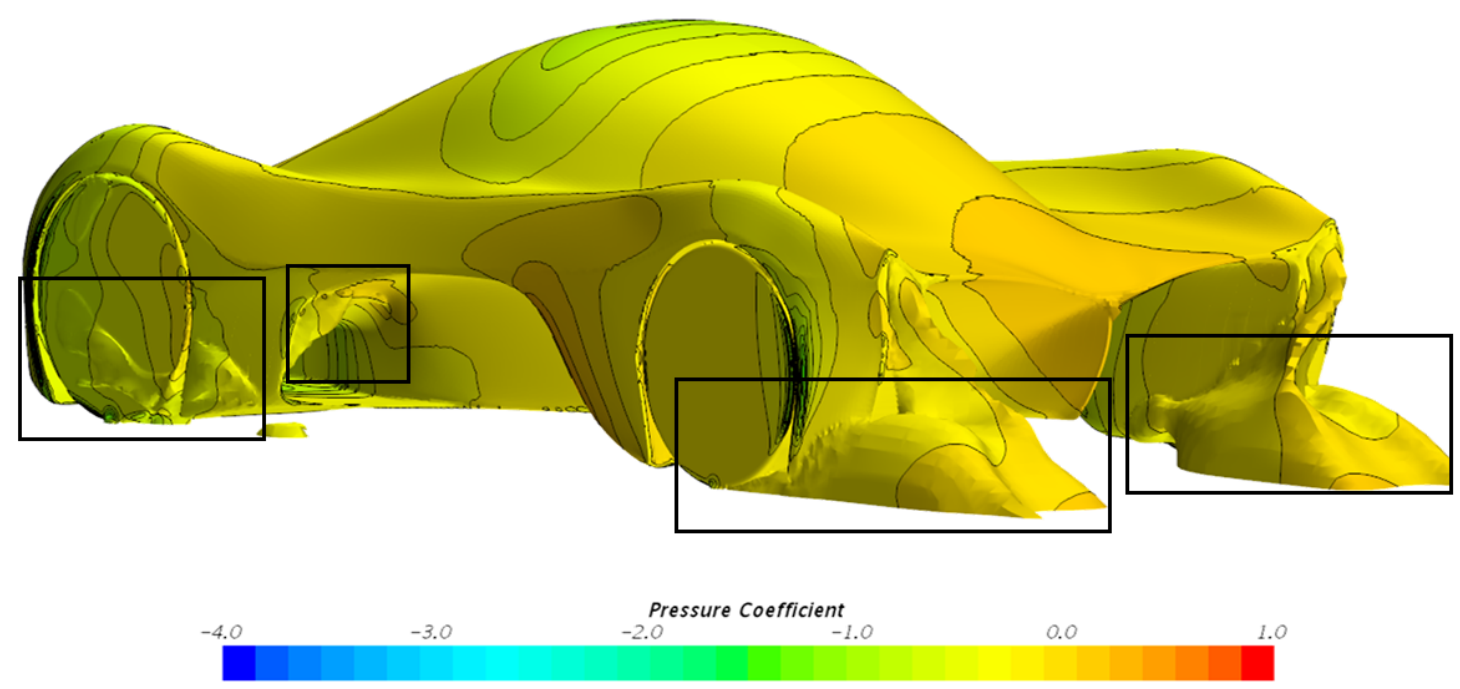

Figure 5.1: Isosurface Showing Longitudinal Velocity Equal to $0.1 \mathrm{~m} / \mathrm{s}$, Baseline Model. (Replication of Figure 3.5)

An understanding of the pressure distribution on the underside of the body is critical in the analysis of the underside. The flow field was probed along the centerline of the front ducts and the diffuser to capture the streamline corresponding to the average flow direction through the vehicle. These probes can be seen in the flow field portion of figure 5.2. Between the duct and the diffuser, the probes follow a straight line that does not vary in lateral location. The flow field was probed at $20.32 \mathrm{~cm}(8$ in) from the ground in each simulation, except for the raised ride height model, which was probed at $22.86 \mathrm{~cm}(9 \mathrm{in})$, to view the flow field at the same vertical location on the body as the baseline. This height was selected to give a cross section of the flow field that was unobstructed by effects from the floor or ceiling of the duct, and not affected by the ground boundary layer in the diffuser. The probe locations were selected to approximate a streamline through the under-body flow field. 


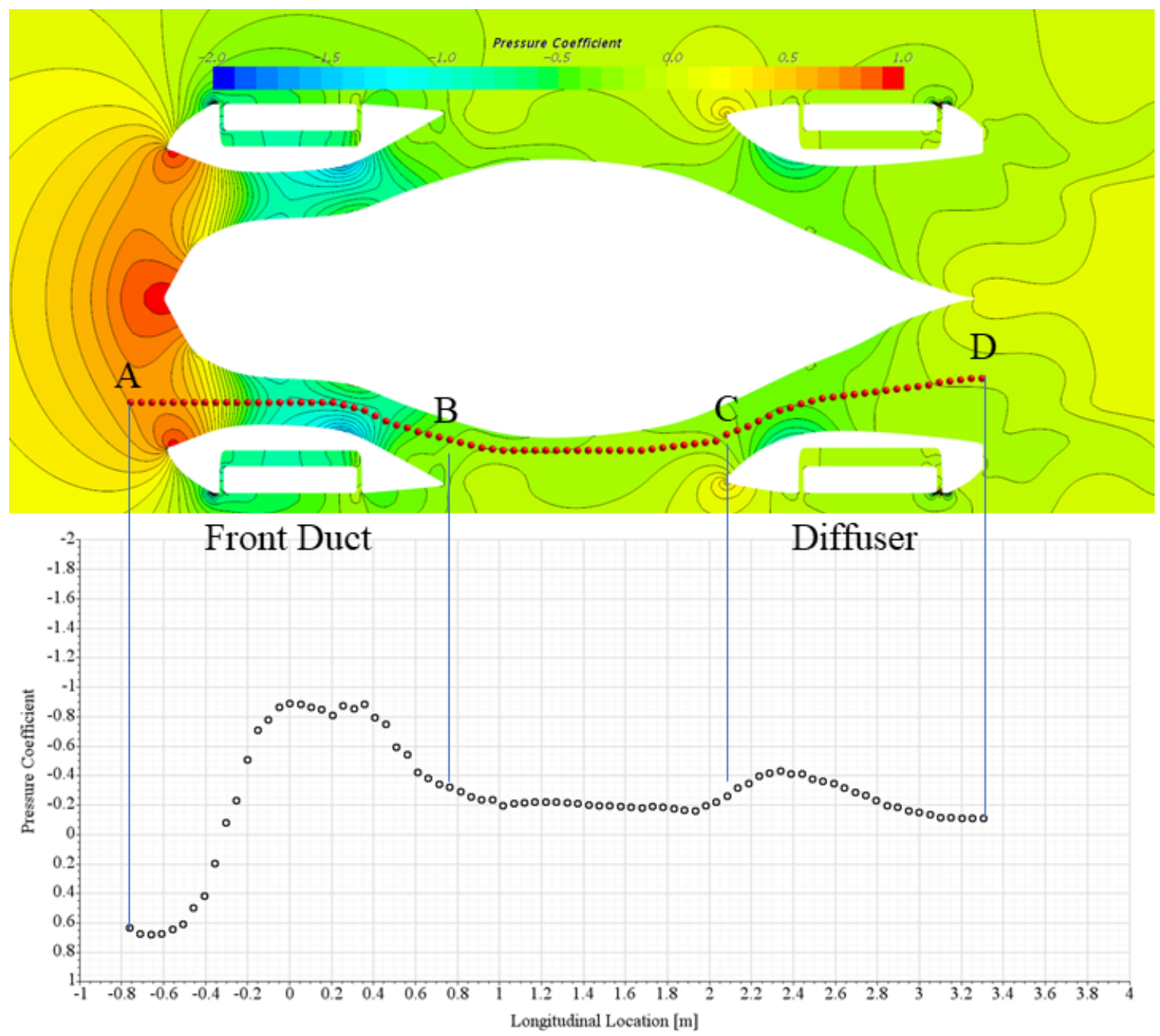

Figure 5.2: $C_{p}$ Behavior on Underside of Baseline Model, $20.32 \mathrm{~cm}$ from Ground

It can be seen from figure 5.2 that there are two areas where the flow experiences the Venturi effect: along the length of the front ducts, and inside the diffuser. The front ducts (between points $\mathrm{A}$ and $\mathrm{B}$ ) experience a large change in $C_{p}$ as the flow is sped up, then slowed down to recover pressure as it is reunited with the flow along the exterior of the vehicle at point B. At point $\mathrm{C}$, the flow enters the diffuser, where the flow pressure lowers before being recovered at point $\mathrm{D}$, the exhaust of the diffuser.

It is evident from the pressure coefficient plot in figure 5.2 that there are adverse gradients in the $C_{p}$ along the probe line. This is an undesirable attribute because 
large, steep, adverse pressure gradients like the one at the front duct exhaust can cause separation, as is happening on the model. Elimination or reduction of said gradient would assist in reduction of separation at the exhaust of the front ducts.

\subsection{Side Skirt}

One attempt at reducing the size of the adverse pressure gradients on the vehicle was to introduce vertical side skirts along the middle section of the vehicle; these can be seen from point $\mathrm{B}$ to point $\mathrm{C}$ in figure 5.3.

The resultant values of the side skirt model are shown in table 5.2. The pressure drag of both models exhibit a similar value. In contrast, there is a large difference in the shear drag. The side skirt model shows an increase of $5.7 \mathrm{~N}$ over the baseline. This change can be attributed to the increase in wetted area due to the side skirts. It is also clear that the side skirts had the known effect of increasing downforce; the downforce increased by over $100 \mathrm{~N}$ over the baseline model.

Table 5.2: Resultant Forces on Side Skirt Model

\begin{tabular}{|c|c|c|}
\hline Parameter & Side Skirt & Baseline \\
\hline \hline Pressure Drag (N) & $154 \pm 2$ & $151 \pm 2$ \\
\hline Shear Drag (N) & $50.1 \pm 0.8$ & $44.4 \pm 0.7$ \\
\hline Lift (N) & $-440 \pm 7$ & $-310 \pm 5$ \\
\hline$C_{D}$ & $0.220 \pm 0.004$ & $0.211 \pm 0.003$ \\
\hline$C_{L}$ & $-0.112 \pm 0.002$ & $-0.080 \pm 0.001$ \\
\hline
\end{tabular}

The addition of the side skirts resulted in reduced pressure compared to freestream along the side of the vehicle, as can be seen between points $\mathrm{B}$ and $\mathrm{C}$ in figure 5.3. As the side of the baseline is exposed to the freestream, this effect can additionally 
be seen in figure 5.4. Literature reports that a reduction in static pressure along the underside of an Ahmed body will increase downforce [6] [7]. This appears to be the case for the Endurance Car as well. Table 5.2 shows the drag of the side skirt and baseline models; it can be seen that there is a large increase in downforce with the addition of side skirts.

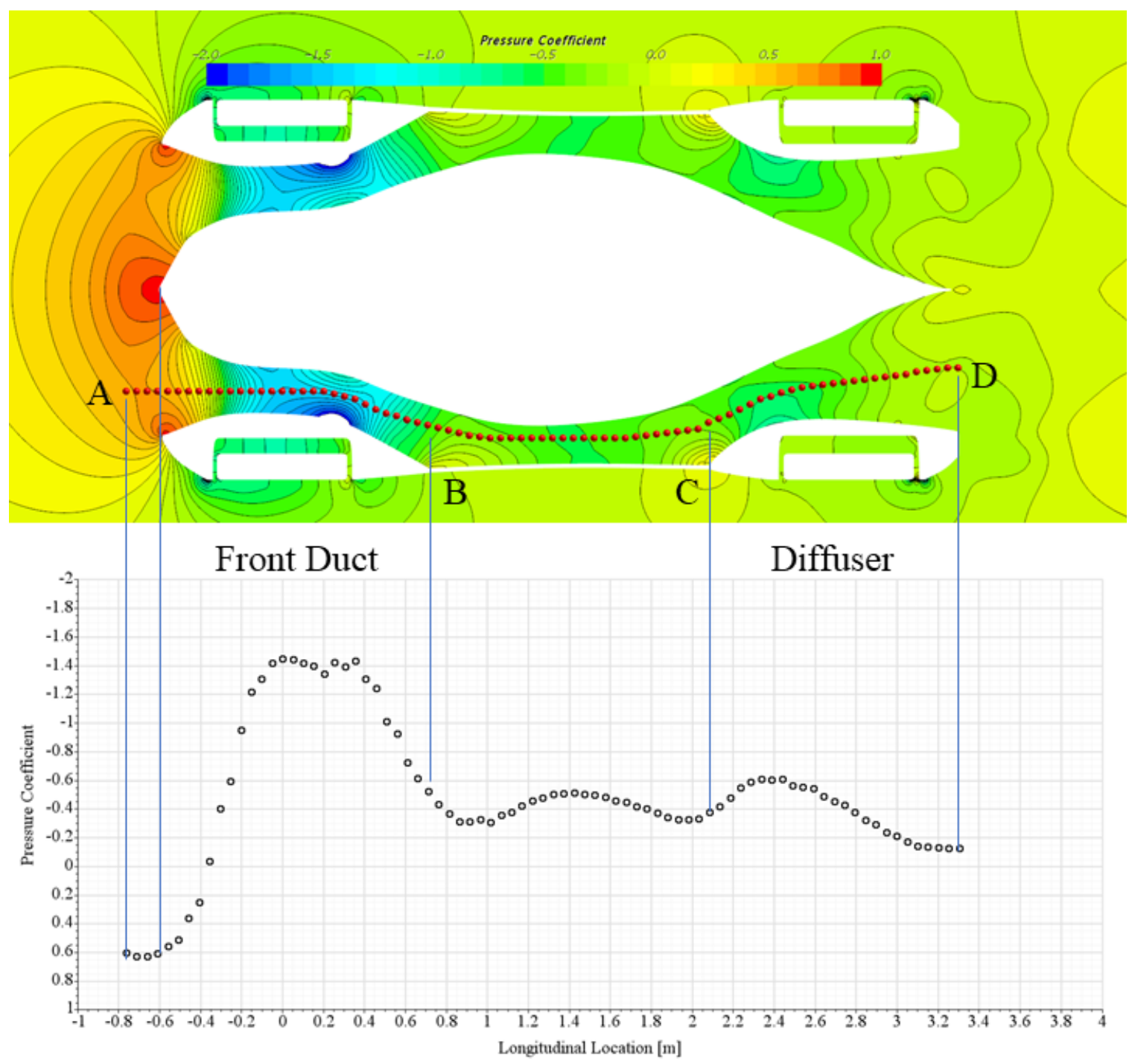

Figure 5.3: $C_{p}$ Behavior on Underside of Side Skirt Model, $20.32 \mathrm{~cm}$ from Ground

In analyzing the results of the side skirt model, it is evident that the addition of side skirts had major effects on the flow field. Most notably, the side skirts have the effect of separating the flow along the underbody from the external flow past 
the wheel housings. This effect can be seen in figure 5.3, where there is a marked difference in the $C_{p}$ activity between points B and C. Most notably, the cross-section of the side now has a venturi shape between those points; this has the effect of adding in a third section of venturi-like behavior along the $C_{p}$ distribution.

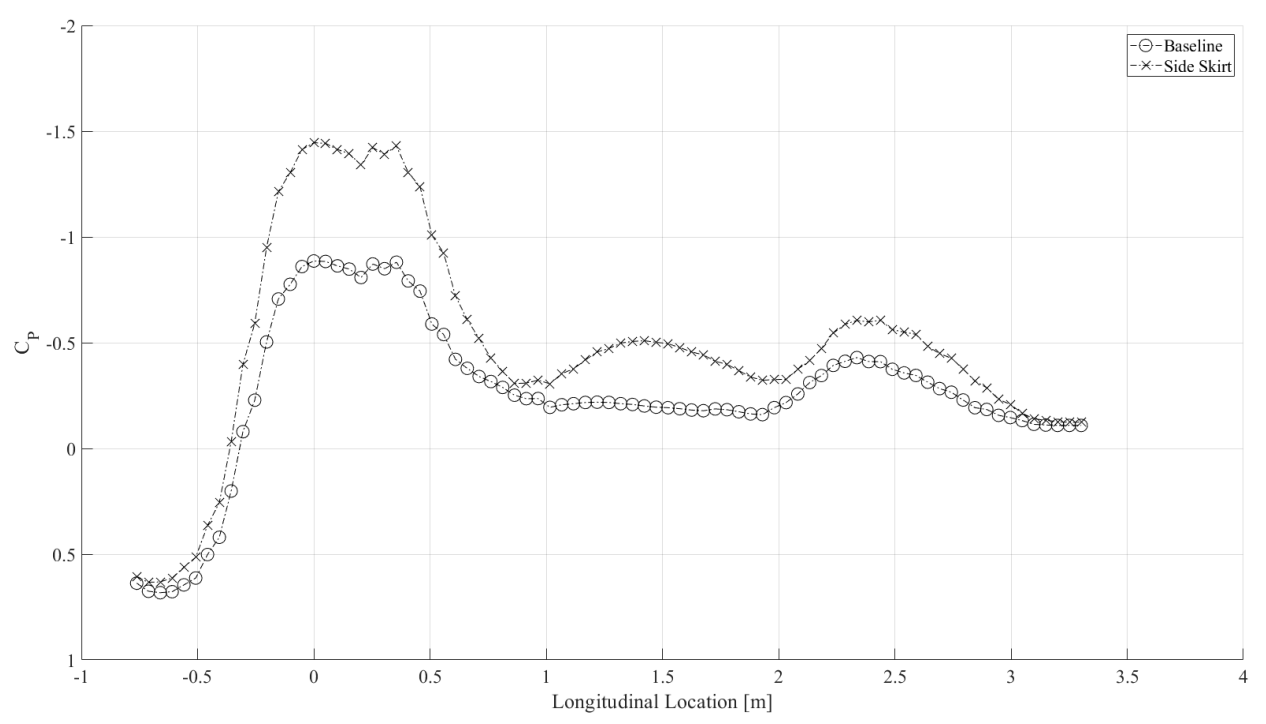

Figure 5.4: Comparison of Baseline and Side Skirt Models' $C_{p}$ Distributions

Figure 5.4 shows a comparison of the $C_{p}$ distributions in the baseline and side skirt models. The figure shows that the side skirts have the effect of magnifying the strength of the Venturi effect inside of the front ducts. This increases the strength of the adverse pressure gradient in the ducts, which increases the likelihood of separation at the location of the pressure gradient. Because of the imposed Venturi effect along the sides, another adverse pressure gradient is created along the side. Additionally, it can be seen from figure 5.4 that the slope of the adverse pressure gradient at the rear (longitudinal locations aft of $2.5 \mathrm{~m}$ ) has increased, and with it the tendency toward separation at the rear fender.

Recalling table 5.2, the pressure drag on the side skirt model was increased by 2.4 $\mathrm{N}$ over the baseline model. This indicates that the side skirts were not effective at 
significantly reducing separation on the vehicle. This can be seen in figure 5.5; the recirculation region inside adn aft of the rear fenders was not eliminated.

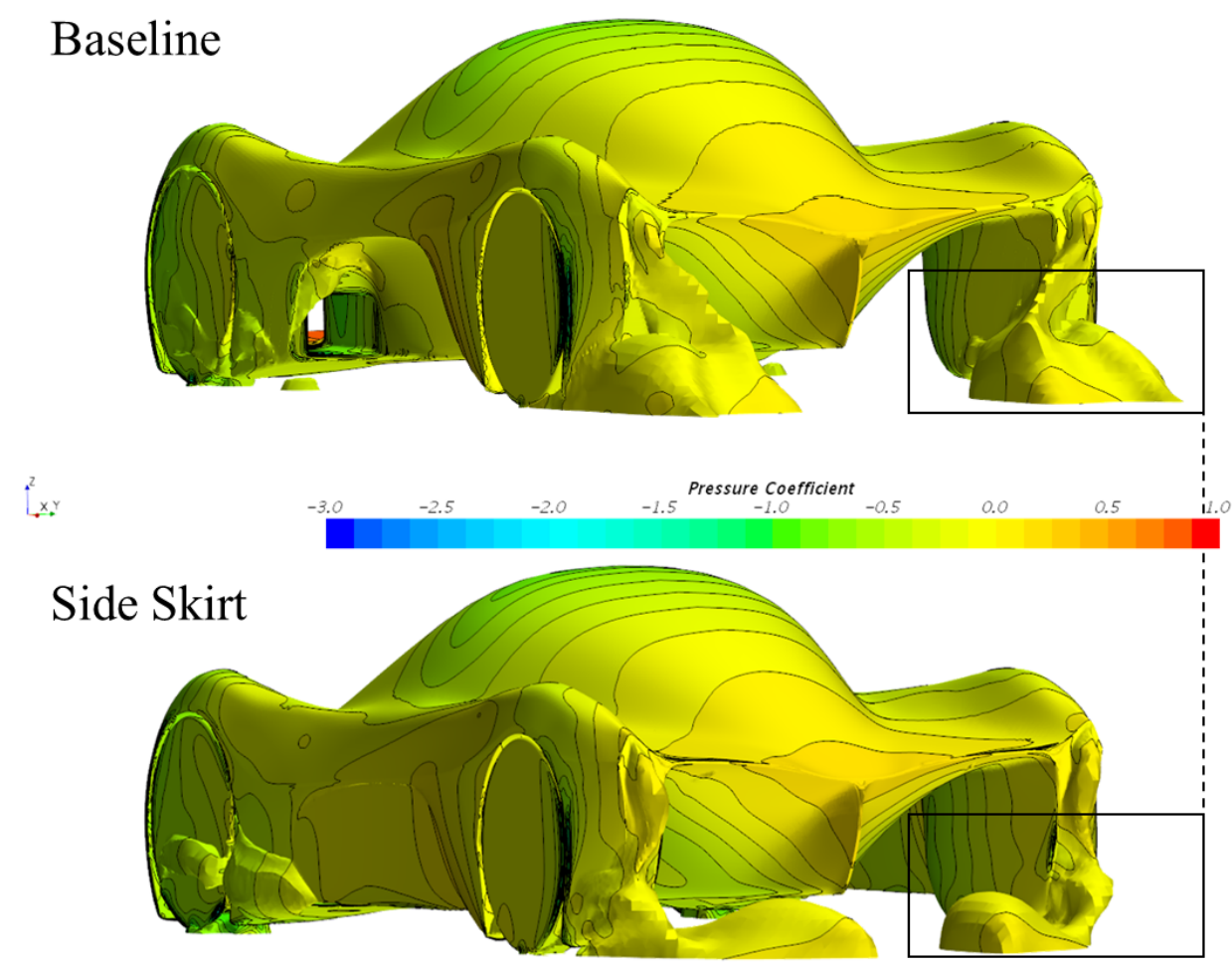

Figure 5.5: Rear Separation Regions, Side Skirt Model and Baseline Model. Isosurface Showing Longitudinal Velocity Equal to $0.1 \mathrm{~m} / \mathrm{s}$. 


\subsection{Ride Height}

Another potential method of reducing the magnitude of adverse $C_{p}$ gradients is in increasing the ride height. The baseline model ride height was increased to $\frac{h}{H}=0.101$ from $\frac{h}{H}=0.079$. The change in the resultant forces from this strategy can be seen from table 5.3.

Table 5.3: Resultant Forces on Raised Ride Height Model

\begin{tabular}{|c|c|c|}
\hline Parameter & Raised Ride Height & Baseline \\
\hline \hline Pressure Drag (N) & $153 \pm 2$ & $151 \pm 2$ \\
\hline Shear Drag (N) & $44.4 \pm 0.7$ & $44.4 \pm 0.7$ \\
\hline Lift (N) & $-290 \pm 5$ & $-310 \pm 5$ \\
\hline$C_{D}$ & $0.213 \pm 0.003$ & $0.211 \pm 0.003$ \\
\hline$C_{L}$ & $-0.075 \pm 0.001$ & $-0.080 \pm 0.001$ \\
\hline
\end{tabular}

Neither the pressure or shear drag on the raised model showed a change in value outside of the error value. This indicates that there was not a significant change in the drag between the baseline and raised models. The downforce decreased from 310 $\mathrm{N}$ to $290 \mathrm{~N}$. This indicates that the most significant change to the resultant values was in the downforce, instead of drag.

The same flow features that are present in the baseline model are present in the flow field of the raised model. As shown in figure 5.6, the front ducts show a large decrease and consequent increase in pressure, as the flow intersects the flow past the outside of the front wheels. The Venturi effect is also present in the diffuser.

The under-body flow implications of the changes to the vehicle ride height can be seen from the $C_{p}$ along the underside. As shown in figure 5.7, there is high correlation 


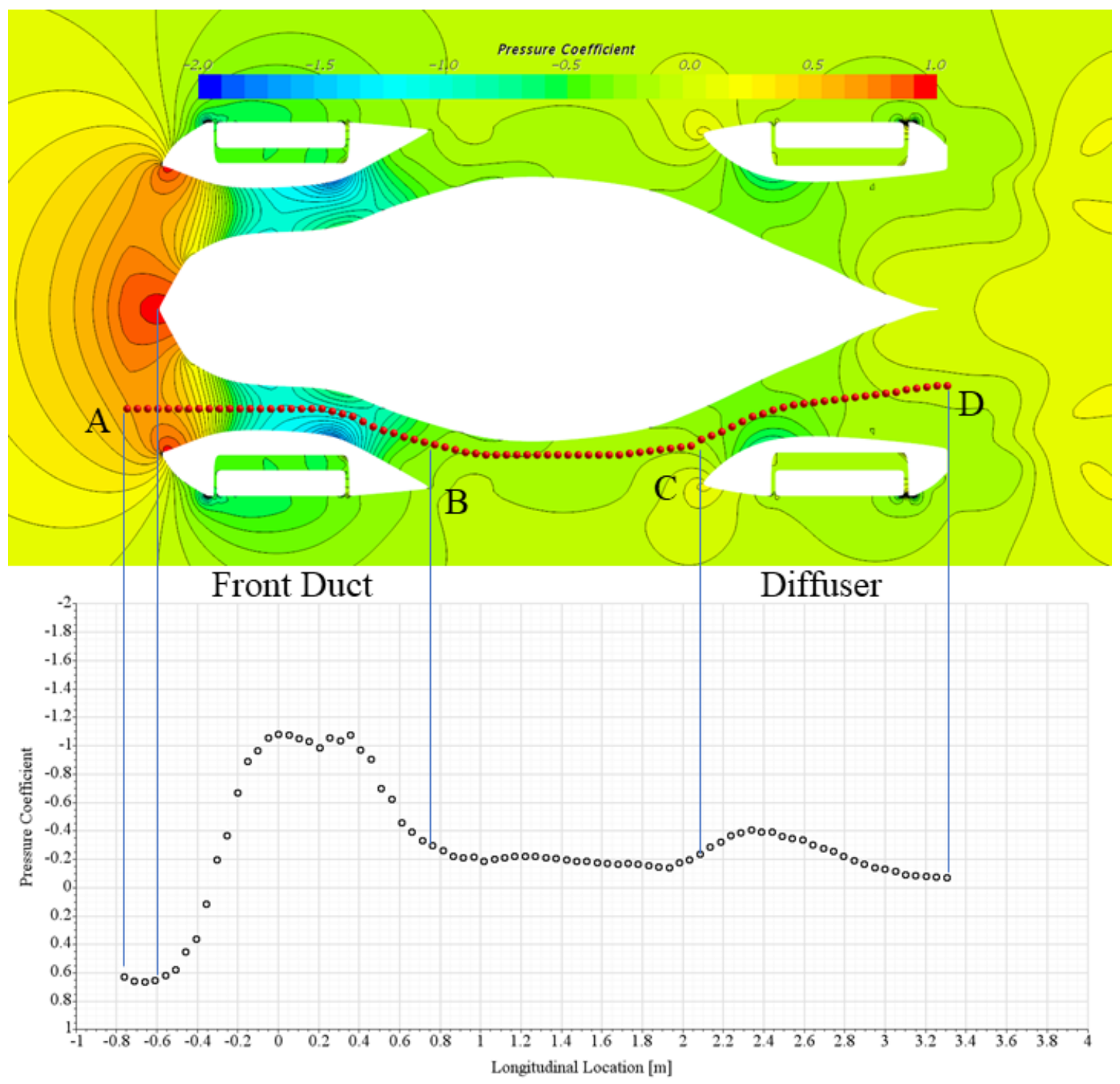

Figure 5.6: $C_{p}$ Behavior on Underside of Raised Ride Height Model, 22.86 cm from Ground

between between the two bodies' $C_{p}$ distributions downstream of $1 \mathrm{~m}$ behind the origin. This provides further evidence that the change in ride height did not have a significant effect on the flow in the diffuser.

Upstream of that point, however, the figure shows that the increased ride height lowered the minimum $C_{p}$ of the flow in the front ducts compared to the baseline. This decrease in $C_{p}$ means that the maximum velocity of the flow inside the front ducts was increased as a result of the change in ride height. As a result of the change 


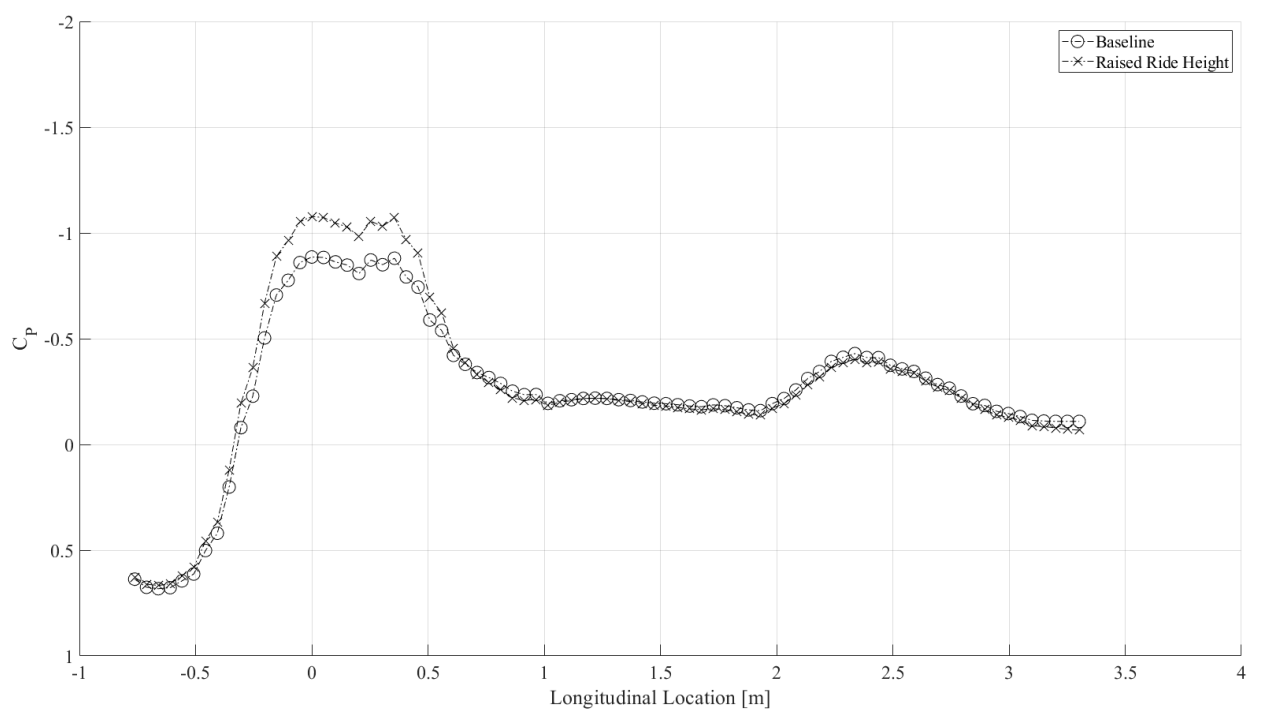

Figure 5.7: Comparison of Baseline and Raised Ride Height Models' $C_{p}$ Distributions

in minimum $C_{p}$, the adverse pressure gradient in the front ducts increased over the baseline model.

The increase in ride height did not significantly change the flow features present in the diffuser, compared to the baseline model. The separation zones at the rear of the baseline model, compared to those in on the raised model, can be seen in figure 5.8. As can be seen in the figure, there remained separation along the inside of the rear fenders. The most significant change over the baseline was the introduction of a new separation zone along the centerline fin at the rear of the vehicle, this can be seen in figure 5.8. 


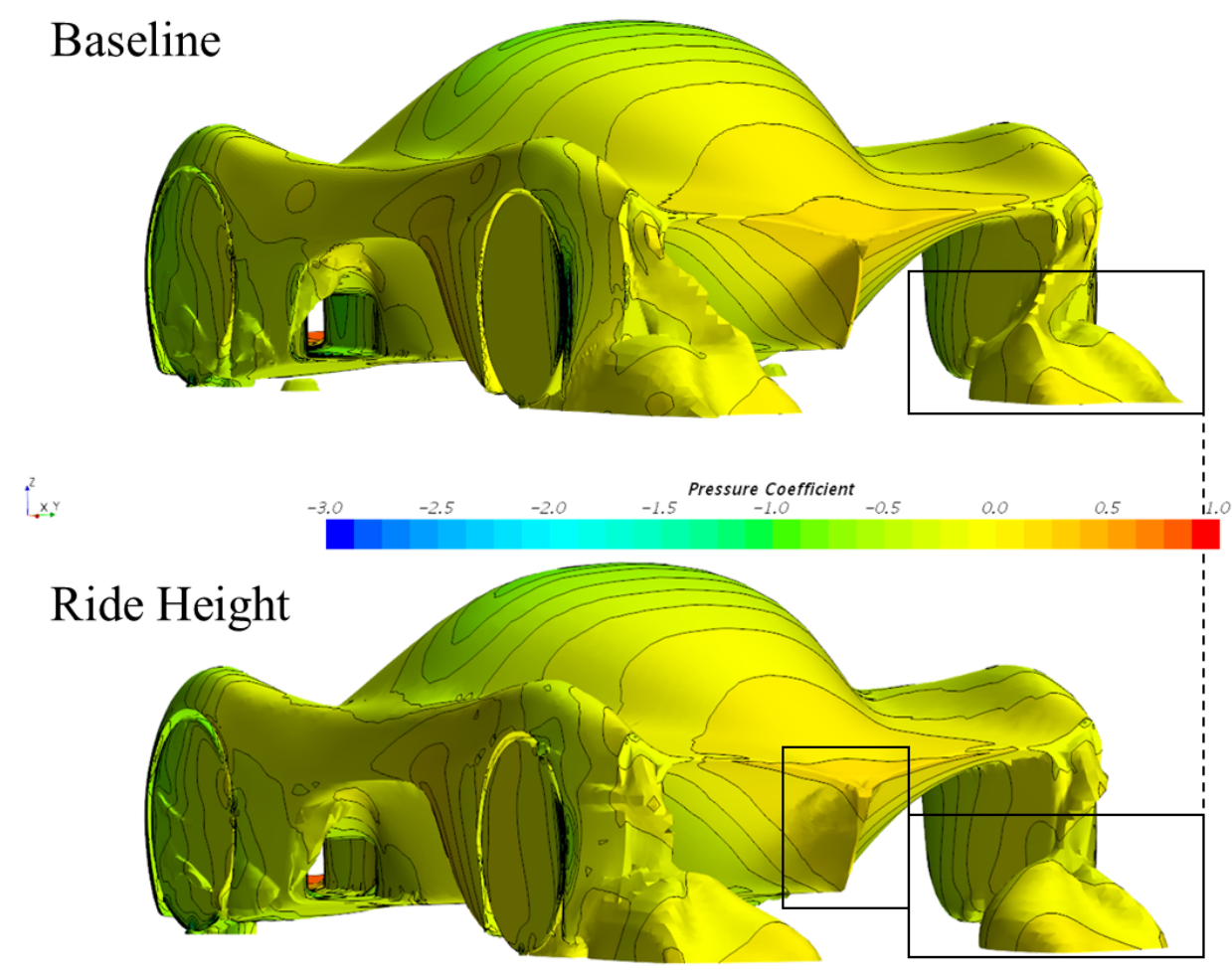

Figure 5.8: Rear Separation Regions, Raised Ride Height Model and Baseline Model. Isosurface Showing Longitudinal Velocity Equal to $0.1 \mathrm{~m} / \mathrm{s}$.

\subsection{Extended Diffuser}

The resultant values on the extended model and the baseline model are shown in table 5.4. As can be seen from the table, the pressure drag decreased by $8 \mathrm{~N}$ and the shear drag decreased by $1.1 \mathrm{~N}$. Combined, these values give a total drag on the body of $186 \mathrm{~N}$, which represents a drop of $9 \mathrm{~N}$ from the baseline model's total drag of 195 N. As shown in the table, the extended model's drag coefficient is $C_{D, \text { extended }}=0.201$, as opposed to the baseline model's drag coefficient of $C_{D}=0.211$.

The pressure field on the underside of the extended model is presented in figure 5.9. The CFD pressure probes in the figure are the same as those used on the baseline model, with the addition of three additional probe points at the rear of the model, to capture the extended length of the diffuser. These probe points were selected to be 
Table 5.4: Resultant Forces on Extended Model

\begin{tabular}{|c|c|c|}
\hline Parameter & Extended & Baseline \\
\hline \hline Pressure Drag (N) & $143 \pm 2$ & $151 \pm 2$ \\
\hline Shear Drag (N) & $43.3 \pm 0.7$ & $44.4 \pm 0.7$ \\
\hline Lift (N) & $-230 \pm 4$ & $-310 \pm 5$ \\
\hline$C_{D}$ & $0.201 \pm 0.003$ & $0.211 \pm 0.003$ \\
\hline$C_{L}$ & $-0.058 \pm 0.001$ & $-0.080 \pm 0.001$ \\
\hline
\end{tabular}

at 15 in $(38.1 \mathrm{~cm})$ from the centerline of the body, to match that of the prior trailing point. In figure 5.9, point $\mathrm{C}$ is kept at the same location as the baseline model, for visual reference.

As seen in the figure, the $C_{p}$ begins to lower at point $\mathrm{C}$, as the flow enters the diffuser. The $C_{p}$ undergoes the Venturi effect in the diffuser as it is turned toward the exit.

Figure 5.10 shows a comparison of the $C_{p}$ distributions on both the baseline and the extended models. It can be seen that the Venturi effect in the front ducts has been much reduced; the pressure gradient at the rear of the front ducts is much less severe than the baseline model. This reduces the tendency of the flow toward separation. This is reduction in pressure drop is an upstream effect from the diffuser geometry change.

Aft of the front ducts, it can be seen from figure 5.10 that the flow along the side correlates closely with that of the baseline model.

As shown in figure 5.10, the extended diffuser had the effect of moving the point of minimum pressure in the diffuser rearward. Additionally, this point appears on 


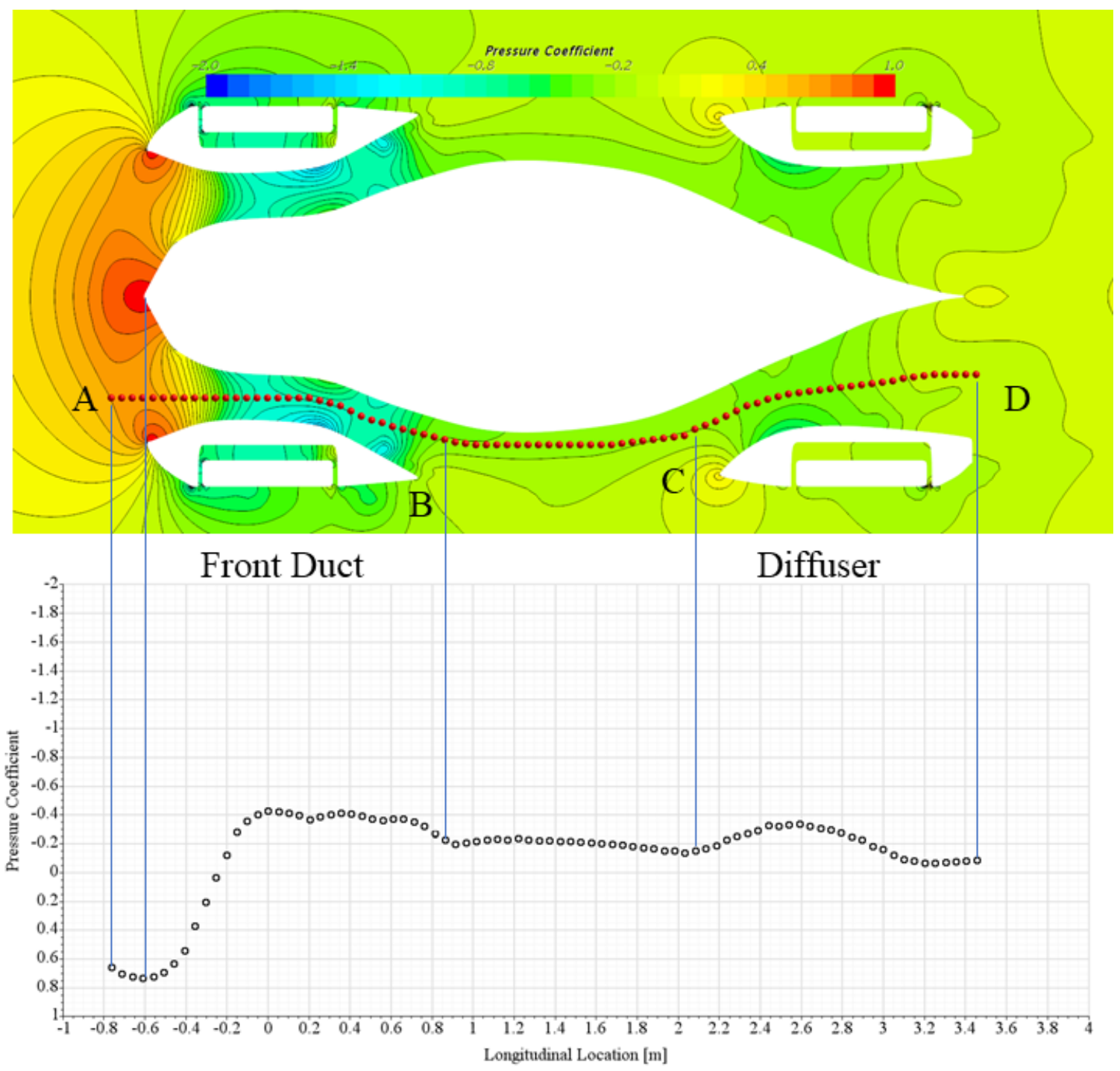

Figure 5.9: $C_{p}$ Behavior on Underside of Extended Model, $20.32 \mathrm{~cm}$ from Ground

the adverse pressure gradient of the baseline model. Past the point of minimum separation, the pressure gradient in the expanded diffuser is similar to that of the baseline model.

An inspection of the flow field in the diffuser in figure 5.11 shows that the recirculation zone at the rear of the diffuser was not eliminated. As in the raised model, an additional separation zone was induced along the central fin in the diffuser. 


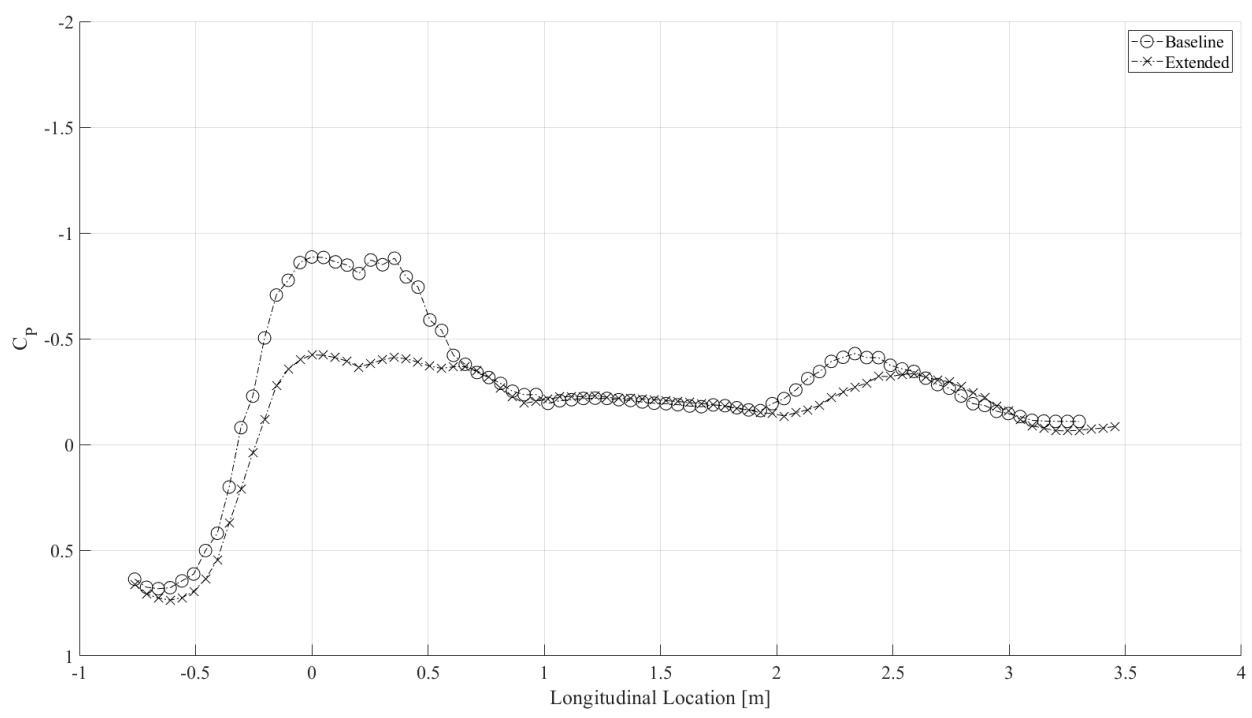

Figure 5.10: Comparison of Baseline and Extended Models' $C_{p}$ Distributions

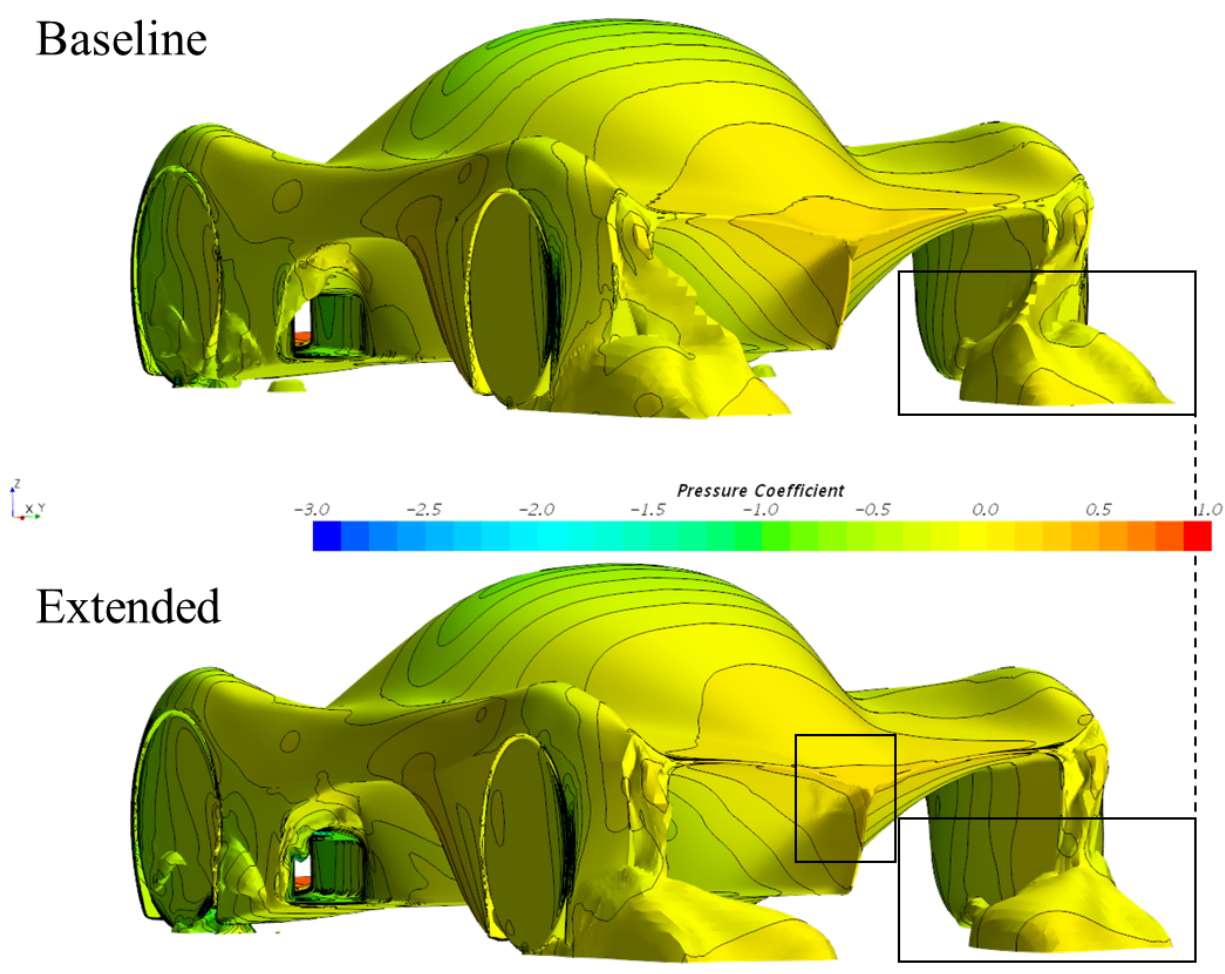

Figure 5.11: Rear Separation Regions, Extended Model and Baseline Model. Isosurface Showing Longitudinal Velocity Equal to $0.1 \mathrm{~m} / \mathrm{s}$. 


\subsection{Widened Tail}

The resultant resultant values of the widened tail model are shown in table 5.5. As can be seen from the table, the pressure drag dropped by $13 \mathrm{~N}$. The shear drag, however, increased from the baseline value by $0.2 \mathrm{~N}$. The lift, in comparison, increased by $190 \mathrm{~N}$ to a value of $-120 \mathrm{~N}$, which represents a $61 \%$ decrease in the downforce.

Table 5.5: Resultant Forces on Wide Rear Model

\begin{tabular}{|c|c|c|}
\hline Parameter & Wide Rear & Baseline \\
\hline \hline Pressure Drag (N) & $138 \pm 2$ & $151 \pm 2$ \\
\hline Shear Drag (N) & $44.6 \pm 0.7$ & $44.4 \pm 0.7$ \\
\hline Lift (N) & $-120 \pm 2$ & $-310 \pm 5$ \\
\hline$C_{D}$ & $0.197 \pm 0.003$ & $0.211 \pm 0.003$ \\
\hline$C_{L}$ & $-0.032 \pm 0.001$ & $-0.080 \pm 0.001$ \\
\hline
\end{tabular}

The $C_{p}$ behavior along the underside of the widened model is shown in figure 5.12. The baseline pressure probe points were modified in the diffuser to approximate the center of the diffuser. As can be seen from the figure, and expected based on the baseline, the Venturi effect is present in the front duct between points A and B. Along the side of the vehicle, from points $\mathrm{B}$ to $\mathrm{C}$ in the figure, the $C_{p}$ increases quasi-linearly with longitudinal location. At point $\mathrm{C}$, the $C_{p}$ lowers again with increased velocity at the inlet to the diffuser.

The $C_{p}$ of the widened rear model is compared to the baseline model in figure 5.13. The widened model has similar behavior to the baseline model in the front ducts; both have a similar-magnitude appearance of the Venturi effect. Along the side of the vehicle, the $C_{p}$ increases linearly. This behavior is not seen on the baseline model. It can be seen in figure 5.12 that in the region between 0.8 and $2.1 \mathrm{~m}$ (points 


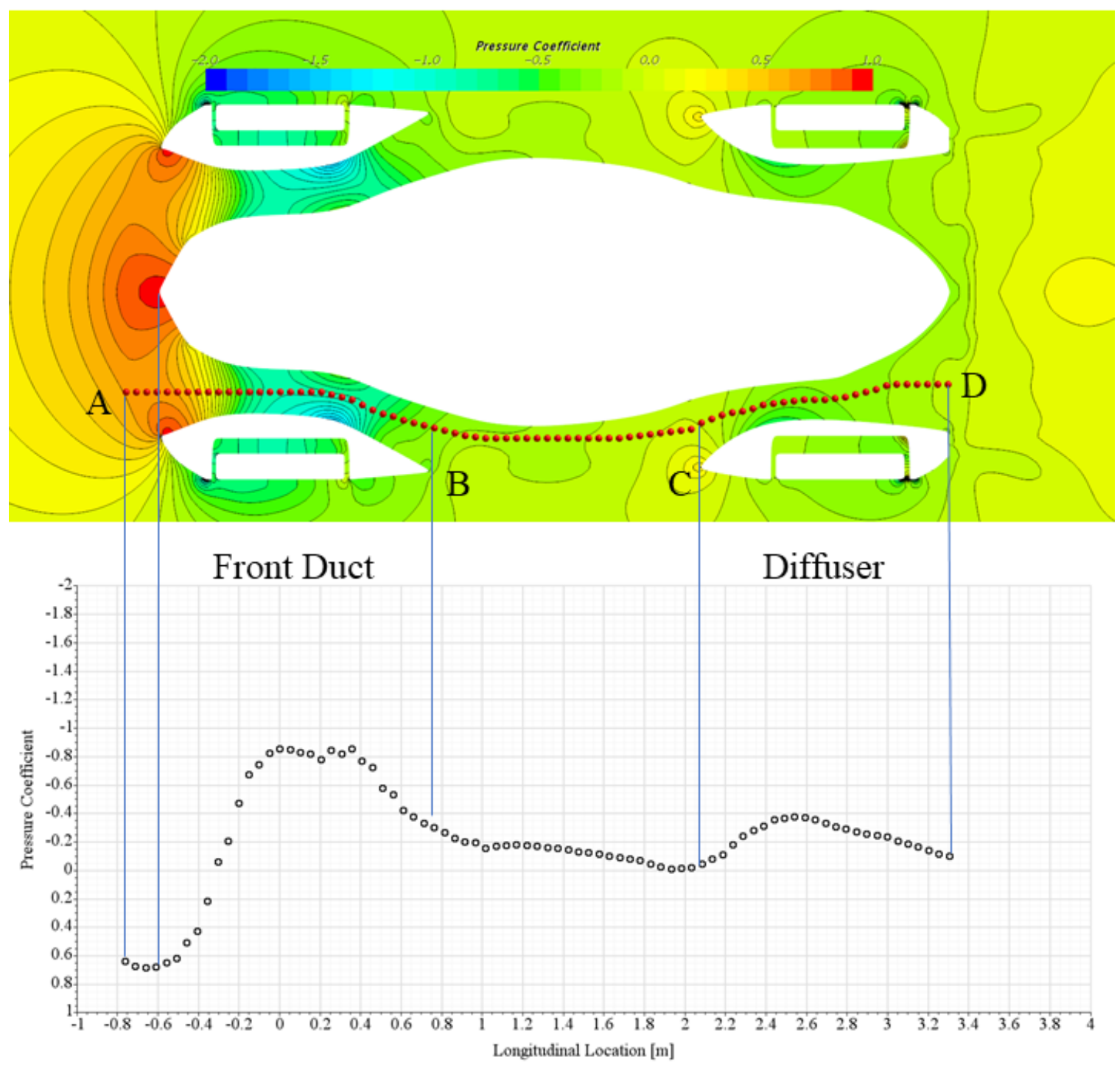

Figure 5.12: $C_{p}$ Behavior on Underside of Widened Model, $20.32 \mathrm{~cm}$ from Ground

$\mathrm{B}$ and $\mathrm{C}$ in figure 5.12), the baseline model's $C_{p}$ stays increases very gradually along the side. The wide rear model, in contrast, shows a large increase in pressure along the side, and a large favorable pressure gradient at the inlet to the diffuser. This can be seen in figure 5.13.

The $C_{p}$ returns to zero at the inlet to the diffuser, which means the flow matches freestream along the side of the body, directly in front of the diffuser. This can be seen in figure 5.12, and it can be seen in figure 5.13 that this does not happen 
in the baseline model. Additionally, compared to the baseline model, the point of minimum $C_{p}$ has been shifted rearward by the geometry change, as can be seen from figure 5.13. The flow expansion in the diffuser has also been modified compared to the baseline model.The widened tail model shows a linear increase in $C_{p}$ from the minimum pressure point, continuing to the trailing edge of the diffuser. As can be seen from figure 5.13, the gradient of the pressure recovery in the widened model's diffuser is much lower than the baseline model's gradient. This indicates that the flow in the diffuser is less prone to separation in the widened tail model than in the baseline model.

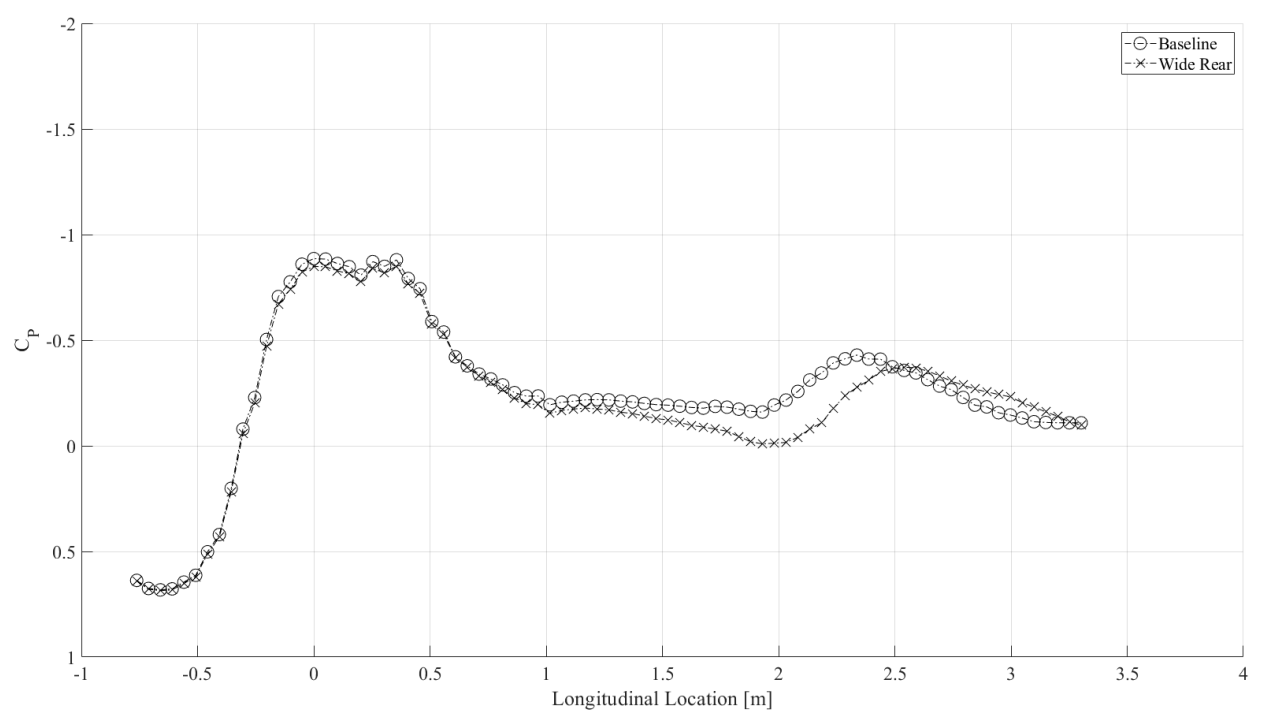

Figure 5.13: Comparison of Baseline and Wide Rear Models' $C_{p}$ Distributions

Figure 5.14 shows that the separation and recirculation region along the inside of the rear fenders has been eliminated. However, the figure also shows that the large base area at the rear of the body hosts a large separation zone. 


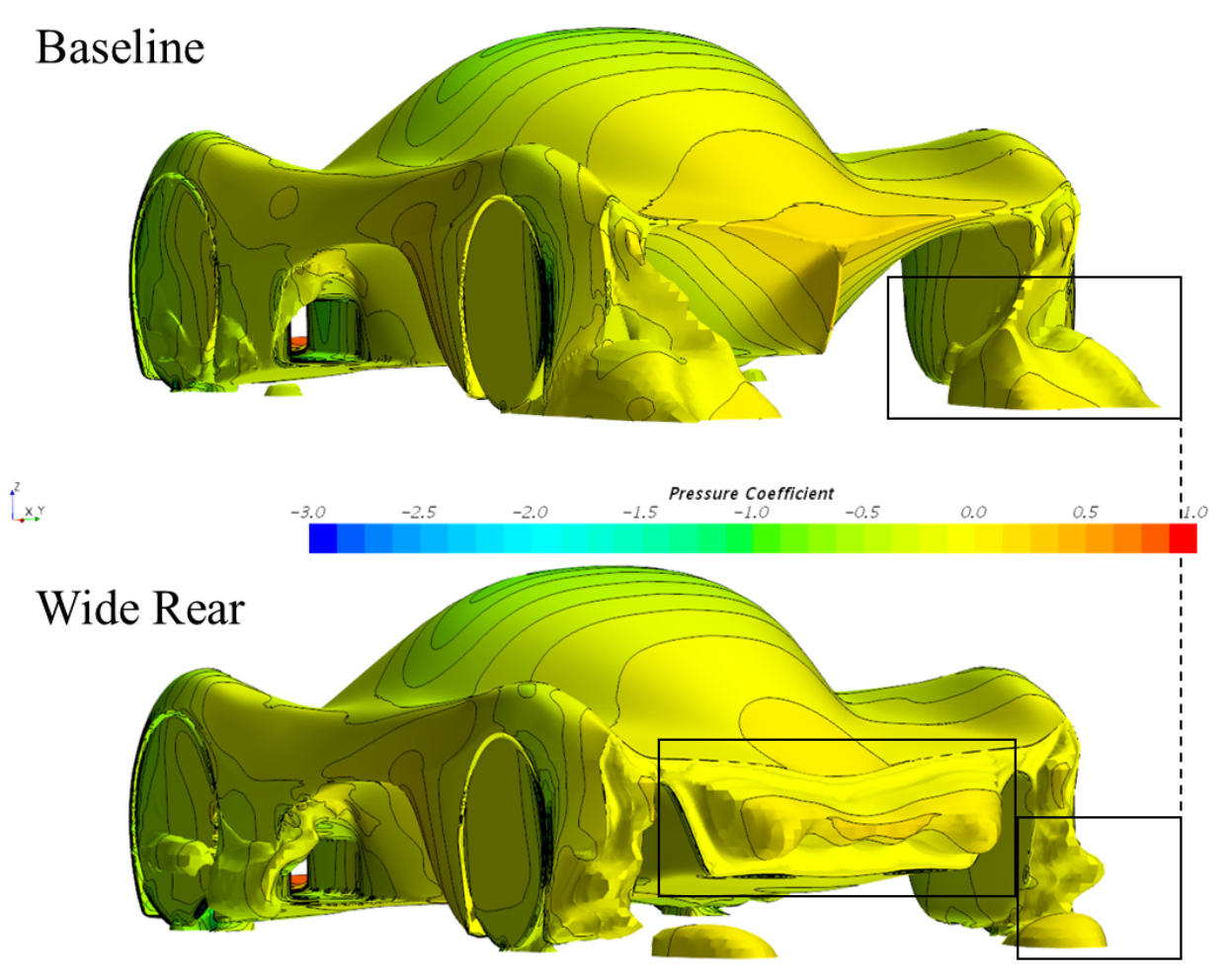

Figure 5.14: Rear Separation Regions, Wide Rear Model and Baseline Model. Isosurface Showing Longitudinal Velocity Equal to $0.1 \mathrm{~m} / \mathrm{s}$.

\subsection{Trends and Comparison}

It can be seen from figure 5.15 that the Venturi effect is present in the flow through the front duct in each case examined, including the baseline model. However, the magnitude of the $C_{p}$ change in the front duct varies greatly between cases. In each case, the pressure drop at the inlet begins to level off at point E, with an inflection point at approximately $0 \mathrm{~m}$.

Although the inlet area and front duct geometry were not altered, it can be seen that downstream effects in the underbody flow field propagate upward from the rear. From figure 5.15, each model had a different minimum $C_{p}$ than the baseline, even though the geometry changes were downstream of the front duct exhaust. The ride height and side skirt models had the two highest pressure drops, as evidenced by their 


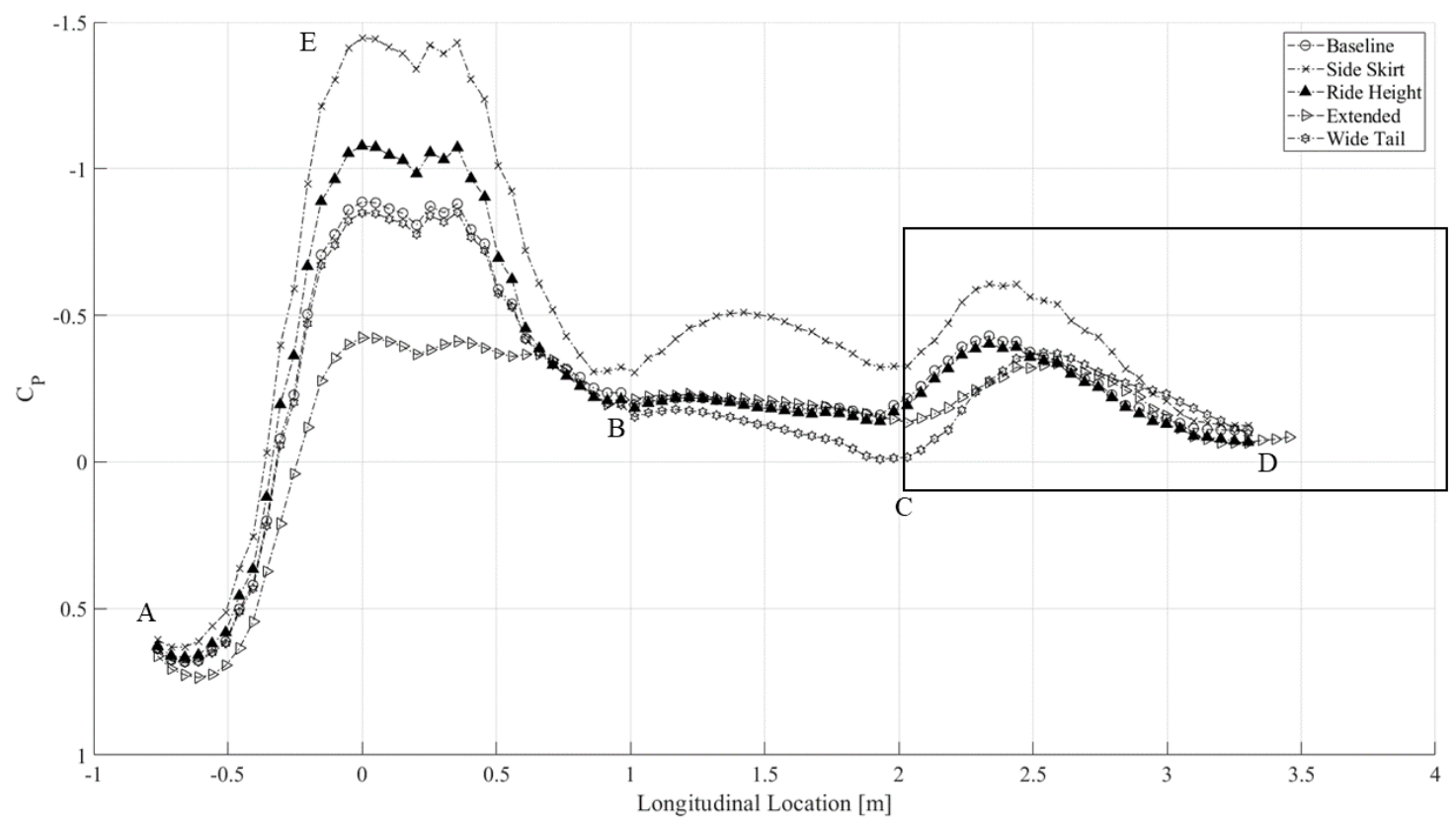

Figure 5.15: $C_{p}$ Behavior of All Cases, $20.32 \mathrm{~cm}$ from Ground. Boxed Area Shown in Figure 5.16.

respective magnitudes at point $\mathrm{E}$. The wide tail model had a pressure drop similar to the baseline model's, and the extended diffuser reduced the magnitude of the pressure drop at the inlet.

It can be seen from figure 5.15 that each case exhibits a double peak at the minimum point $C_{p}$ after point $\mathrm{E}$. This is caused by the turning section of the front duct, directly aft of the front wheels, which causes a velocity change to accommodate the turn. This has the effect of splitting a singular peak in the $C_{p}$ into two.

Following the flow downstream of point $\mathrm{B}$, figure 5.15 shows that all models but the side skirt version have an overall adverse pressure gradient along the side of the underbody. In contrast, the side skirt model shows an additional $C_{p}$ peak between points $\mathrm{B}$ and $\mathrm{C}$. This is due to the geometry of the model between points $\mathrm{B}$ and $\mathrm{C}$, the side of the vehicle and the side skirt act as a venturi in this region, as they constrict, then expand the flow cross-section area. 


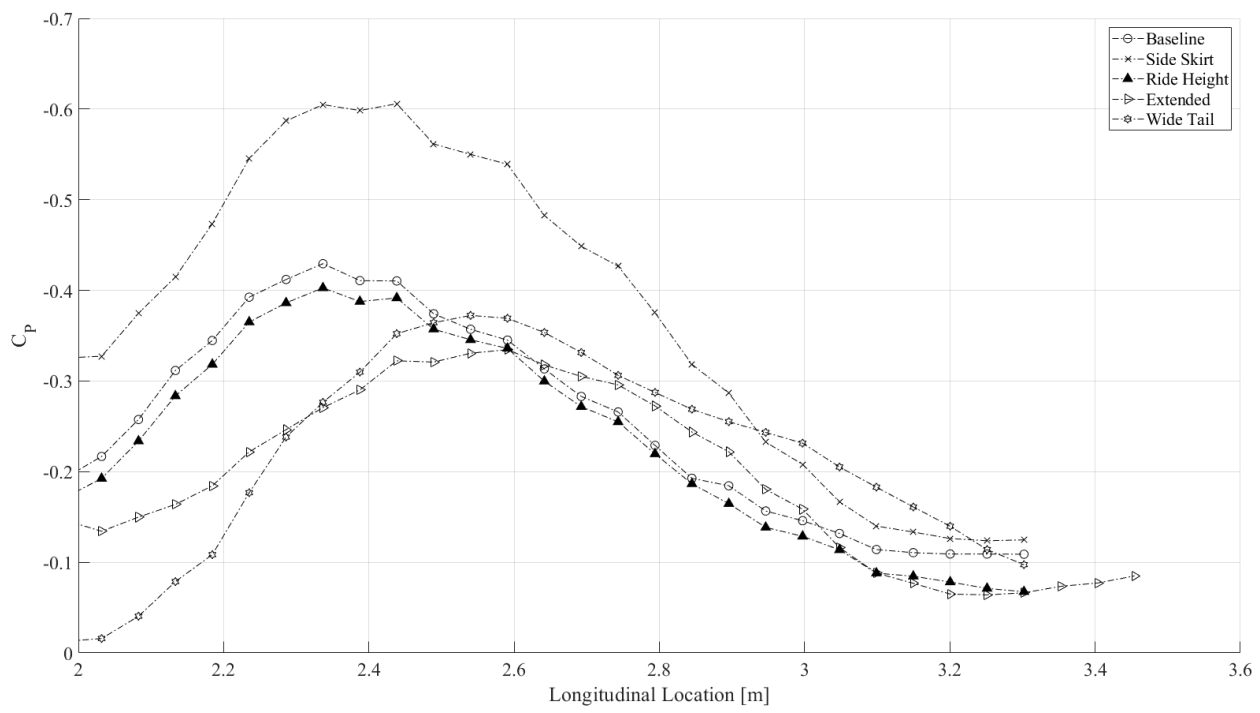

Figure 5.16: Detail of $C_{p}$ in Diffuser for All Cases, $20.32 \mathrm{~cm}$ from Ground

Figure 5.15 shows that the diffuser of each model acts as a venturi. As with the front duct behavior, the magnitudes of the $C_{p}$ in each flow varies between models. As shown in figures 5.15 and 5.16 , the $C_{p}$ of the raised model closely matches that of the baseline model. The wide rear and extended models both push the $C_{p}$ peak rearward. In contrast, the side skirt model magnified the Venturi effect of the baseline model, and has a much higher pressure gradient than any of the other diffuser variants. It is also of note that the wide tail model and the extended model shifted the minimum $C_{p}$ point of the diffuser venturi rearward compared to the baseline model.

In figure 5.16, both the raised ride height model and the extended model show a decrease in $C_{p}$ at the trailing edge of the diffuser. This indicates that the flow is accelerating as it leaves the diffuser.

The side skirt model has the highest adverse pressure gradient in the diffuser of the models tested, due to the high acceleration that the flow sees at the inlet of the diffuser. In contrast, the wide rear model exhibits the lowest adverse pressure gradient in the diffuser. 


\subsection{Results Summary}

The resultant values of each version of the vehicle are compared in table 5.7. As can be seen from the table, all cases reduced the total drag on the vehicle. The extended diffuser model had a favorable drag and downforce combination, but is outclassed by the wide tail model, which exhibited the lowest total drag and lowest downforce of any of the configurations, including the baseline.

Table 5.6: Case Force and Lift Data I

\begin{tabular}{|c|c|c|c|}
\hline Value & Baseline & Side Skirt & Ride Height \\
\hline \hline Pressure Drag (N) & $151 \pm 3$ & $154 \pm 1$ & $153 \pm 2$ \\
\hline Shear Drag (N) & $44.4 \pm 0.7$ & $50.1 \pm 0.7$ & $44.4 \pm 0.7$ \\
\hline Total Drag (N) & $195 \pm 3$ & $204 \pm 3$ & $198 \pm 3$ \\
\hline Lift (N) & $-310 \pm 5$ & $-436 \pm 5$ & $-292 \pm 5$ \\
\hline$C_{D}$ & $0.211 \pm 0.003$ & $0.220 \pm 0.003$ & $0.213 \pm 0.003$ \\
\hline$C_{L}$ & $-0.079 \pm 0.001$ & $-0.112 \pm 0.001$ & $-0.075 \pm 0.001$ \\
\hline
\end{tabular}

Table 5.7: Case Force and Lift Data II

\begin{tabular}{|c|c|c|}
\hline Value & Extended & Wide Tail \\
\hline \hline Pressure Drag (N) & $143 \pm 2$ & $138 \pm 2$ \\
\hline Shear Drag (N) & $43.3 \pm 0.7$ & $44.6 \pm 0.7$ \\
\hline Total Drag (N) & $186 \pm 3$ & $183 \pm 3$ \\
\hline Lift (N) & $-234 \pm 5$ & $-124 \pm 3$ \\
\hline$C_{D}$ & $0.201 \pm 0.003$ & $0.197 \pm 0.003$ \\
\hline$C_{L}$ & $-0.058 \pm 0.001$ & $-0.032 \pm 0.001$ \\
\hline
\end{tabular}


While the wide rear case was able to reduce the drag of the vehicle, the models with both the highest and lowest drag values did not represent large changes in drag magnitude. The drag of the side skirt height model was the highest at $204 \mathrm{~N}$. The drag of the wide tail model is $183 \mathrm{~N}$, a decrease of $6 \%$ over the baseline model.

\subsection{Implications for the Endurance Car}

As drag and maximum battery size (in relation to both geometry and capacity) are two of the most important metrics of the vehicle, the most favorable model is the wide rear model. In addition to the reduced drag, the increased rear volume allows for more flexibility in non-aerodynamic design. This assists in battery, chassis, and suspension packaging. The entire battery pack will be located in the rear of the vehicle; thus the additional space afforded by the wide rear model allows a $180 \mathrm{kWh}$ battery to be realistically packaged in the rear.

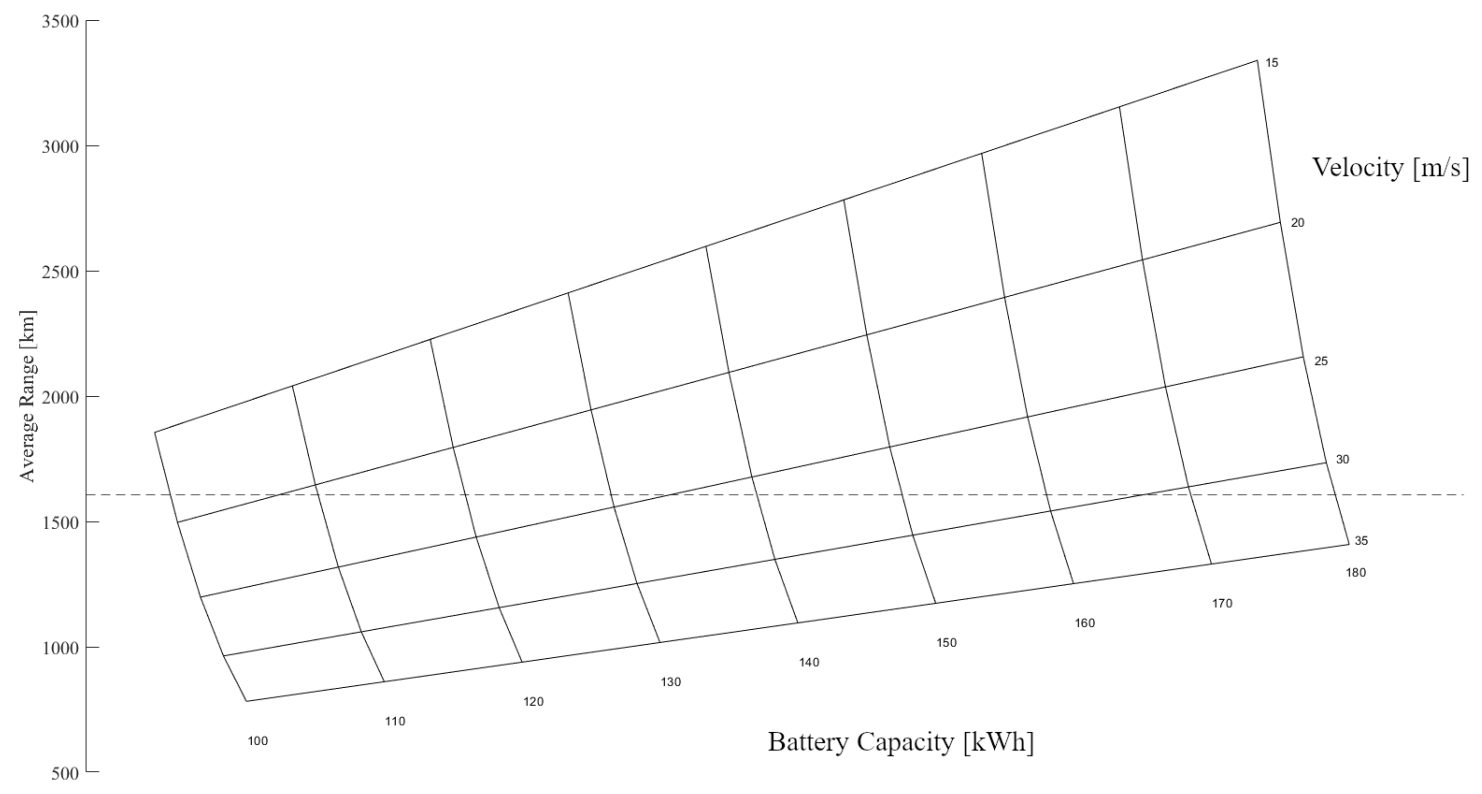

Figure 5.17: Range of Wide-Rear Model with Velocity and Battery Pack Size Variation 
In figure 5.17, the range of the vehicle as a function of velocity and battery pack size can be seen. The increased amount of space and reduced drag are beneficial in allowing the team more flexibility in trading off speed, range, and battery capacity. Between these metrics and a reduced exterior shell drag, the vehicle will be more than capable of achieving the design objective. 
Chapter 6

CONCLUSION

\subsection{General Conclusions}

Overall, it can be seen that changes to the diffuser have implications for the flow field along the entirety of the underbody, with the changes to the divergence angle having the greatest beneficial effect.

The first change was to add side skirts onto the sides of the Endurance Car, to model endplates on a diffuser. The addition of side skirts increased the propensity for separation on the under-body significantly increased. Not only did the scale of the adverse pressure gradients increase, but the addition of side skirts itself caused a third example of the Venturi effect to appear.

Literature suggests that increasing the ride height of a diffuser in ground effect will lower the drag and the downforce on the body. However, this is not the case on the Endurance Car, as an increase in ride height lowered downforce but increased drag. The under-body flow field of the raised model did not vary significantly in structure compared to the baseline configuration. However, the magnitude of the adverse pressure gradient in the front ducts increased over the baseline.

It has also been found that reducing the diffuser divergence angle can reduce the drag and downforce on the body. This was most easily manifested by extending the length of the Endurance Car body.

The extended model offered a significantly reduced total drag and reduced downforce over the baseline model. The drag was reduced by $4.6 \%$, and the downforce was 
reduced by $24.5 \%$ In addition, it offers marginally increased space for passenger or battery packaging over the baseline model. The divergence angle reduction afforded by the diffuser expansion moved the $C_{p}$ peak in the diffuser rearward, but did not completely eliminate the separation on the inside of the rear fenders.

As discussed in the literature review, published results indicate that an Ahmed body with no diffuser will have a lower drag than a body with a diffuser, even if that is not necessarily true for a defined vehicle shape, such as a SAAB 9-3.

The widened model eliminated the separation off the inside of the rear fenders of the vehicle, and reduced the drag by a net of $6.2 \%$ to $183 \mathrm{~N}$. The wide tail model has a new large base area at its rear; this base area reduces additional drag reduction that the wide rear model has over the baseline by inducing additional form drag. In effect, the model traded separation along the ducts for separation off the rear base. This trade-off is beneficial for this particular geometry, as the pressure drag from the new base area is smaller than that lost by reducing the diffuser divergence angle.

\subsection{Future Work}

The results generated in this study are not yet validated by experimental results. Validation could be performed via wind tunnel testing or full-scale real-world testing. Because the simulations in this study were set up to approximate freestream conditions, wind tunnel testing would have to utilize a wind tunnel that can approximate freestream with a moving ground. In addition, the facility would would have to match the design velocity of the simulations. Real-world testing could utilize coast-down testing to find the $C_{D}$ of the vehicle. 
Further refinements to the simulations to better approximate a vehicle could be made in several areas. First, the suspension and steering assemblies could be modeled in the simulation for improved accuracy in the wheel houses. In addition, the front wheel house would be modeled with a realistic depth to accommodate steering. The model was also generated without panel gaps or seams; these could be modeled to better represent a realistic vehicle int eh simulation.

Further reductions in drag could come from modifications to the geometry to reduce separation on the front fender, and on the outside of the rear fender. The steepest adverse pressure gradient on the baseline model comes from the pressure recovery at the exhaust of the front ducts. Because the flow cannot accommodate the rapid expansion of the duct, a large amount of separation occurs in this area. Elimination of this separation would compliment the work done in this thesis. As a final effort, the flow separates on the fenders aft of both the front and rear wheels. Reduction of separation in this region would additionally help to reduce the pressure drag. 


\section{BIBLIOGRAPHY}

[1] BAKKeR, A. Boundary layers and separation. web, 2006. http://www. bakker.org/dartmouth06/engs150/11-bl.pdf.

[2] Bakker, A. Lecture 5 - Solution Methods: Applied Computational Fluid Dynamics. Web, 2006. http://www. bakker.org/dartmouth06/engs150/05-solv.pdf.

[3] Barlow, J. Low-Speed Wind Tunnel Testing, 3 ed. John Wiley and Sons, 605 Third Ave New York, NY 10158-0012, 1999.

[4] Barnard, R. Road Vehicle Aerodynamic Design: An Introduction, 3rd ed. MechAero Publishing, 2015.

[5] Cal Poly Aerospace Engineering Department. Bishop Full Specifications, 2017. https://aero.calpoly.edu/static/media/uploads/hpc_specs.pdf.

[6] Cooper, K., Bertenyi, T., Dutil, G., Syms, J., and Sovran, G. The Aerodynamic Performance of Automotive Underbody Diffusers. Society of Automotive Engineers International 980030 (2 1998), 1-30.

[7] Cooper, K., Syms, J., And Sovran, G. Selecting Automotive Diffusers to Maximise Underbody Downforce. Society of Automotive Engineers International 2000-01-0354 (3 2000), 1-16.

[8] Desai, S., Lo, C.-M. B., And George, A. A Computational Study of Idealized Bluff Bodies, Wheels, and Vortex Structures in Ground Effect. Society of Automotive Engineers (4 2008), 1-30. SAE 2008-01-0327. 
[9] D’Hooge, A., Plain, R. B., Johnson, S., Duncan, B., And

Gargoloff, J. I. The Aerodynamic Development of the Tesla Model S Part 2: Wheel Design Optimization. Society of Automotive Engineers International, 2012-01-0178 (4 2012), 1-9.

[10] Eberle, U., And von Helmolt, R. Sustainable Transporation Based On Electric Vehicle Concepts: A Brief Overview. Energy and Environmental Science (3 2010).

[11] EhiRIM, O. Aerodynamics and Performance Enhancement of a Ground-Effect Diffuser. PhD thesis, Cranfield University, Cranfield Wharley End Bedford UK, 102017.

[12] Ehirim, O., Knowles, K., Saddington, A., Finnis, M., and Lawson, N. On the Near-Wake of a Ground-Effect Diffuser with Passive Flow Control. International Journal of Automotive Technology 20, 1 (1 2019), $11-23$.

[13] Ehirim, O., Knowles, K., And Saddington, A. J. A Review of Ground-Effect Diffuser Aerodynamics. Journal of Fluids Engineering 141, 20801 (2 2019), 1-19.

[14] Estrada, Z. Proterra's big electric bus can go 1,102 miles on one charge. https://www . theverge. com/2017/9/19/16333996/proterras-bigelectric-bus-can-go-1102-miles-on-one-charge, 9.

[15] GLON, R. https://www.digitaltrends.com/cars/itap-recycled-bmw-evnews-video-specs-range/, 62017.

[16] Goy, A. The Electric VW ID.R Keeps Proving It's the Very Fast Future of Racing. Jalopnik (7 2019). https://jalopnik.com/the-electric-vwid-r-keeps-proving-it-s-the-very-fast-f-1836188357. 
[17] Guinness. Fastest Solar-Powered Vehicle, 2014.

http://www .guinnessworldrecords . com/world-records/fastestsolar-powered-vehicle.

[18] Guinness. Greatest Distance by Electric Vehicle, Single Charge (Non-solar), 2017. http://www . guinnessworldrecords . com/world-records/greatestdistance-by-electric-vehicle-single-charge-(non-solar).

[19] Hucho, W. H., And Sovran, G. Aerodynamics of Road Vehicles. Annual Review of Fluid Mechanics 25 (1993), 485-537.

[20] Huminic, A., And Huminic, G. Computational Study of Flow in the Underbody Diffuser for a Simplified Car Model. Society of Automotive Engineers International (4 2010), 1-11.

[21] Huminic, A., And Huminic, G. Aerodynamic Study of a Generic Car Model with Wheels and Underbody Diffuser. International Journal of Automotive Technology 18, 3 (6 2017), 397-404.

[22] Huminic, A., Huminic, G., And Soica, A. Study of Aerodynamics for a Simplified Car Model with the Underbody Shaped as a Venturi Nozzle. International Journal of Vehicle Design 58, 1 (3 2012), 15-32.

[23] IEA. Global Electric Vehicle Outlook 2018. Tech. rep., The International Energy Agency, 31-35 rue de la Fédération, 75739 Paris Cedex 15 France, 5 2018.

[24] Jowsey, L. An Experimental Study of Automotive Underbody Diffusers. PhD thesis, Loughborough University, 2013. 
[25] Jowsey, L., And Passmore, M. Experimental Study of Multiple-Channel Automotive Underbody Diffusers. Institute of Mechanical Engineers, Part D: Journal of Automotive Engineering (3 2010), 865-879.

[26] Jung, M., Sirkin, D., Gur, T., And Steinert, M. Displayed Uncertainty Improves Driving Experience and Behavior: The Case of Range Anxiety in an Electric Car. CHI Crossings 2015 (4 2015), 2201-2210.

[27] Katz, J. Race Car Aerodynamics: Designing for Speed, 2 ed. Bentley Publishers, Cambridge, MA 02138, 1995.

[28] Katz, J. Aerodynamics of Race Cars. Annual Review of Fluid Mechanics 38 (1 2006), 27-63.

[29] Kim, J. J., And LeE, S. J. Drag-reducing underbody flow of a heavy vehicle with side skirts. Journal of Visualization 7, 401 (10 2016), 1-10.

[30] Koitrand, S., And Rehnberg, S. A Computational Investigation of Wheel and Underbody Flow Interaction. Master's thesis, Chalmers University of Technology, Göteborg, Sweden, 2013.

[31] Lanfrit, M. Best Practice Guidelines for Automotive External Aerodynamics with Fluent. web, 2005.

https://www. southampton.ac.uk/ nwb/lectures/GoodPracticeCFD/ Articles/Ext_Aero_Best_Practice_Ver1_2.pdf.

[32] Le Good, G., Johnson, C., Clough, B., and Lewis, R. The Aesthetics of Low Drag Vehicles. Society of Automotive Engineers (6 2011). SAE paper 2011-37-0016. 
[33] Levin, J., And Rigdal, R. Aerodynamic Analysis of Drag Reduction Devices on the Underbody for Saab 9-3 by Using CFD. Master's thesis, Chalmers University of Technology, Gothenburg, Sweden, 2011.

[34] Mavuri, S. P. Aerodynamic Analysis of Vehicle Wheel-Housings. PhD thesis, Royal Melbourne Institute of Technology, Melbourne, Victoria, Australia, 3 2009.

[35] Nurburgring YouTube Channel. Electric Record Nordschleife — Full Lap Volkswagen ID.R. video. https: //www . youtube . com/watch?v=lRHIi JjWhWo.

[36] Palin, R., Johnson, V., Johnson, S., D’Hooge, A., Duncan, B., And Gargoloff, J. I. The Aerodynamic Development of the Tesla Model S Part 1: Overview. Society of Automotive Engineers International (4 2012), 1-12. 2012-01-0177.

[37] Paterson, S., Vijayaratnam, P., Perera, C., and Doig, G. Sunswift eVe solar vehicle: a Record-Breaking Electric Car. Institution of Mechanical Engineers (1 2016), 1-15.

[38] Pentrány, M. The Electric Volkswagen I.D. R Is the Fastest Car to Ever Climb Pikes Peak. Road and Track (7 2018). https: //www.roadandtrack. com/motorsports/a21929211/the-electricvolkswagen-id-r-is-the-fastest-car-to-ever-climb-pikes-peak/.

[39] Regert, T., and Lajos, T. Description of Flow Field in the Wheelhouses of Cars. International Journal of Heat and Fluid Flow, 28 (4 2007), 616-629.

[40] Roache, P. J. Quantification of Uncertainty in Computational Fluid Dynamics. Annual Review of Fluid Mechanics 29 (1997), 123-160. 
[41] Ruhrmann, A., And Zhang, X. Influence of Diffuser Angle on a Bluff Body in Ground Effect. Journal of Fluids Engineering 125 (3 2003), 201-213.

[42] Runstadler, P., and Dolan, F. Diffuser Data Book, 1 ed. Creare Incorporated, P.O. Box 71 Hanover, NH 03755, 51975.

[43] Schlichting, H. Boundary-Layer Theory, 7 ed., vol. 1. McGraw-Hill Book Company, New York City, USA, 1979.

[44] Slater, J. W. Examining Spacial (Grid) Convergence. web, 2008. https://www.grc.nasa.gov/WWW/wind/valid/tutorial/spatconv.html.

[45] Smits, A. Drag of blunt bodies and streamlined bodies. web, 1997. https://www.princeton.edu/ asmits/Bicycle_web/blunt.html.

[46] Tamai, G. The Leading Edge: Aerodynamic Design of Ultra-Streamlined Land Vehicles, 1 ed. Robert Bentley, Inc, 1734 Massachusetts Ave Cambridge, MA, 1999.

[47] US Department of Energy. Timeline: History of the Electric Vehicle. online. https://www.energy.gov/timeline/timeline-history-electric-car.

[48] US Department of Energy. Where the Energy Goes: Gasoline Vehicles and Where the Energy Goes: Electric Cars. online. https://www.fueleconomy.gov/feg/atv-ev.shtml.

[49] Wasserman, S. Choosing the Right Turbulence Model for Your CFD Simulation. Web, 112016.

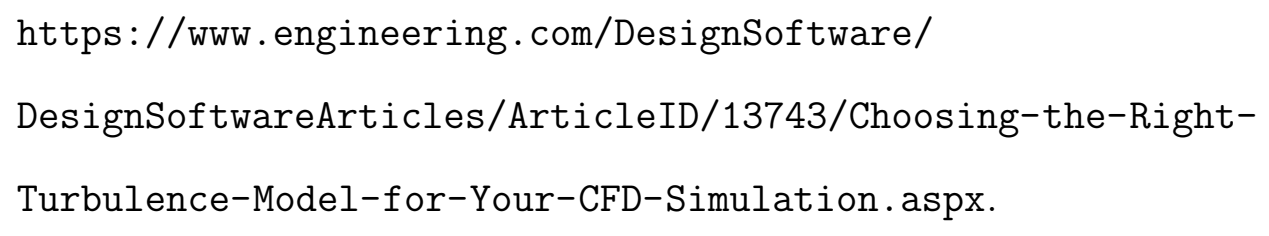


[50] Wilcox, D. C. Basic Fluid Mechanics, 5 ed. DCW Publishing, La Cañada Flintridge, California, USA, 2012. 
A

\section{Design Renderings}

The designer that worked with PROVE Lab on the project provided several sets of designs. These renders are from the last two sets of designs, and represent the most mature versions of the car design renders. These renderings were used as the basis for the design of the Endurance Car. Modifications were made to the design to reduce the number of drag-inducing features on the vehicle.

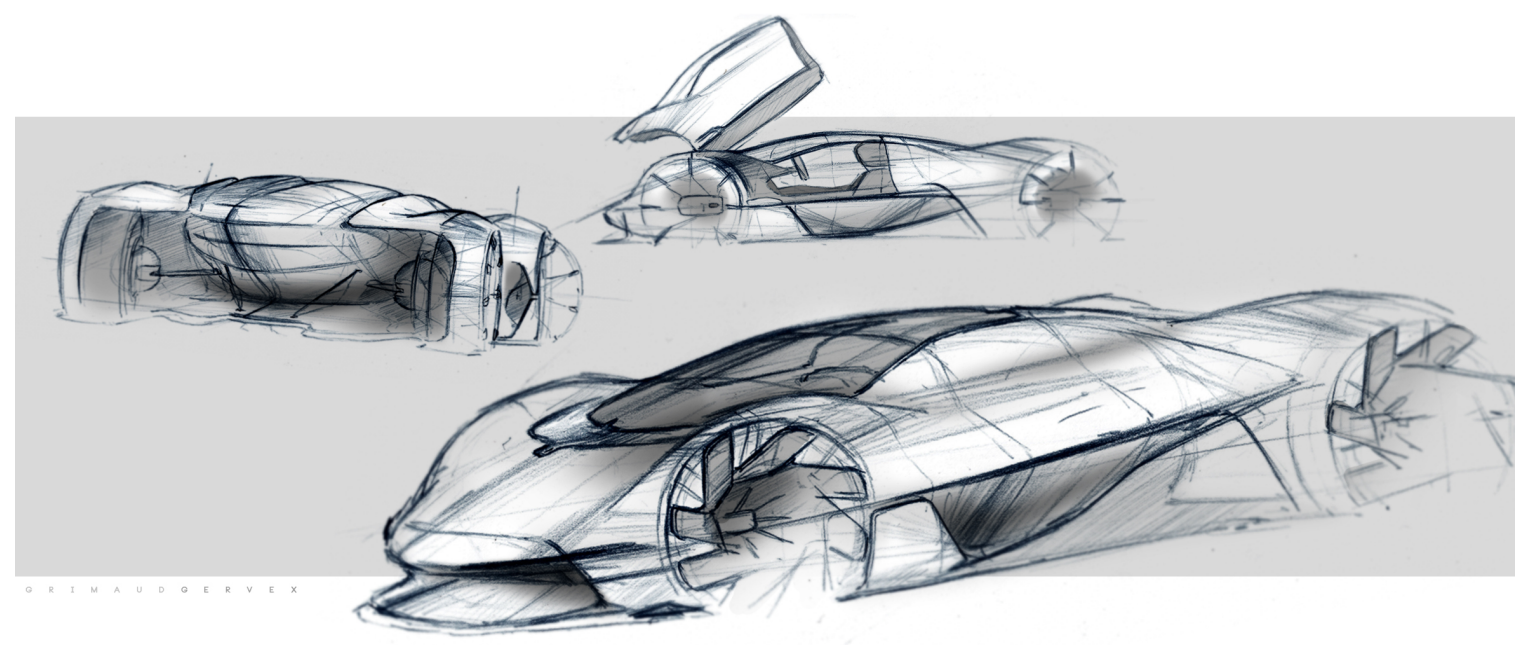

Figure A.1: Design Rendering A

These design renderings show the major features that made it into the CAD model; notably a sharp belt line that slopes upward at an angle from the nose to tail, a sharp leading edge on the rear fender, a body that slopes up at the rear, and a long, gradual sloping roofline that descends to the tail of the vehicle. 
Figures A.1 and A.2 show renders from the penultimate series of design renderings. Figures A.4, A.5 show the design renderings from the last batch of designs received from the designer.

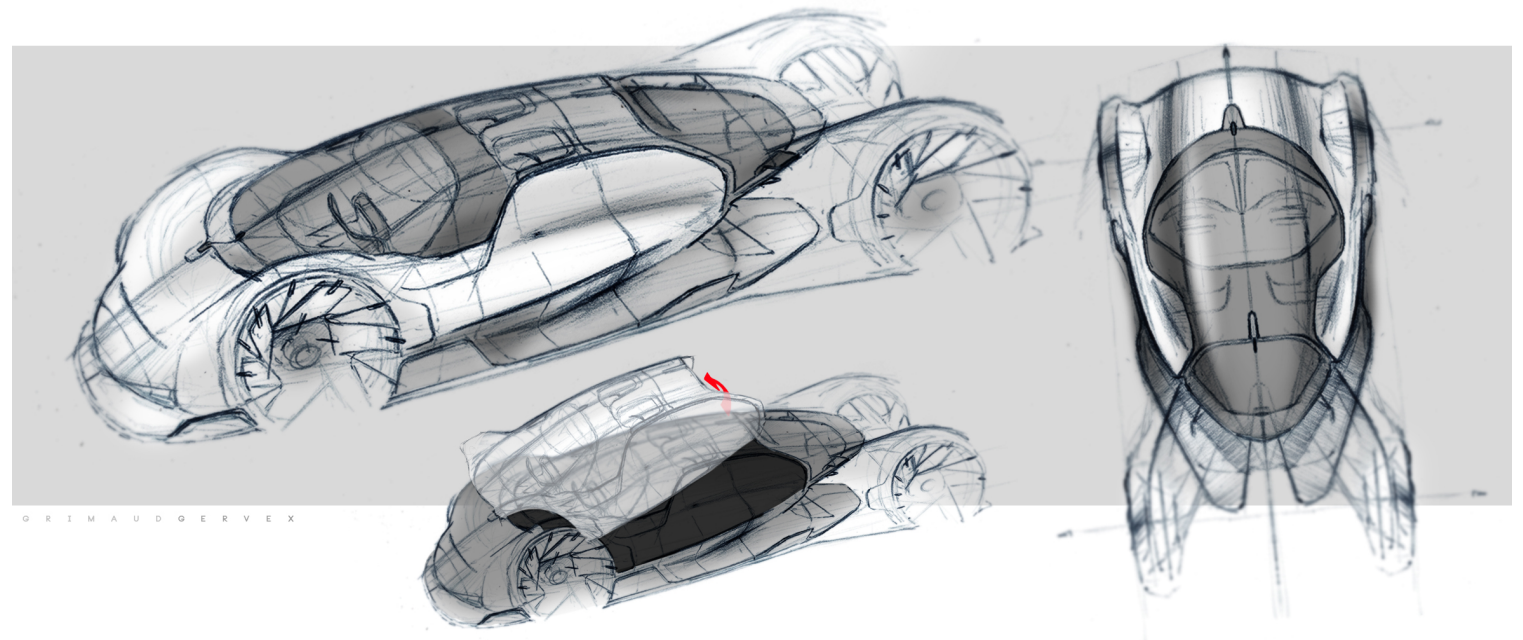

Figure A.2: Design Rendering B 


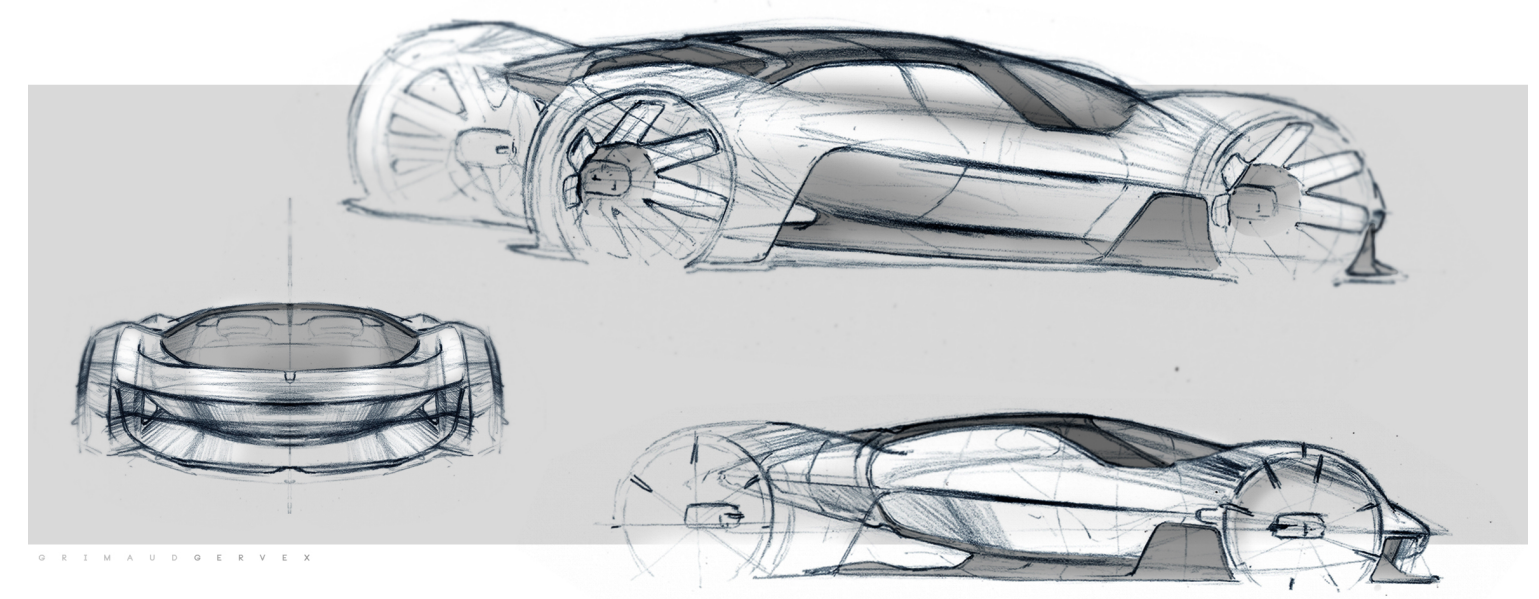

Figure A.3: Design Rendering C

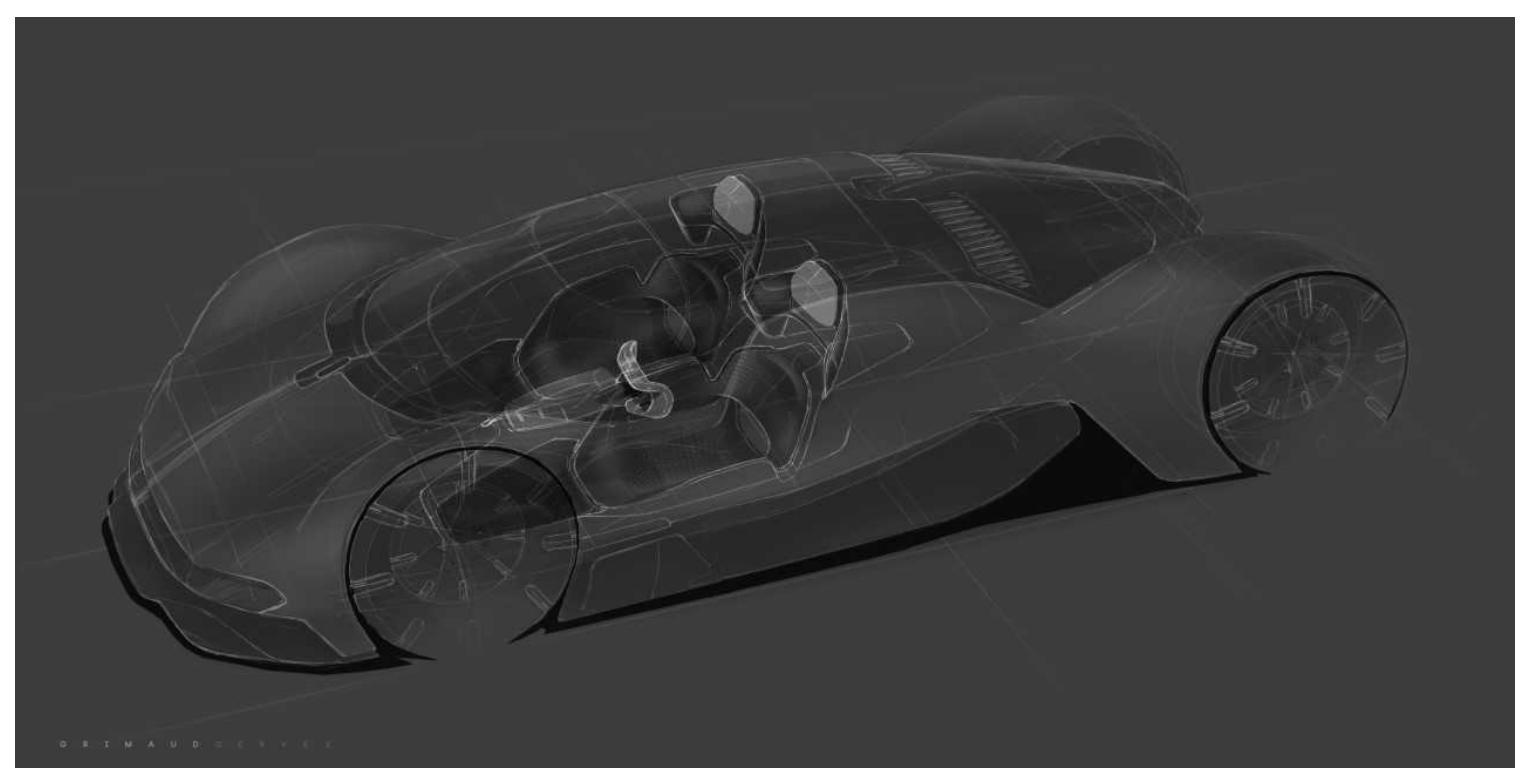

Figure A.4: Design Rendering D 


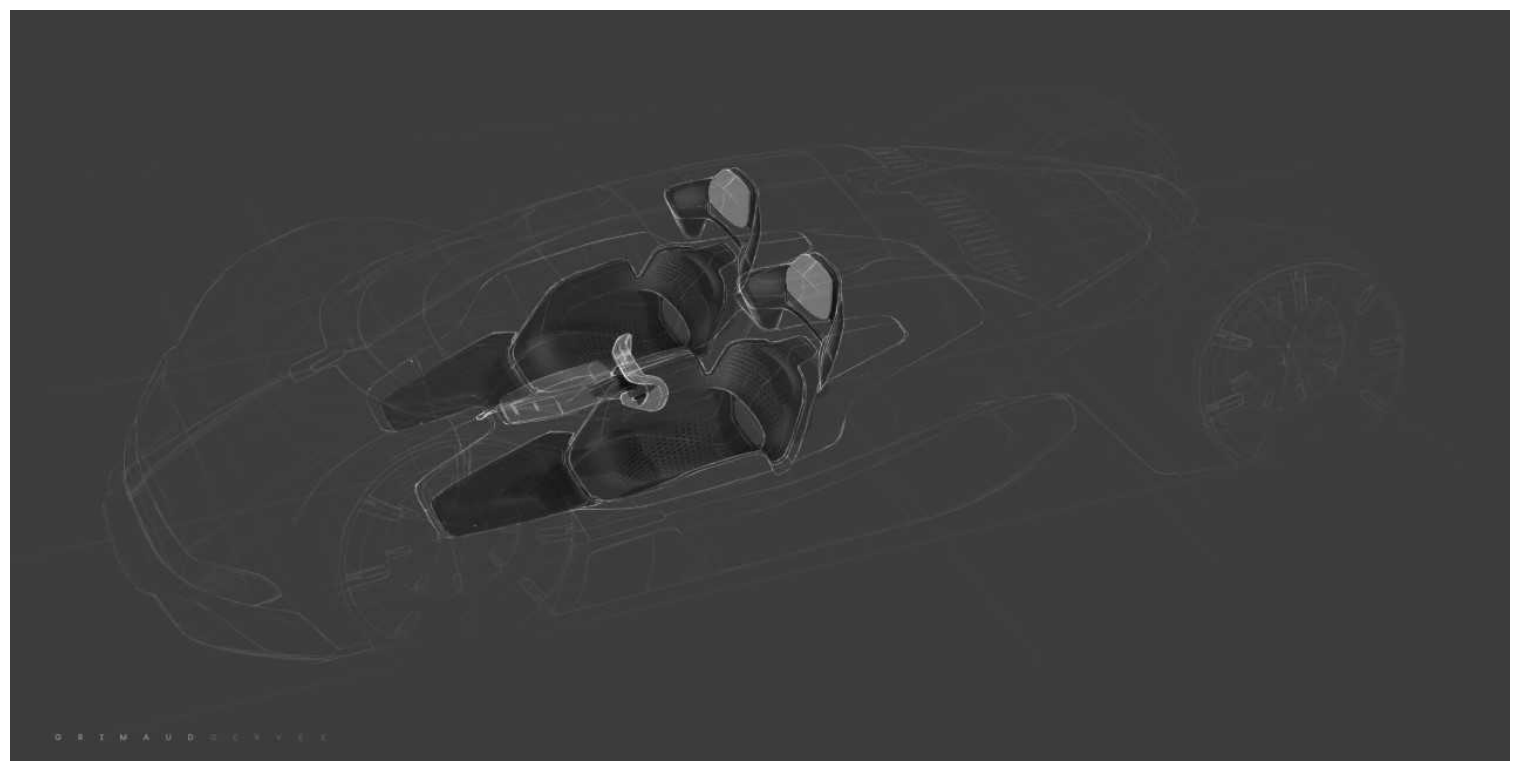

Figure A.5: Design Rendering E 